\title{
Passive and Active Radiation Measurements Capability at the INL Zero Power Physics Reactor (ZPPR) Facility
}

Robert Neibert John Zabriskie Collin Knight James L. Jones

December 2010

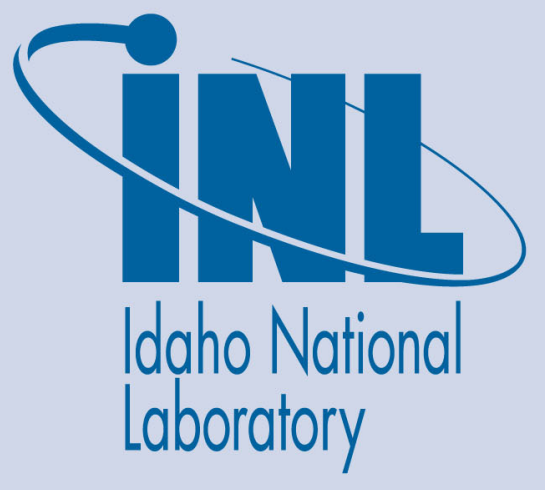

The INL is a U.S. Department of Energy National Laboratory operated by Battelle Energy Alliance 


\section{DISCLAIMER}

This information was prepared as an account of work sponsored by an agency of the U.S. Government. Neither the U.S. Government nor any agency thereof, nor any of their employees, makes any warranty, expressed or implied, or assumes any legal liability or responsibility for the accuracy, completeness, or usefulness, of any information, apparatus, product, or process disclosed, or represents that its use would not infringe privately owned rights. References herein to any specific commercial product, process, or service by trade name, trade mark, manufacturer, or otherwise, does not necessarily constitute or imply its endorsement, recommendation, or favoring by the U.S. Government or any agency thereof. The views and opinions of authors expressed herein do not necessarily state or reflect those of the U.S. Government or any agency thereof. 
INL/EXT-11-20876

\title{
Passive and Active Radiation Measurements Capability at the INL Zero Power Physics Reactor (ZPPR) Facility
}

\author{
Robert Neibert \\ John Zabriskie \\ Collin Knight \\ James L. Jones
}

December 2010

\begin{abstract}
Idaho National Laboratory
Idaho Falls, Idaho 83415
\end{abstract}

http://www.inl.gov

Prepared for the

U.S. Department of Energy

Office of National Nuclear Security Administration

Under DOE Idaho Operations Office

Contract DE-AC07-05ID14517 



\section{SUMMARY}

The Zero Power Physics Reactor (ZPPR) facility is a Department of Energy facility located in the Idaho National Laboratory's (INL) Materials and Fuels

Complex. It contains various nuclear and non-nuclear materials that are available to support many radiation measurement assessments. User-selected, single-type nuclear materials can be readily utilized via ZPPR clamshell containers with almost no criticality concerns. If custom, multi-material configurations are desired, the ZPPR clamshell or an approved aluminum Inspection Object (IO) Box container may be utilized, yet each specific material configuration will require a criticality assessment. As an example of the specialized material configurations possible, the National Nuclear Security Administration's (NNSA) Office of Nuclear Verification has sponsored the assembly of six material configurations. These are shown in the Appendices and have been designated for semi-permanent storage that can be available to support various radiation measurement applications. 


\section{CONTENTS}

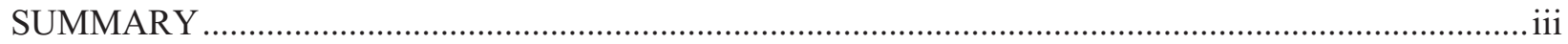

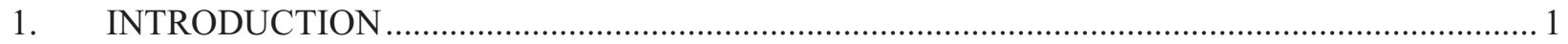

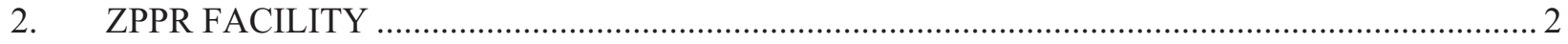

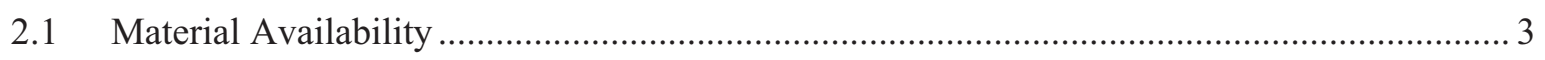

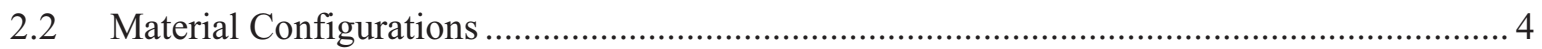

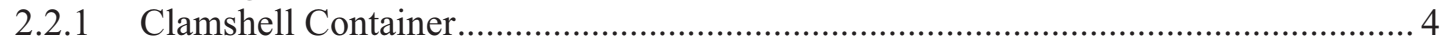

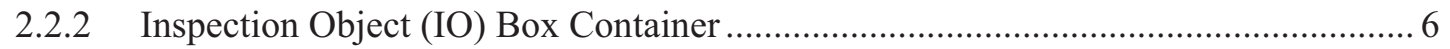

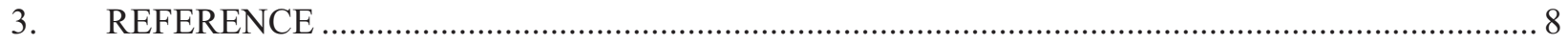

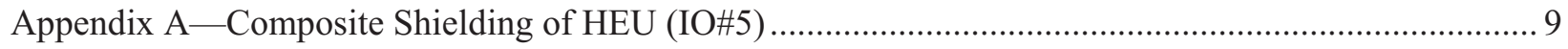

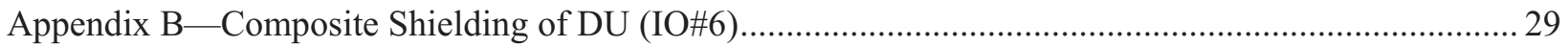

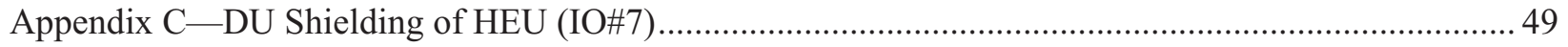

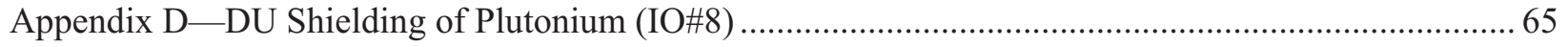

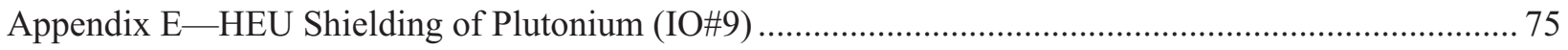

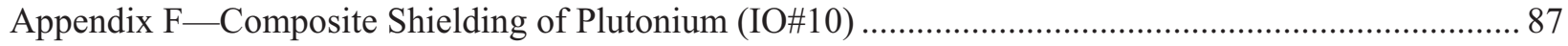

\section{FIGURES}

Figure 1. Materials and Fuel Complex site. ..................................................................................... 1

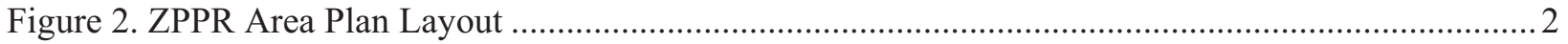

Figure 3. Background radiation levels at various locations in the workroom and at the ZPPR

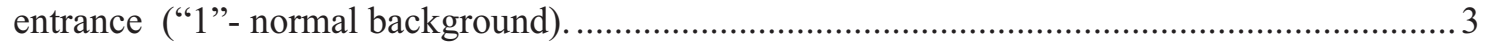

Figure 4. A representative ZPPR fuel-plate clamshell (partially filled with PuAl fuel plates)...................5

Figure 5. A schematic of the ZPPR fuel-plate clamshell design..............................................................5

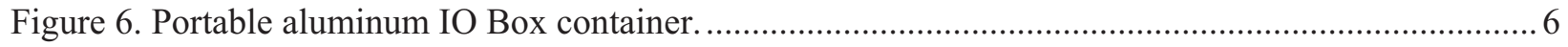

Figure 7. The Aluminum IO Box schematic for customized configurations.......................................... 7

\section{TABLES}

Table 1. Select ZPPR nuclear materials and related compositional percentages..................................... 4

Table 2. Key components of each aluminum-box IOs.............................................................................. 7 


\section{Passive and Active Radiation Measurements Capability at the INL Zero Power Physics Reactor (ZPPR) Facility}

\section{INTRODUCTION}

The Zero Power Physics Reactor (ZPPR) is a Department of Energy (DOE) facility within the Materials and Fuels Complex (MFC) (See Figure 1) located at the Idaho National Laboratory. The site is about 35 miles west of Idaho Falls, Idaho. The facility, previously operated by Argonne National Laboratory-West for decades, has helped define many of today's nuclear reactor core designs through the use of standard, $2.54 \mathrm{~cm}$-wide nuclear (e.g., up to DOE Category I) and non-nuclear materials. Many of these materials (Ref. 1) are still stored at the facility. The ZPPR core consisted of two large, verticallypositioned, $\sim 1-\mathrm{m}$ wide halves that could be brought together to enable reactor physics studies of various material core loadings. Each core half consisted of an array of removable, horizontally oriented trays loaded with selected materials. To provide maximum core assessment flexibility, each core material was configured in rectangular segments of 2.54-cm wide, thicknesses up to $2.54 \mathrm{~cm}$ [with some having stainless steel cladding], and lengths up to $20.2 \mathrm{~cm}$. While active ZPPR testing ended in the late 1990's, it was not until early 2010 that the ZPPR reactor halves were permanently removed and dispositioned. Also during this period, DOE has been considering numerous disposition options for the ZPPR core materials. Many of the materials, especially the nuclear materials, are still available to support radiation measurements. These measurements can range from advanced detector assessment characterizations to nonproliferation-based application measurements to national security applications studying various types of shielded nuclear material configurations.

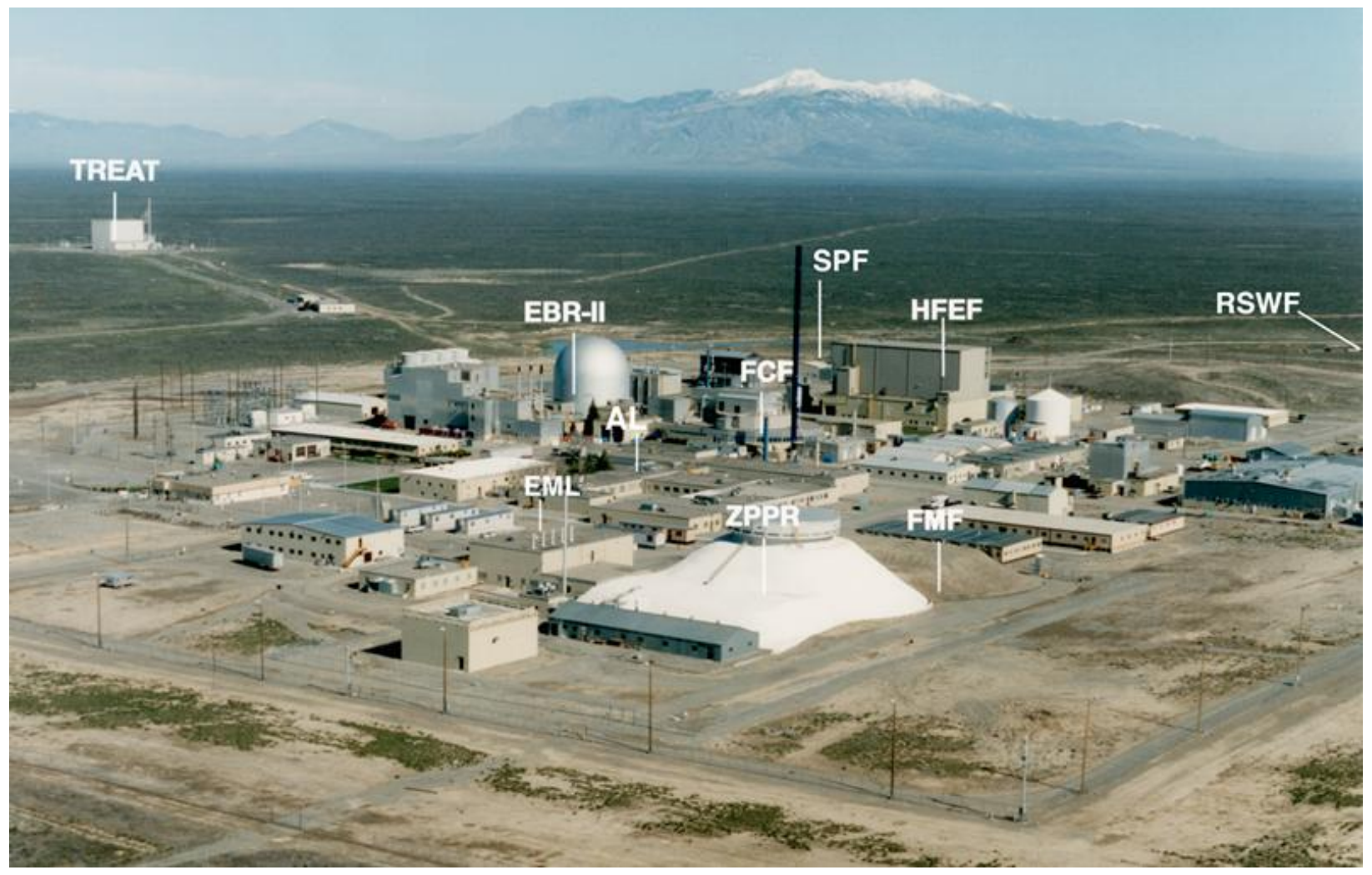

Figure 1. Materials and Fuel Complex site. 


\section{ZPPR FACILITY}

The ZPPR facility layout is shown in Figure 2. It consists primarily of the ZPPR cell, the workroom, its interconnecting hallway, a storage vault, and the control room. The material storage vault is adjacent to the workroom. Due to stored inventory in the vault, the workroom will have a higher-than-normal background radiation levels, especially as one approaches the vault door (see Figure 3). With the exception of two loading hoods positioned in the center of the workroom, the remaining areas in the workroom, the main cell, and the hallway is available for possible testing. However since the shutdown of the reactor, no nuclear material has been allowed in the cell or the interconnecting hallway. To overcome this limitation, a new safety basis study is underway and expected to be completed in late 2011 that will allow nuclear material in the cell and hallway. In support of radiation measurements, some basic background radiation measurements taken in the main cell have already shown background levels less than half of the natural Idaho background in the area. Finally, a control room area, outside the ZPPR access portal, has a cable-access portal to the hallway region that can be used to support remote data acquisition operations.

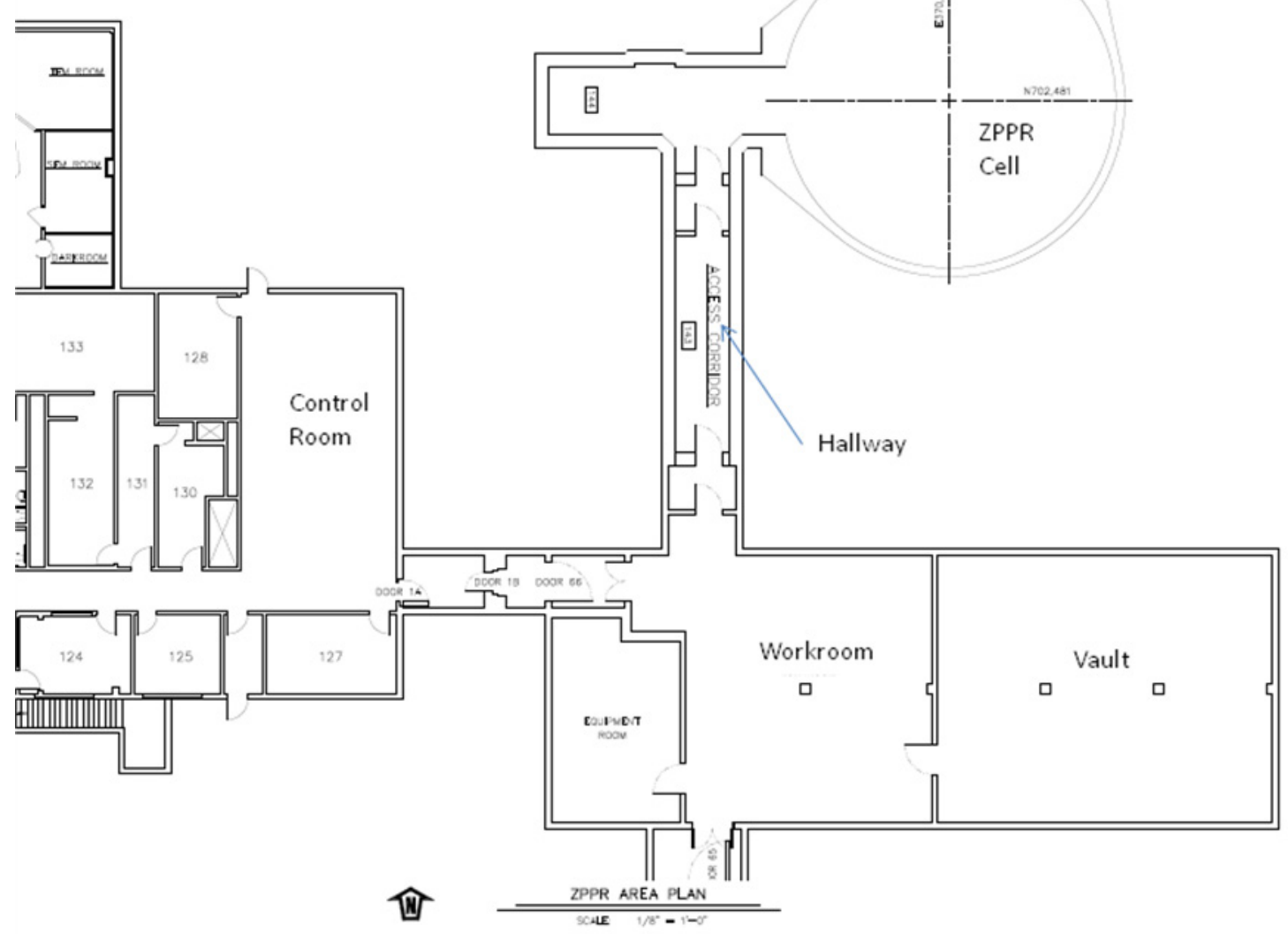

Figure 2. ZPPR Area Plan Layout 


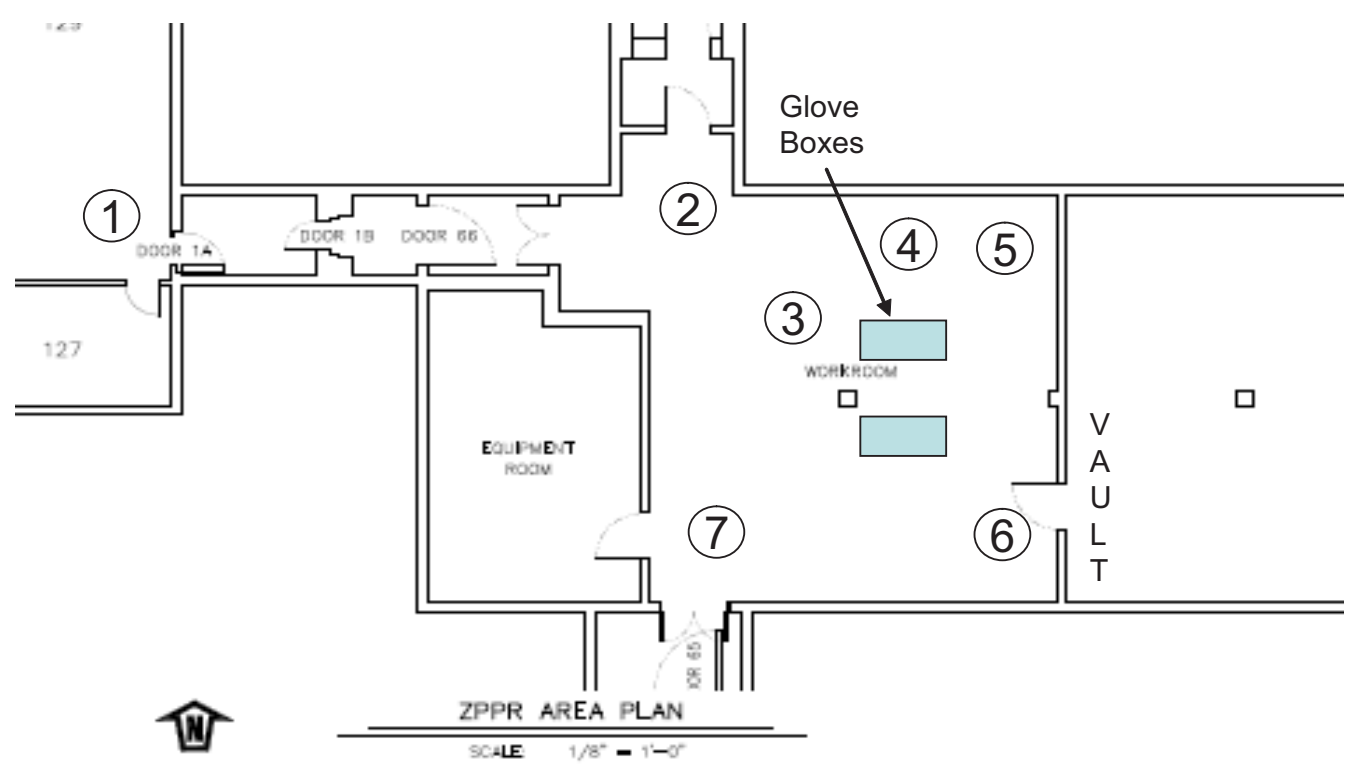

\begin{tabular}{|c|c|c|c|c|c|}
\hline \multirow{3}{*}{$\begin{array}{l}\text { Measurement } \\
\text { Location }\end{array}$} & \multirow{2}{*}{$\begin{array}{l}\text { Bictron }(\gamma) \\
\mu \text {-meter }{ }^{\circledR}\end{array}$} & \multirow{2}{*}{$\begin{array}{c}\text { Eberline (n) } \\
\text { NRD } \\
\text { RemBall® } \\
\end{array}$} & \multicolumn{3}{|c|}{ Ortec Detective $\mathbb{R}$} \\
\hline & & & $\gamma$-Dose & n-counts & $\gamma$-counts \\
\hline & $\mu \operatorname{Rem} / \mathrm{h}( \pm 20 \%)$ & $\mu \operatorname{Rem} / \mathrm{h}( \pm 20 \%)$ & $\mu \operatorname{Rem} / \mathrm{h}(<20 \%)$ & $\# / \mathrm{s} \quad(<20 \%)$ & $\# / \mathrm{s} \quad(<20 \%)$ \\
\hline 1 & - & - & 7 & 3 & 140 \\
\hline 2 & 2 & $<1$ & 8 & 5 & 160 \\
\hline 3 & 1 & $<1$ & 11 & 15 & 250 \\
\hline 4 & 2 & $<1$ & 12 & 19 & 230 \\
\hline 5 & 4 & $<1$ & 30 & 56 & 316 \\
\hline 6 & 8 & $<1$ & 50 & 165 & 600 \\
\hline 7 & 2 & $<1$ & 15 & 210 & 250 \\
\hline
\end{tabular}

Figure 3. Background radiation levels at various locations in the workroom and at the ZPPR entrance ("1"- normal background).

\subsection{Material Availability}

Various nuclear and non-nuclear materials were assembled (Ref 1) to study and validate the physics behavior of different reactor core designs. (Today, due to the age of this reference and a continuing Department of Energy effort to disposition some of the ZPPR materials, the availability of specific materials types and sizes in storage will require verification.) To enable maximum flexibility in the possible core designs, each ZPPR material type was configured in $2.5 \mathrm{~cm}$-wide rectangular segments having thicknesses up to $2.5 \mathrm{~cm}$ [with some nuclear material having stainless steel (SS) cladding] and lengths up to $20.2 \mathrm{~cm}$. Despite the continuing material disposition effort, a significant quantity of these materials is still held in the ZPPR facility and is available to support radiation measurement needs.

While various nuclear materials (elements and alloys) are available, some key nuclear materials stored at ZPPR include PuAl alloy (SS cladded), highly enriched uranium (HEU), depleted uranium (DU), thorium, and natural uranium. Table 1 provides the composition data for select materials. 
Table 1. Select ZPPR nuclear materials and related compositional percentages.

\begin{tabular}{|l|l|}
\hline \multicolumn{1}{|c|}{ Nuclear Materials } & \multicolumn{1}{|c|}{ Percent (\%) } \\
\hline PuAl & 1.39 (Selections ranging from 1 to 5) \\
\hline -Al/PuAl & 94.0 (Selections ranging from 70 to 95.4$)$ \\
\hline -Pu239/PuAl & $69.71(\mathrm{Fe}), 18.45(\mathrm{Cr}), 8.95(\mathrm{Ni}), 1.70(\mathrm{Mn}), 1.19$ (other) \\
\hline $\begin{array}{l}\text {-SS Cladding }(\sim 10 \mathrm{~g} / 2.54 \mathrm{~cm} \text { of axial plate } \\
\text { length }\end{array}$ & \\
\hline HEU & 93.20 \\
\hline -U235/U & \\
\hline DU & 0.22 \\
\hline -U235/U238 & \\
\hline Natural Uranium & 0.72 \\
\hline -U235/U238 & \\
\hline Natural Thorium & 100 \\
\hline -Th232/Th &
\end{tabular}

\subsection{Material Configurations}

While non-nuclear materials can be utilized quite freely, nuclear material usage requires fixed material configurations with criticality-assessment approvals. Typically, these fixed configurations are enclosed in containers that also provide an approved storage function. This section presents two types of ZPPR-approved storage and use containers. Any other containers must obtain separate approvals.

\subsubsection{Clamshell Container}

For storage considerations at the ZPPR facility, engineers designed clamshell storage containers such that any nuclear material enclosed would remain in a subcritical configuration. Today the criticalityhazards control statement only allows one nuclear material type in a clamshell.

A typical clamshell, see Figure 4, is shown with internal positioning pegs and a partial fuel plate loading. It is made from ASTM-B85-63/SC84A die-cast aluminum alloy and has maximum inside dimensions (for a complete clamshell configuration) of $16.172 \mathrm{~cm}\left(6.367^{\prime \prime}\right)$ wide by $21.394 \mathrm{~cm}\left(8.423^{\prime \prime}\right)$ long by $5.699 \mathrm{~cm}\left(2.244^{\prime \prime}\right)$ tall. There are three types of clamshells: fuel-plate clamshells, fuel-pin clamshells and clamshells that have the internal pegs removed (not for use with nuclear material). Each clamshell has $1.27 \mathrm{~cm}\left(0.5^{\prime \prime}\right)$ thick side walls and a $0.635 \mathrm{~cm}\left(0.25^{\prime \prime}\right)$ thick top and bottom wall. An Oring creates a seal between the top and bottom clamshell pieces, which are held together by two wingnuts. A valve allows the clamshell to be purged and filled with inert atmosphere. The fuel-plate clamshell has $820.635-\mathrm{cm}(0.25$ ") full-diameter pegs and 28 half-diameter pegs inside the clamshell, creating fuel plate slots slightly larger than $0.635 \mathrm{~cm}$ in width. The pegs create 12 slots running the length of the clamshell or 16 slots running the width of the clamshell. Fuel-pin clamshells are also made from ASTM-B8563/SC84A die-cast aluminum alloy and have maximum internal dimensions of $16.509 \mathrm{~cm}\left(6.5^{\prime \prime}\right)$ wide by $25.242 \mathrm{~cm}\left(9.938^{\prime \prime}\right)$ long by $5.557 \mathrm{~cm}\left(2.188^{\prime \prime}\right)$ tall. The fuel-pin clamshell holds 5 rows of pins. The first four rows hold 26 pins per row, and the fifth row, 24 pins. Depending on clamshell type, each weighs between about 2.7 and $2.9 \mathrm{~kg}$ with the latter corresponding to the fuel-plate type. 


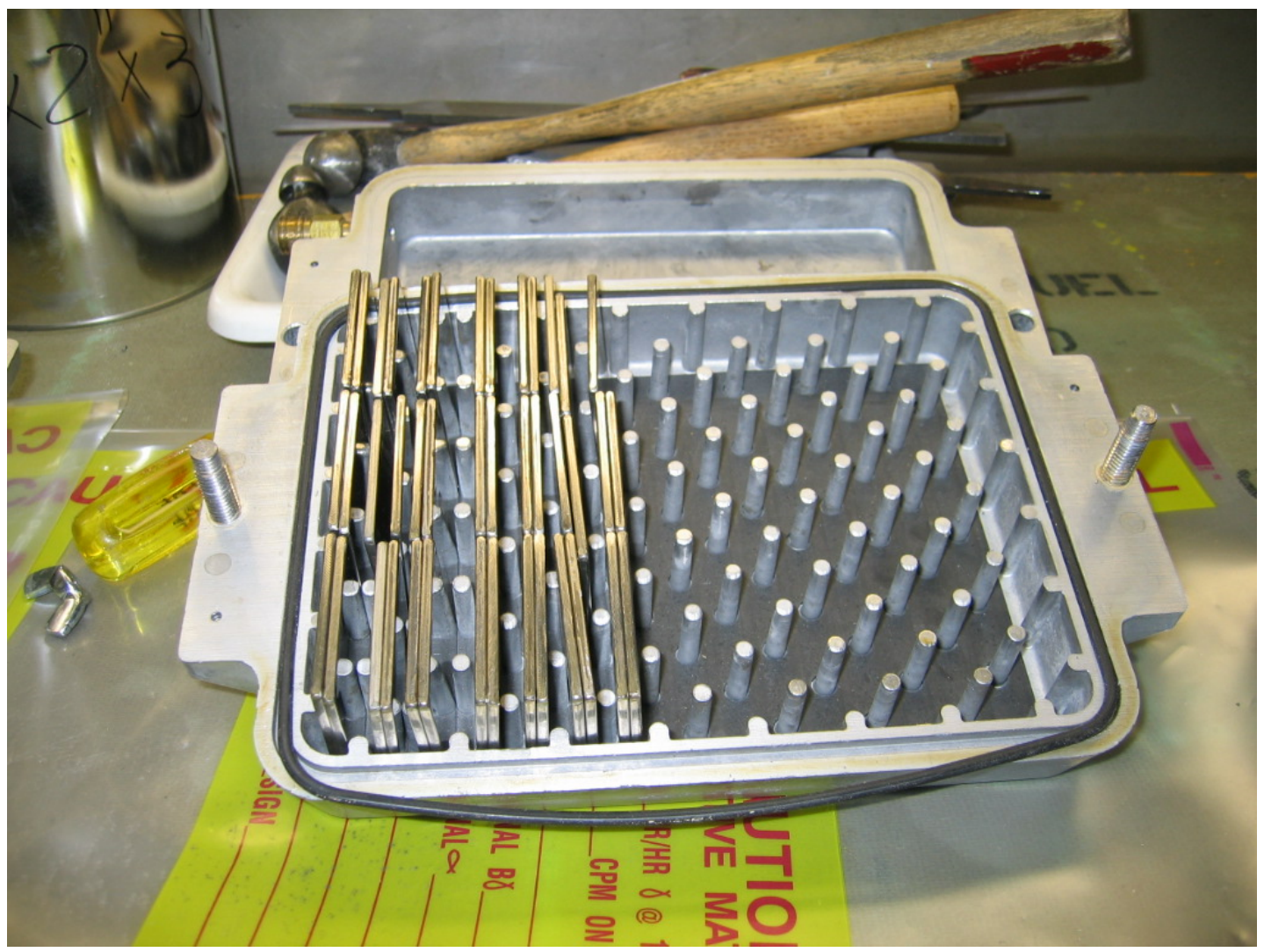

Figure 4. A representative ZPPR fuel-plate clamshell (partially filled with PuAl fuel plates).

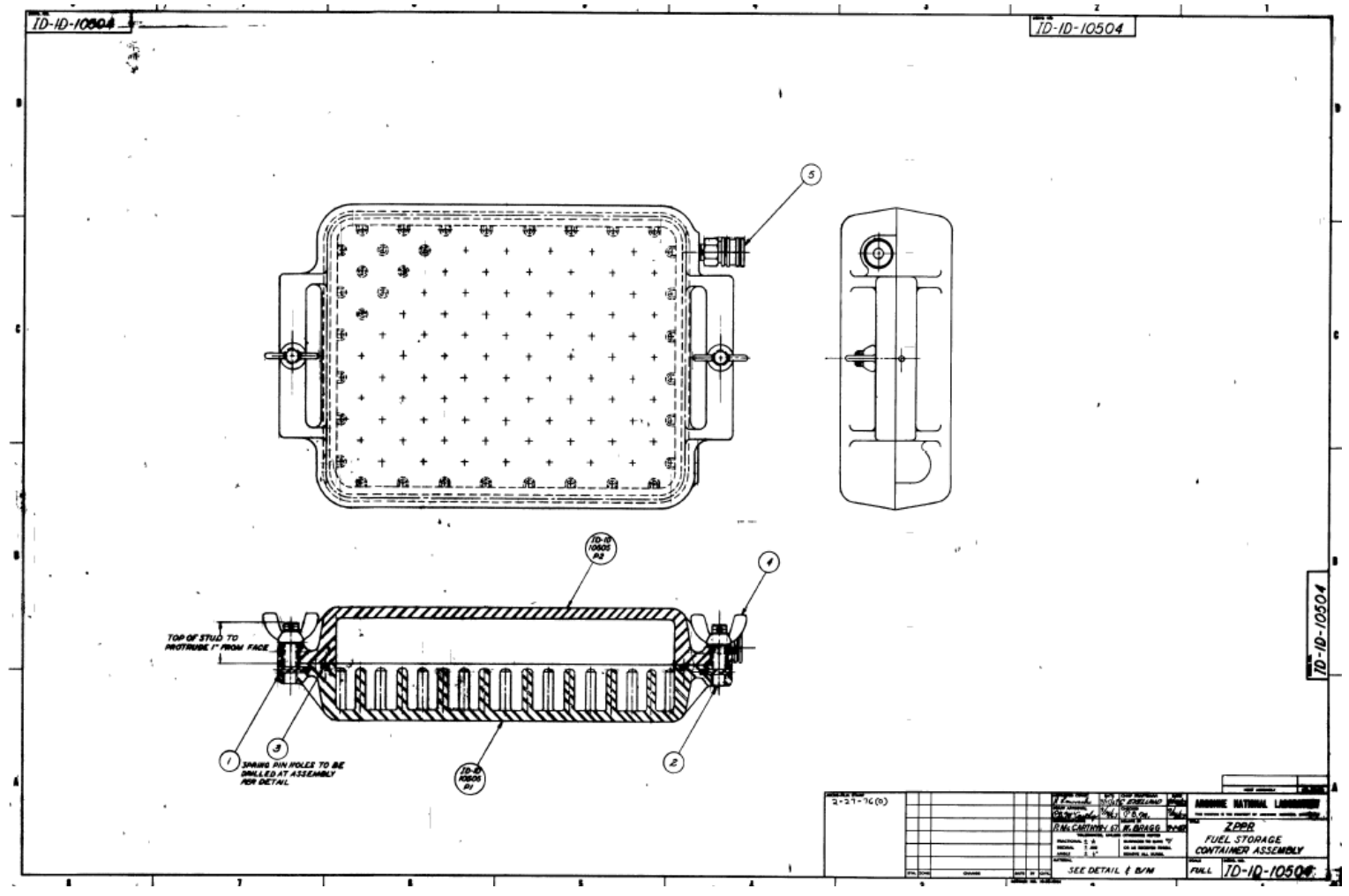

Figure 5. A schematic of the ZPPR fuel-plate clamshell design. 


\subsubsection{Inspection Object (IO) Box Container}

Another approved handling configuration (the IO box) is shown in Figures 6 and 7 that has an empty weight of $7.9 \mathrm{~kg}$. A nuclear material-loaded IO Box is stored in a 30-gallon 7A drum. Currently six IO Boxes have been loaded. An IO Box consists of six sides of 1.27-cm-thick aluminum (6010-T6) enclosing an inside cubic dimension of $20.32 \mathrm{~cm}$ (8"). Each IO Box is uniquely numbered, and each side has an alphabetic letter designation (with the lid designated as "A") to assist in recording relative orientations for the radiation measurements. Each unit is a single welded, open-box configuration with a removable lid. The lid is secured with a series of 12 bolts: the heads of which include a small hole to allow for a cable seal to support content inventory accountability. The lid has a pressure valve and is sealed with a pressure gasket to allow for the addition of an inert atmosphere. The box thickness was selected to accommodate the lid bolts and the pressure gasket and to provide strong structural rigidity. The specific box size was selected to support the inclusion of almost any standard-sized ZPPR materials while still enabling oneman-type portability of most loaded contents. Unfortunately, this container volume may still allow for nuclear configurations that can result in nuclear-criticality concerns; hence, while the IO Box is approved for ZPPR vault storage, any custom material contents and configuration must be assessed for nuclear criticality concerns.
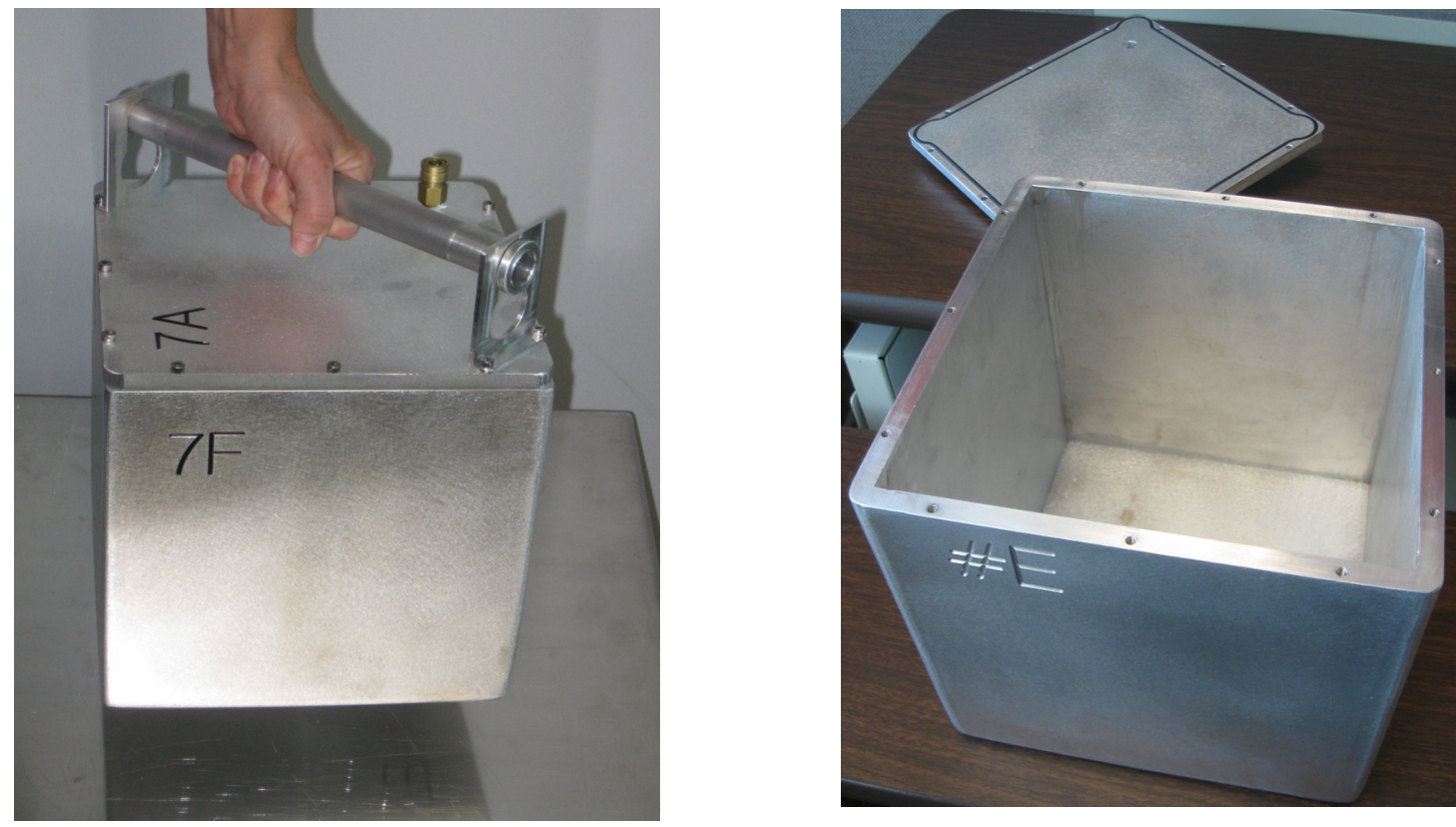

Figure 6. Portable aluminum IO Box container.

To provide examples of what can be assembled with the various nuclear and non-nuclear ZPPR materials available, six IOs are presented in Appendices A-F and summarized in Table 2. These units have been assembled to allow characterization of various shield materials (including nuclear shield materials) with one or more enclosed nuclear materials. A criticality assessment for each IO has provided two $\mathrm{K}_{\text {eff }}$ values: an actual configuration prediction and a conservative criticality safety estimate. These values are included in Table 2 to provide system neutron multiplication estimates (i.e., $\left.1 /\left(1-\mathrm{K}_{\mathrm{eff}}\right)\right)$ for each IO. These IO configurations are expected to remain in semi-permanent storage and available for future radiation measurements. 
Table 2. Key components of each aluminum-box IOs.

\begin{tabular}{|c|c|c|c|c|c|c|c|}
\hline $\begin{array}{l}\text { Inspection } \\
\text { Object } \\
\text { (IO) }\end{array}$ & $\begin{array}{l}\text { Total IO } \\
\text { Config- } \\
\text { uration }\end{array}$ & \multicolumn{2}{|c|}{$\begin{array}{l}\text { Key Nuclear } \\
\text { Material }\end{array}$} & \multicolumn{2}{|c|}{ Key Shield Material } & \multicolumn{2}{|c|}{$\mathrm{K}_{\mathrm{eff}}$} \\
\hline \# & $\begin{array}{c}\text { Total } \\
\text { Mass (kg) }\end{array}$ & Type & $\begin{array}{l}\text { Elemental } \\
\text { Mass (kg) }\end{array}$ & Type & $\begin{array}{l}\text { Elemental } \\
\text { Mass (kg) }\end{array}$ & $\begin{array}{c}\text { MCNP } \\
\text { Calc. } \\
\text { Value }\end{array}$ & $\begin{array}{l}\text { Crit. } \\
\text { Safety } \\
\text { Value }\end{array}$ \\
\hline 5 & 29.9 & HEU & 4.5 (U235) & $\mathrm{DU} / \mathrm{LiH}$ & $\begin{array}{l}6.2 \text { (U238) } \\
2.5(\mathrm{Li} 7)\end{array}$ & $\begin{array}{l}0.522 \pm \\
0.0004\end{array}$ & 0.593 \\
\hline 6 & 27.9 & DU & $\begin{array}{l}5.5 \\
(\mathrm{U} 238)\end{array}$ & $\mathrm{W} / \mathrm{LiH}$ & $\begin{array}{l}5.7(\mathrm{~W}) \\
2.5(\mathrm{Li} 7)\end{array}$ & $\begin{array}{l}0.092 \pm \\
0.0001\end{array}$ & 0.113 \\
\hline 7 & 32.7 & HEU & $\begin{array}{l}4.9 \\
(\mathrm{U} 235)\end{array}$ & DU & 17.3 (U238) & $\begin{array}{l}0.544 \pm \\
0.0004 \\
\end{array}$ & 0.606 \\
\hline 8 & 17.2 & PuAl & $1.2(\mathrm{Pu} 239)$ & DU & $5.6(\mathrm{U} 238)$ & $\begin{array}{l}0.247 \pm \\
0.0002 \\
\end{array}$ & 0.307 \\
\hline 9 & 17.0 & PuAl & $1.2(\mathrm{Pu} 239)$ & HEU & 4.5 (U235) & $\begin{array}{l}0.327 \pm \\
0.0002 \\
\end{array}$ & 0.455 \\
\hline 10 & 20.8 & PuAl & $1.2(\mathrm{Pu} 239)$ & DU/Poly & $\begin{array}{l}5.6 \text { (U238) } \\
8.2 \text { (Poly- } \\
\text { ethylene) }\end{array}$ & $\begin{array}{l}0.410 \pm \\
0.0005\end{array}$ & 0.479 \\
\hline
\end{tabular}

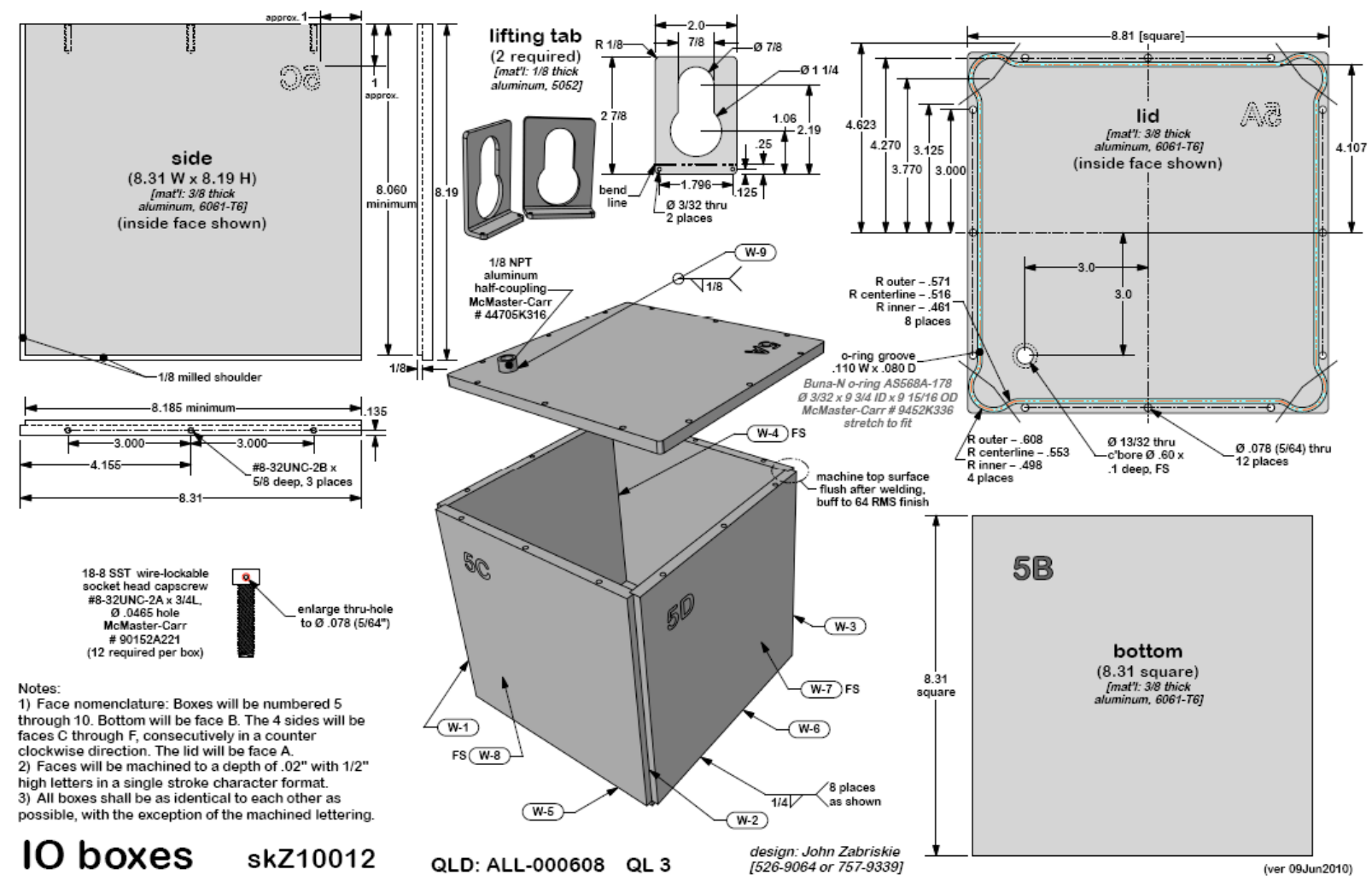

Figure 7. The Aluminum IO Box schematic for customized configurations. 


\section{REFERENCE}

1. R.T. Klann, B.D. Austin, S.E. Aumeier, and D. N. Olsen, "Inventory of Special Nuclear Materials from the Zero Power Physics Reactor," ANL-NT-176, April 2001. 
Appendix A

Composite Shielding of HEU (IO\#5) 


\section{Appendix A}

\section{Composite Shielding of HEU (IO\#5)}

This appendix presents an inspection object (IO\#5) that was designed to assess the effect of a multicomponent shield around a HEU sample. The relative position of the aluminum IO Box is also shown to visually assist the reader. It begins with an exploded view of all components and then presents the key steps in the assembly of the IO. For further clarification, assembly photos are included at selected steps in the assembly process. The upper left table below identifies the material parts with the "ID\#" being a specific ZPPR material identification (see Ref. 1), the "part names" provides the material type (with plate thickness, width, and length in inches within parenthesis), and the number of plates used ("qty"). Items not having a unique ID\# for this IO indicate custom-made aluminum components required for the final assembly. The lower left table presents the elemental mass $(\mathrm{kg})$ for each material component ("Mele") [U235 for HEU, U-238 for DU, and $\mathrm{Li}-7$ for $\mathrm{LiH}$ ], the total mass of that material component ("Mtot"), and the total mass of the assembled IO (with the aluminum IO Box). LiH had a density of $0.34 \mathrm{~g} / \mathrm{cc}$ and a lithium composition of $6.38 \mathrm{wt} \% \mathrm{Li}-6$ and $80.91 \mathrm{wt} \% \mathrm{Li}-7$. All spacers are made of standard 6061-T6 aluminum.
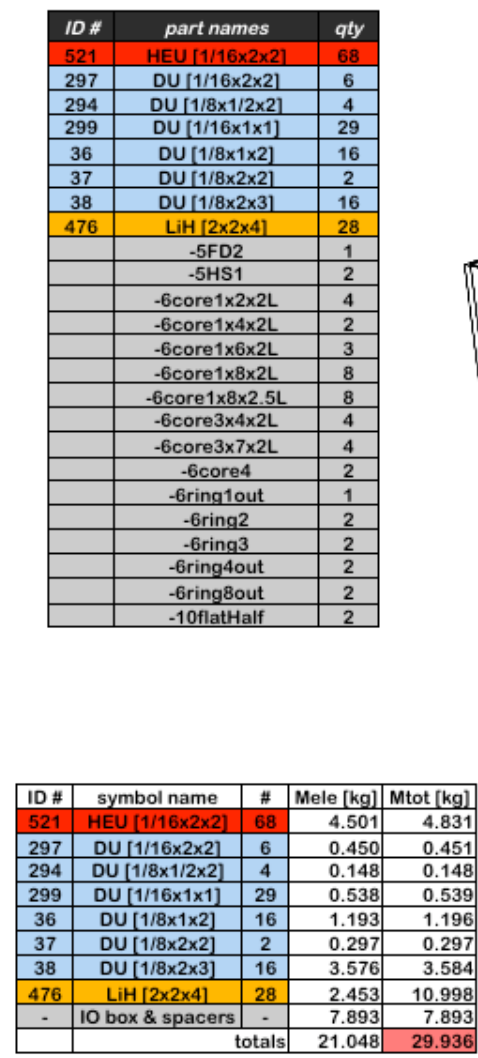

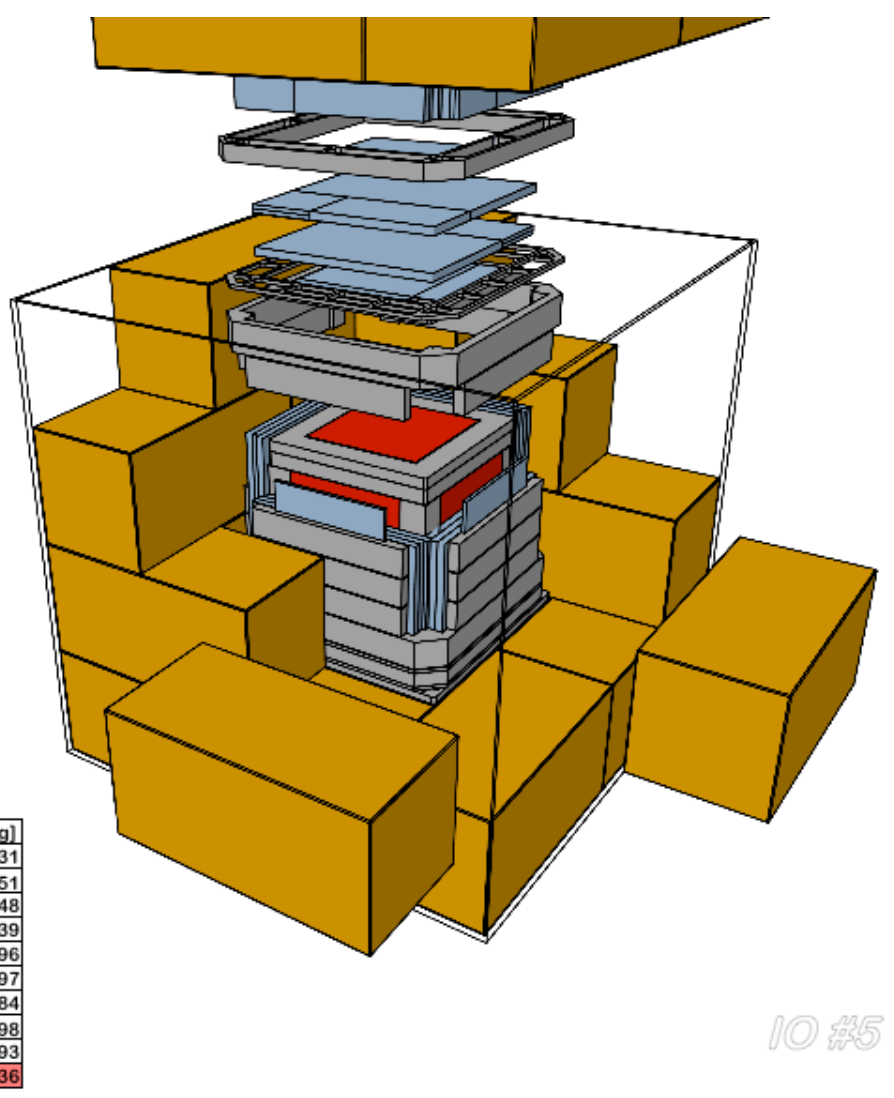



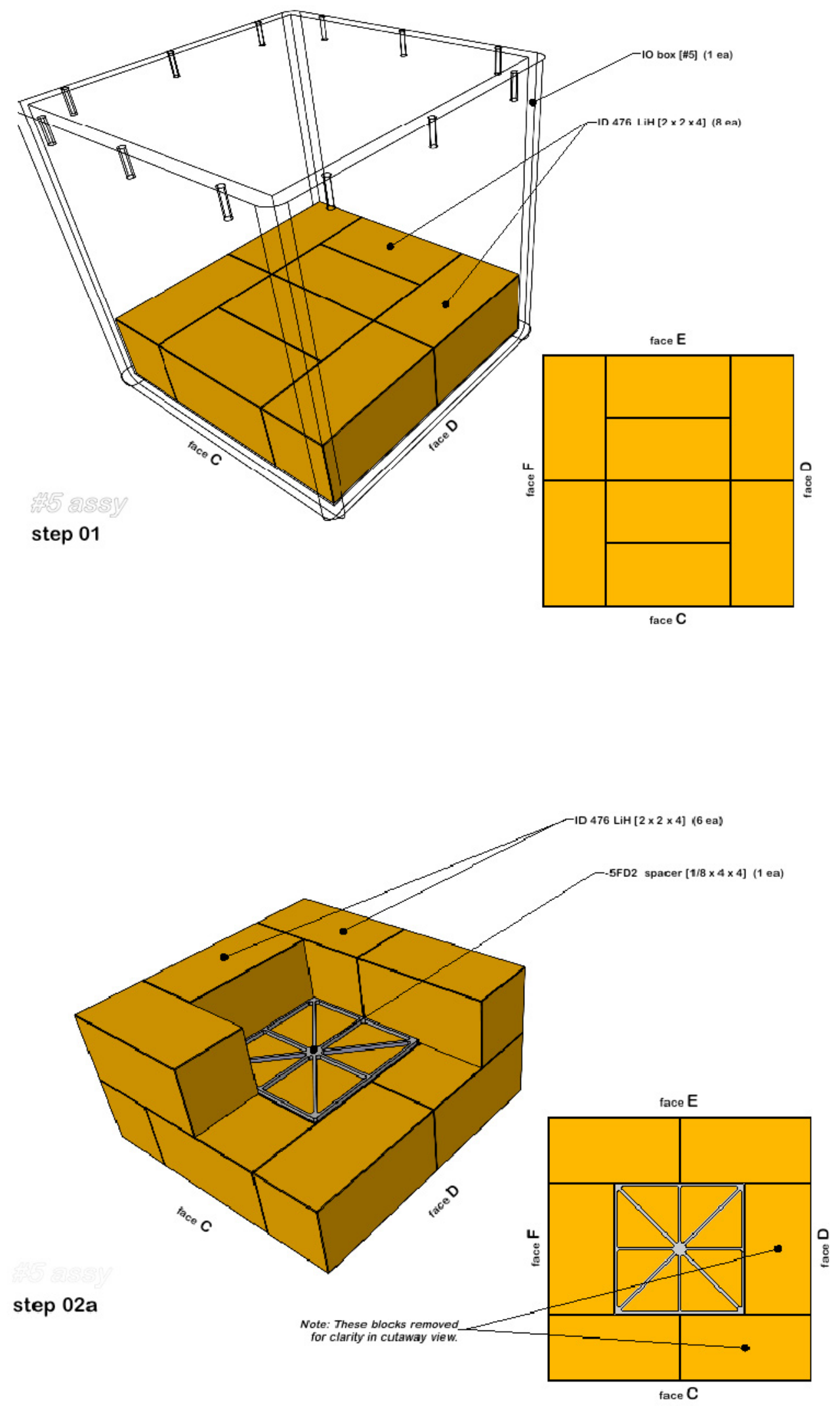

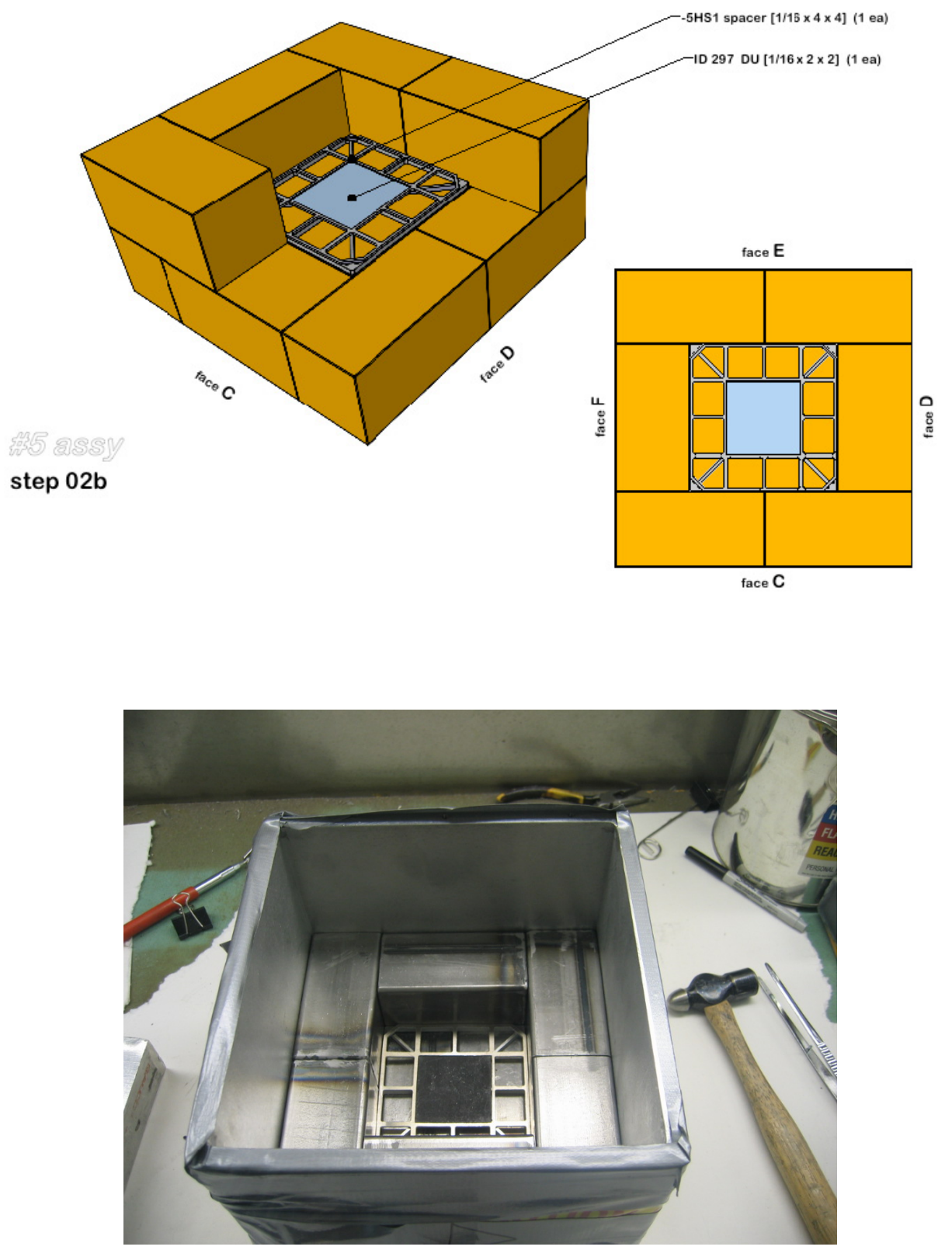

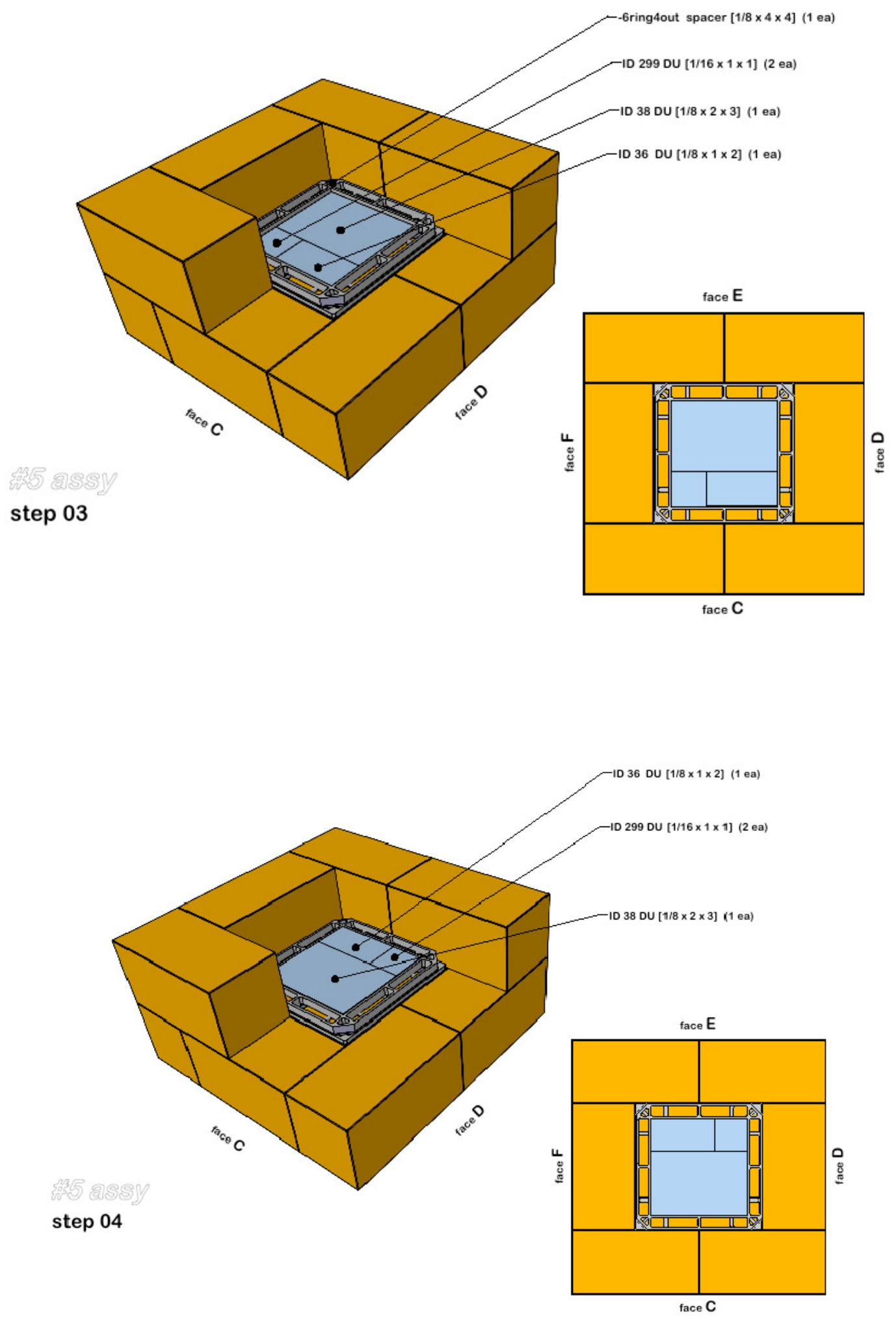

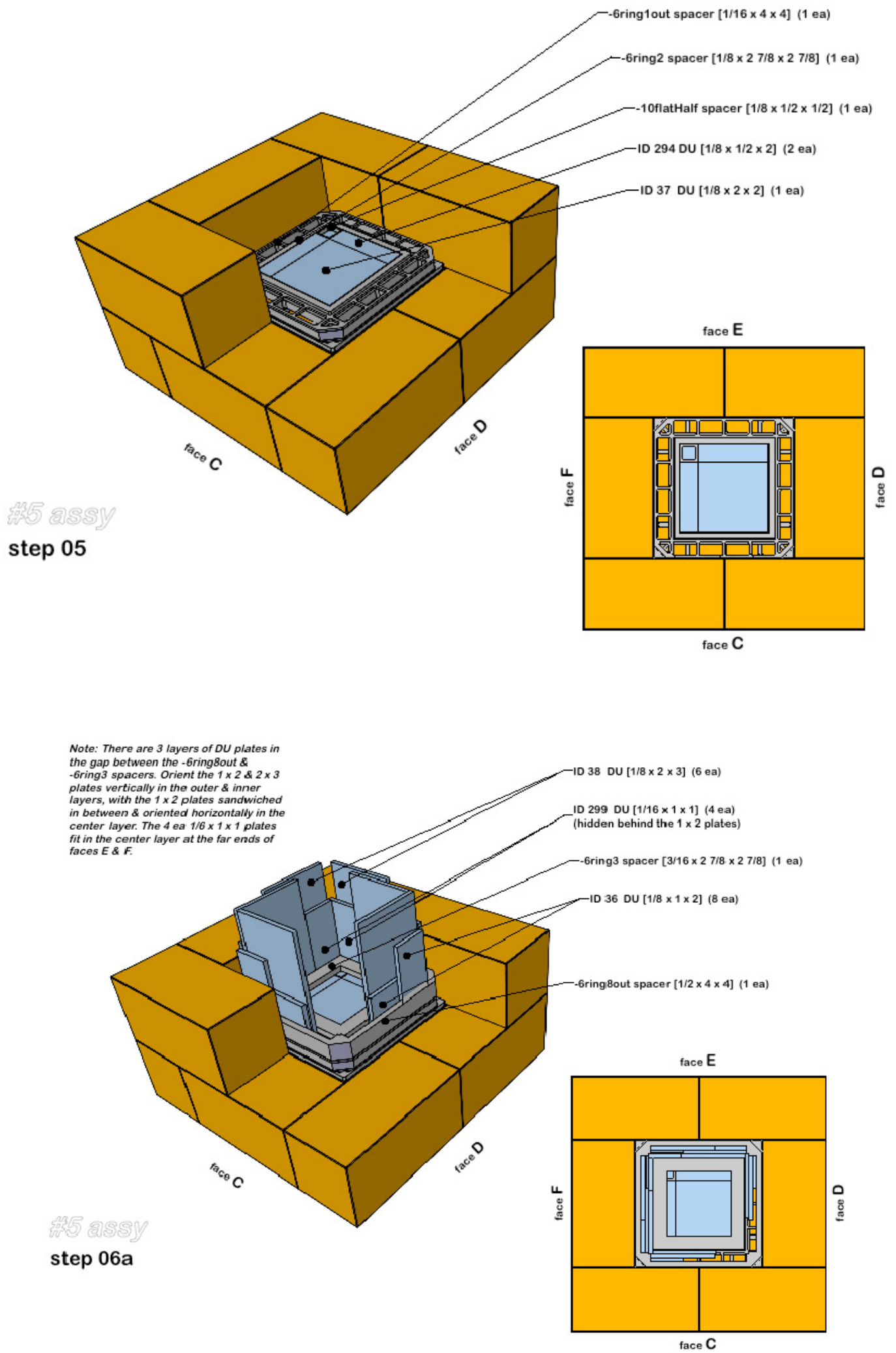

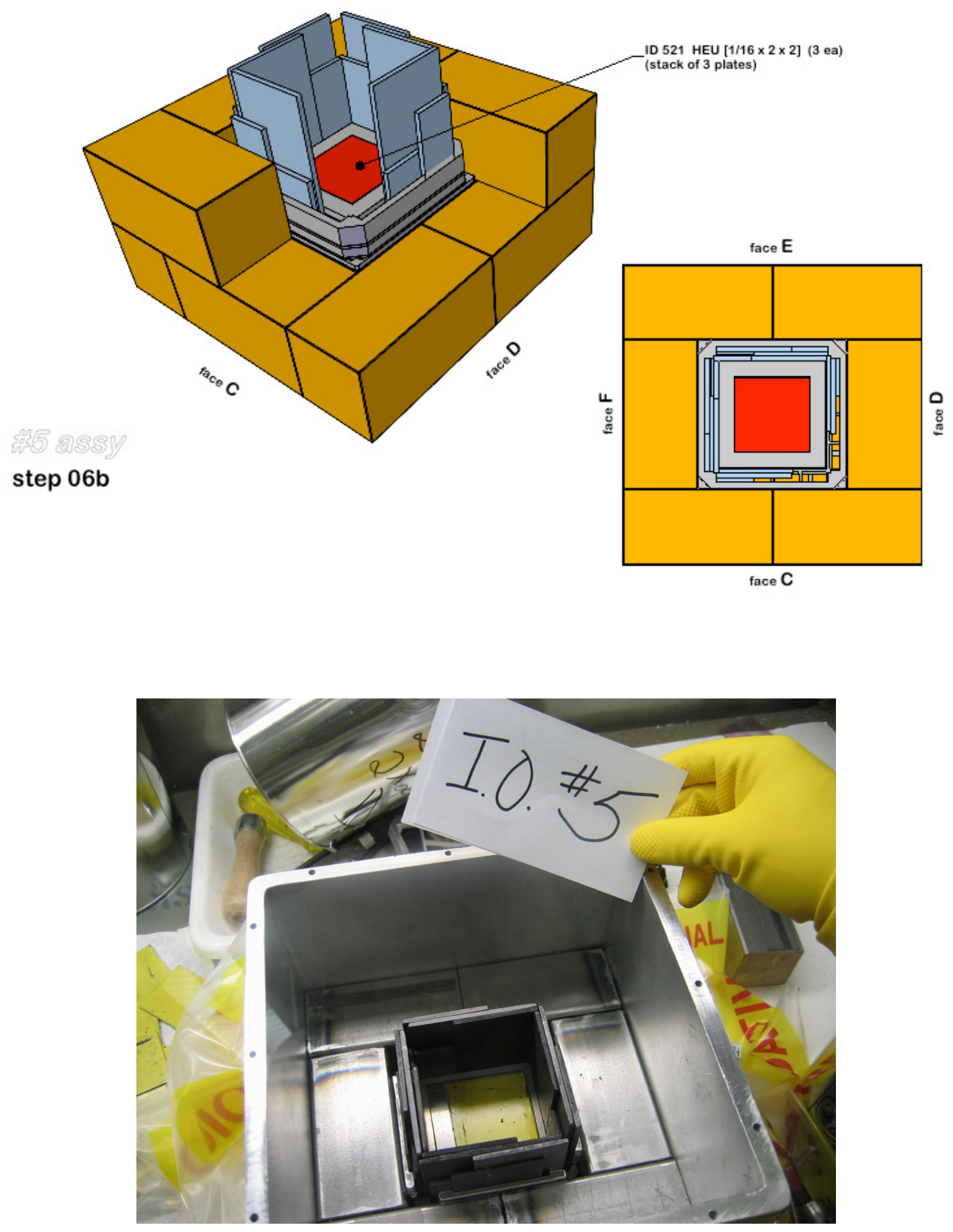

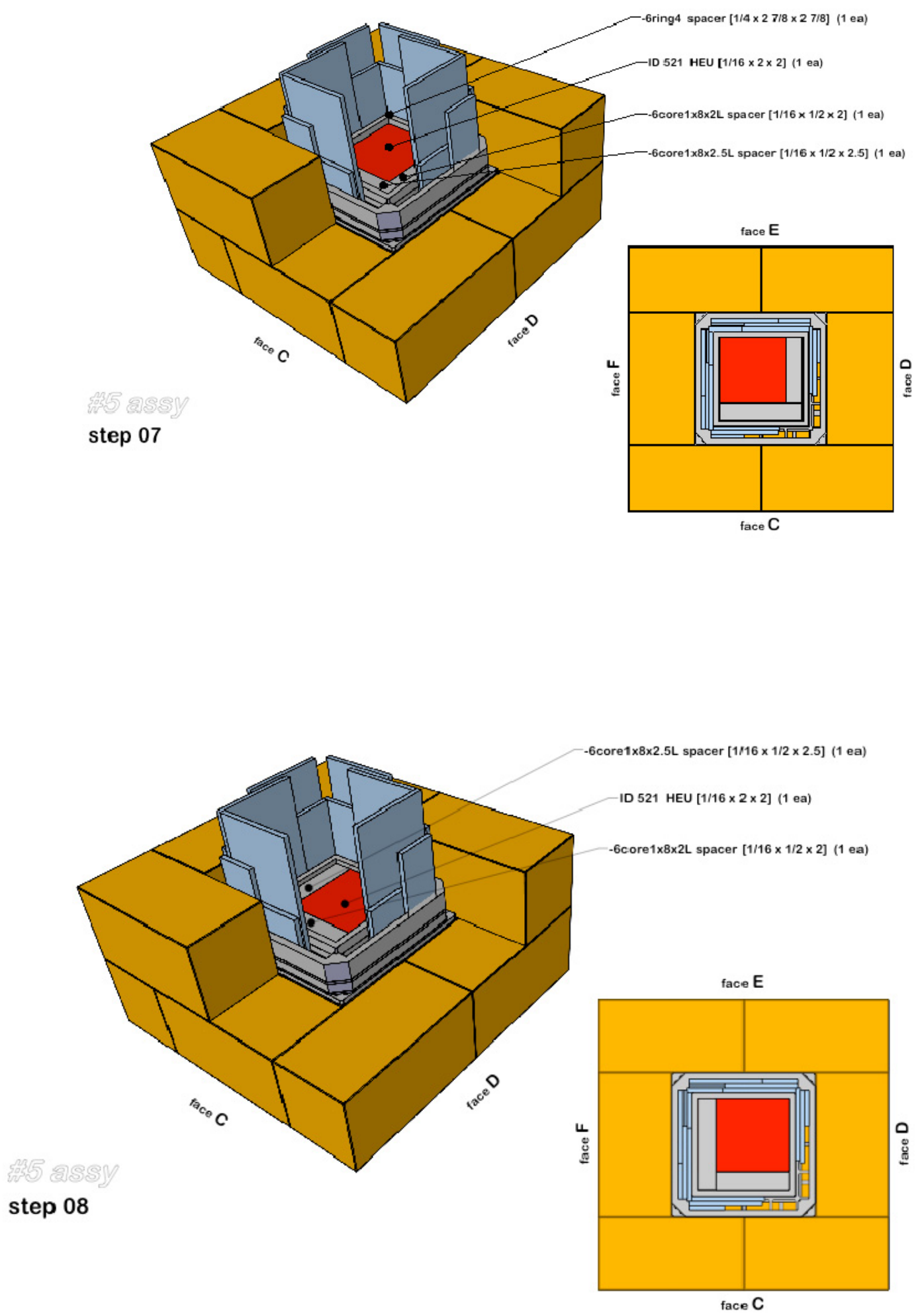

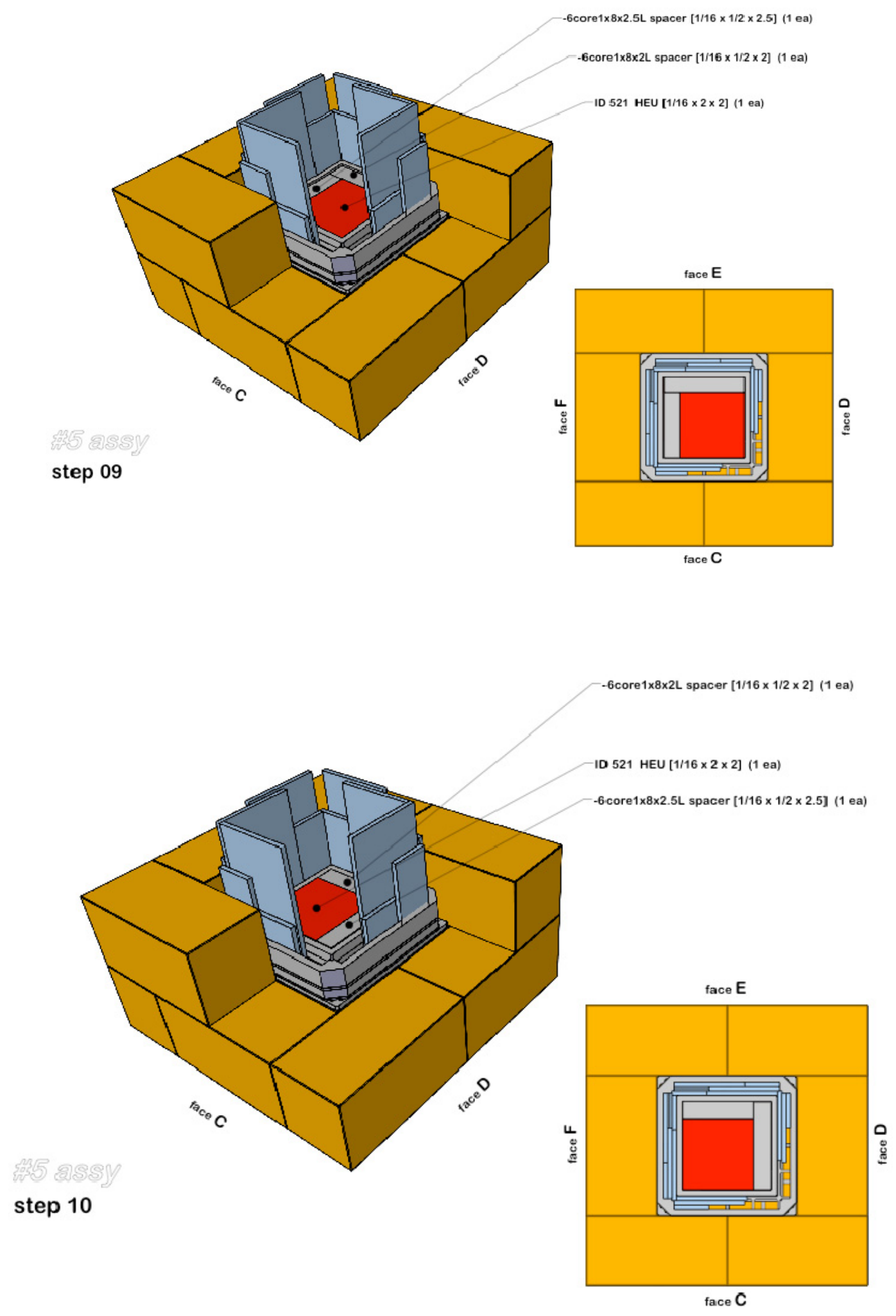

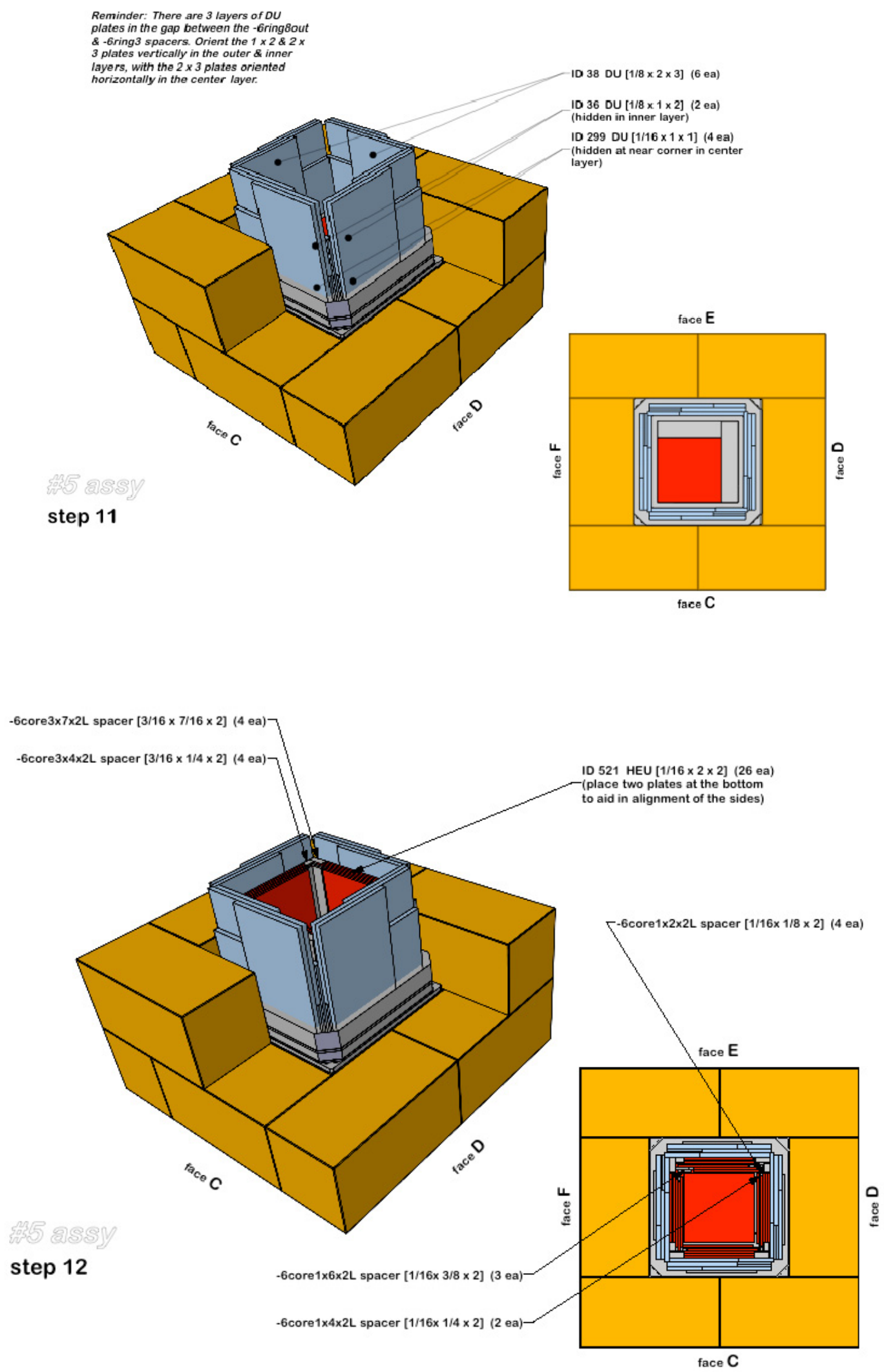

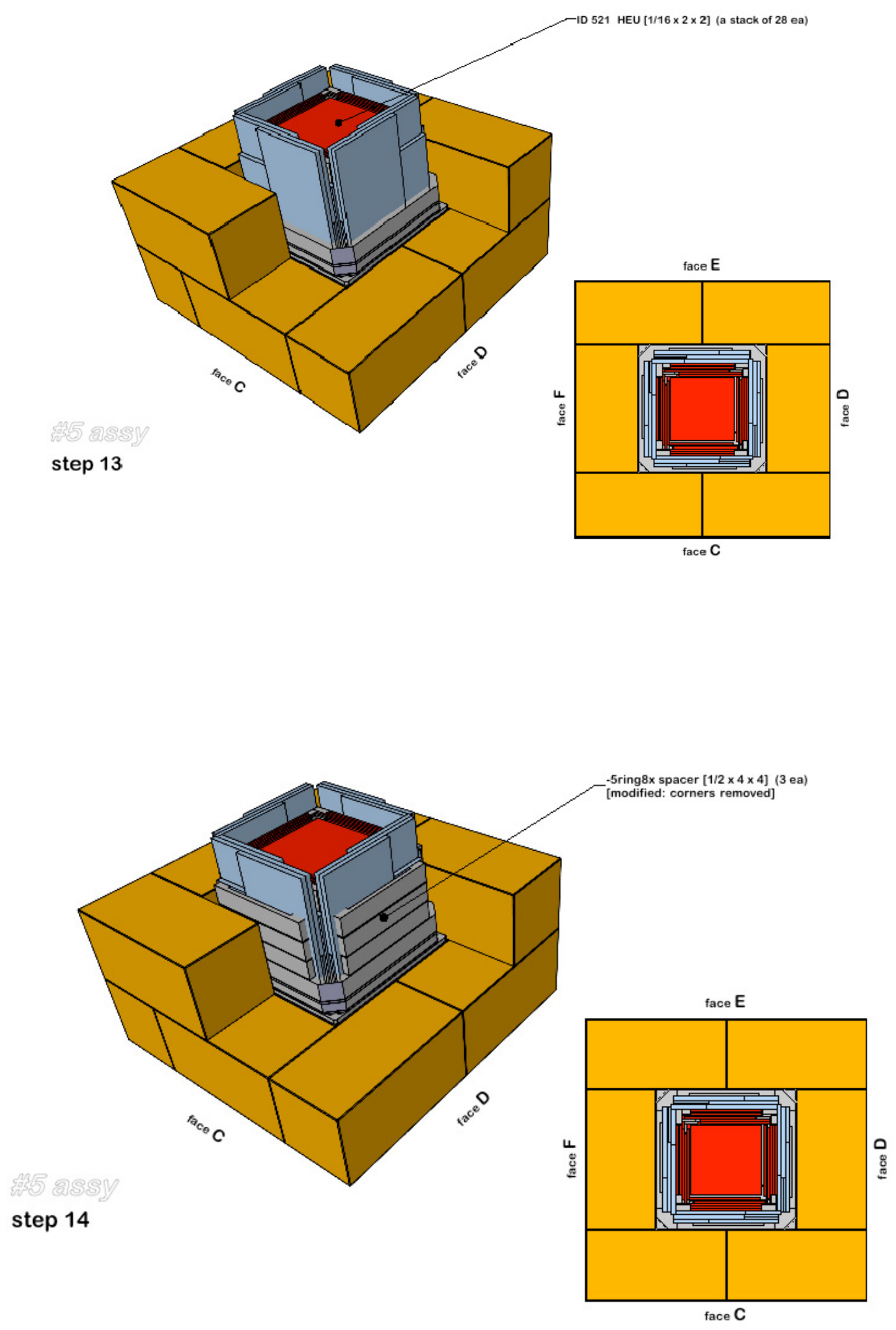

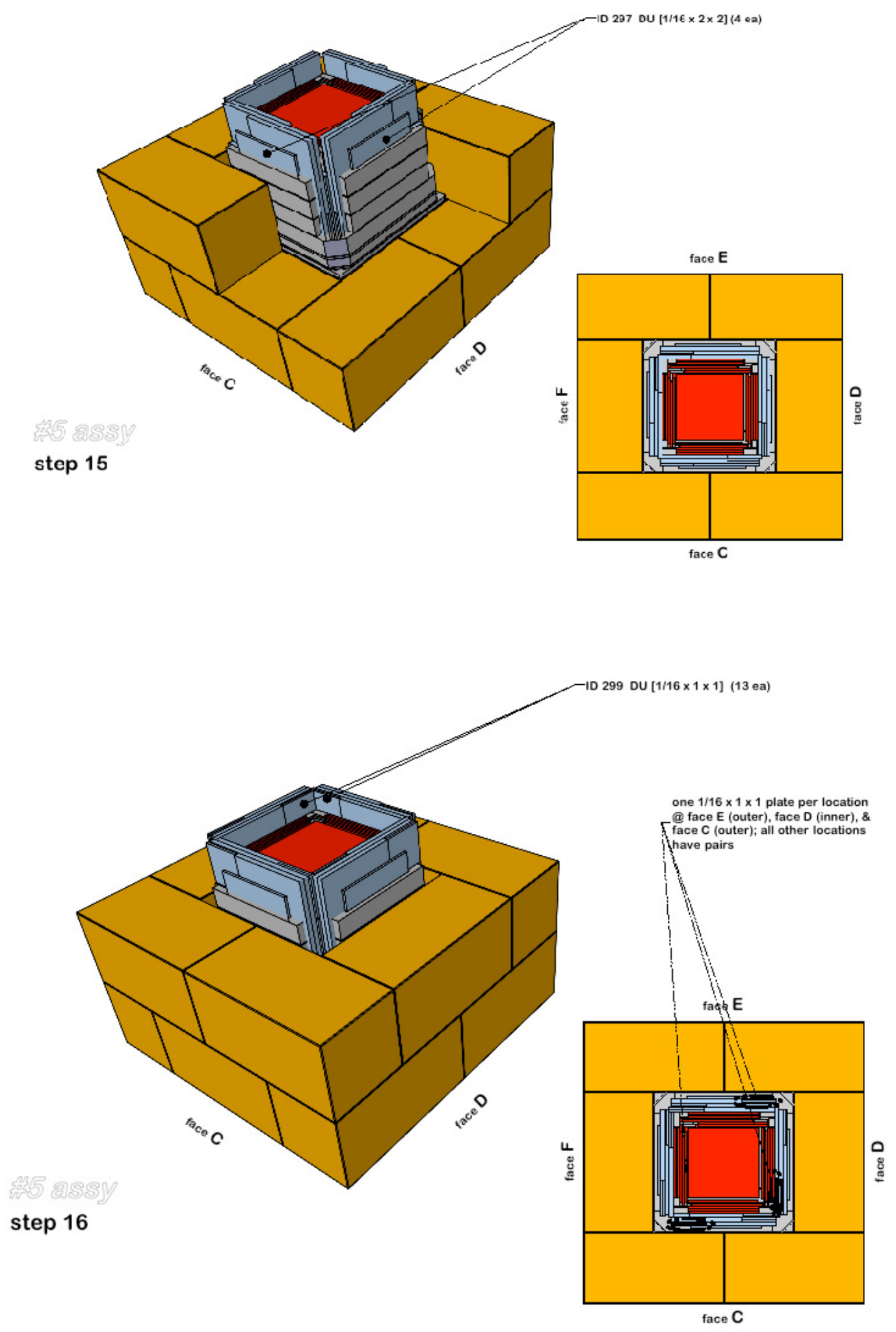

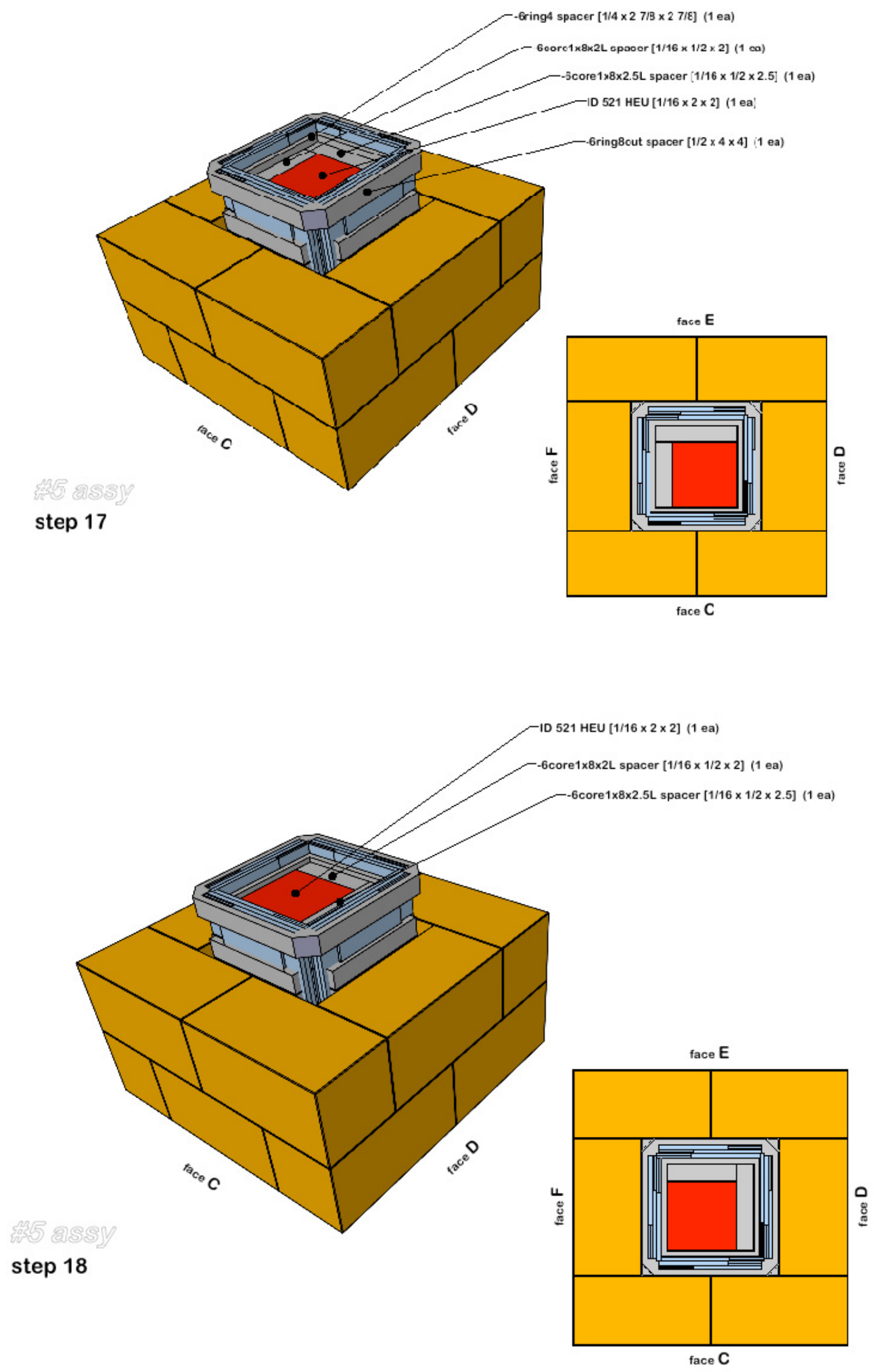

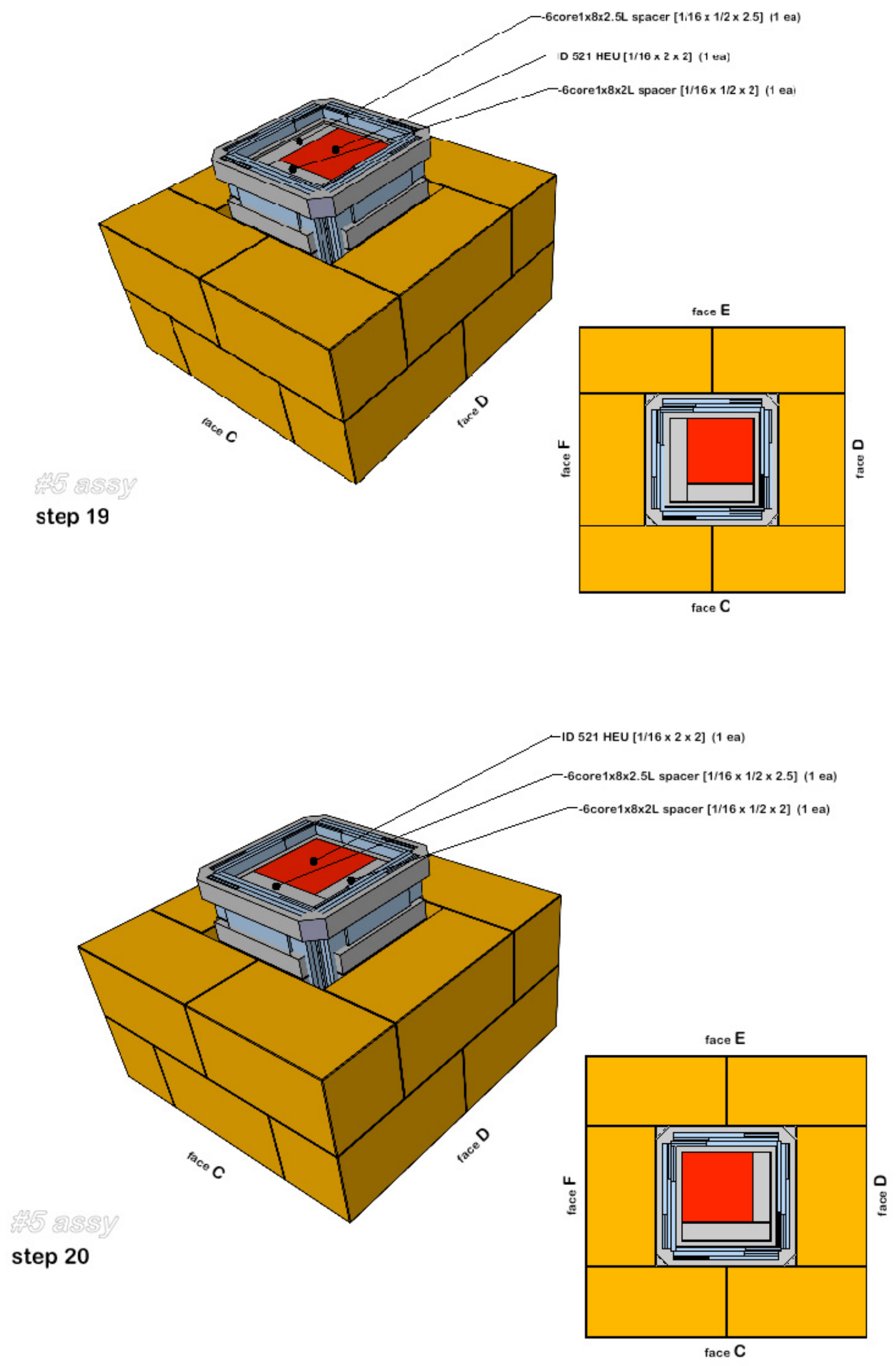

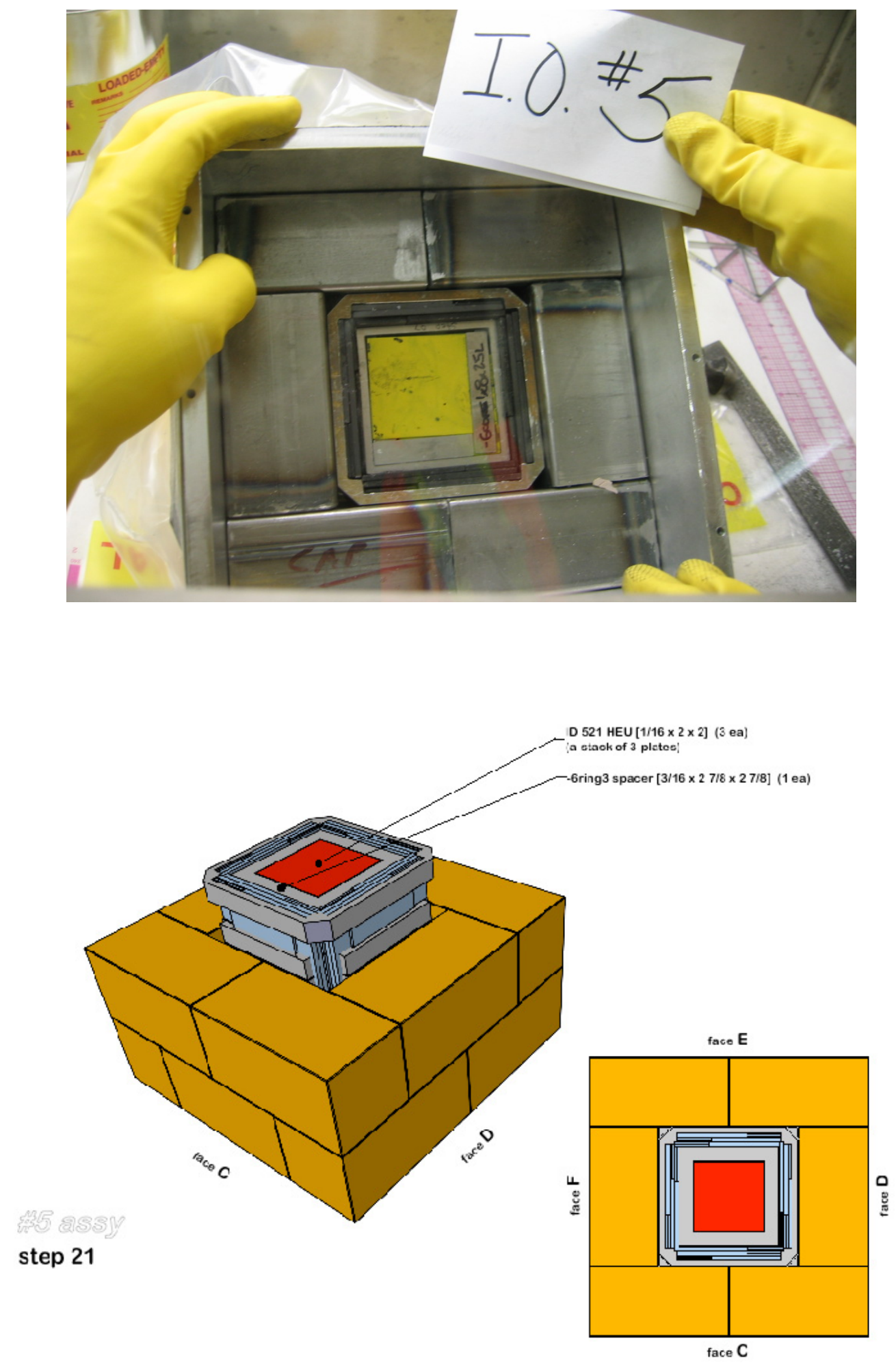

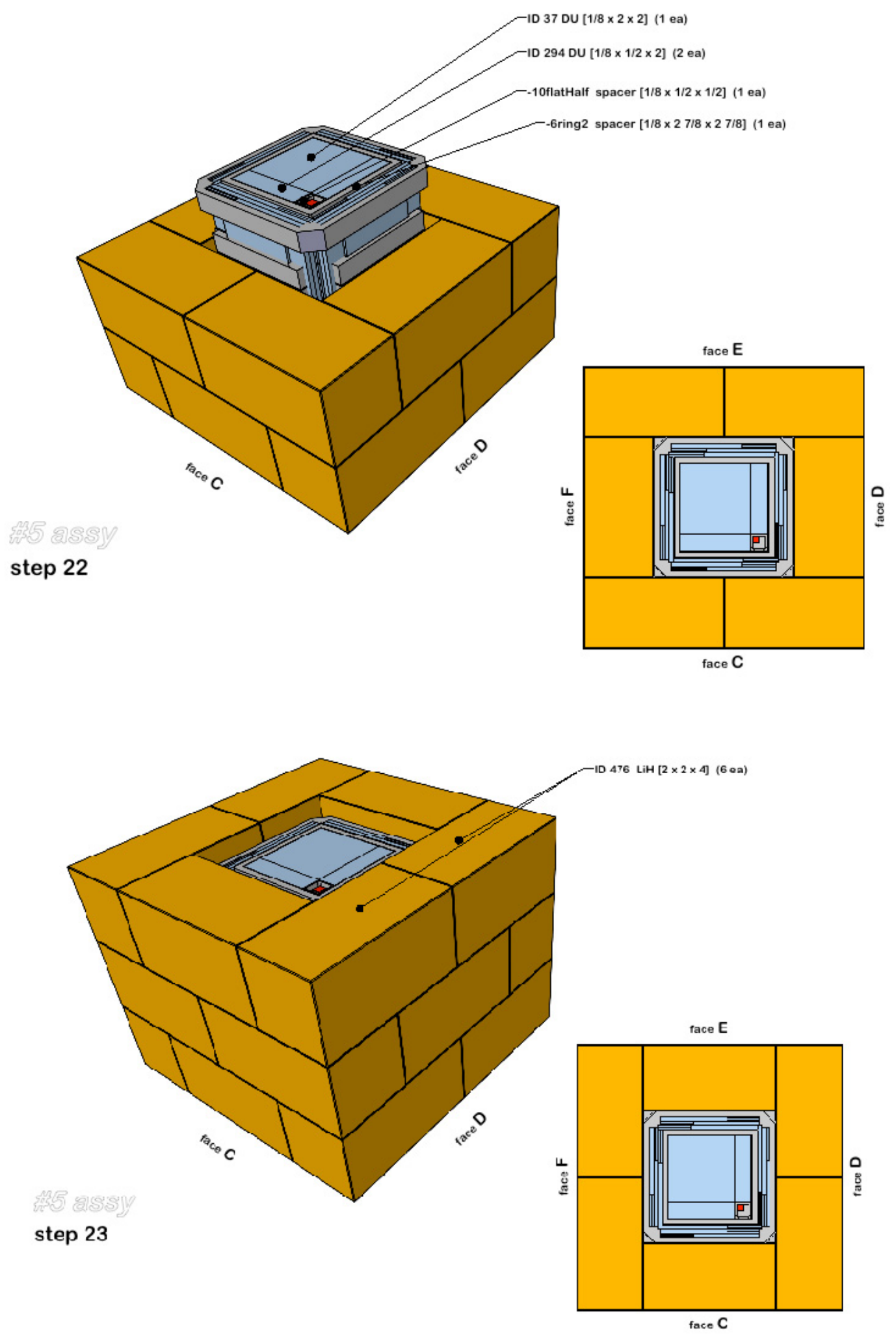

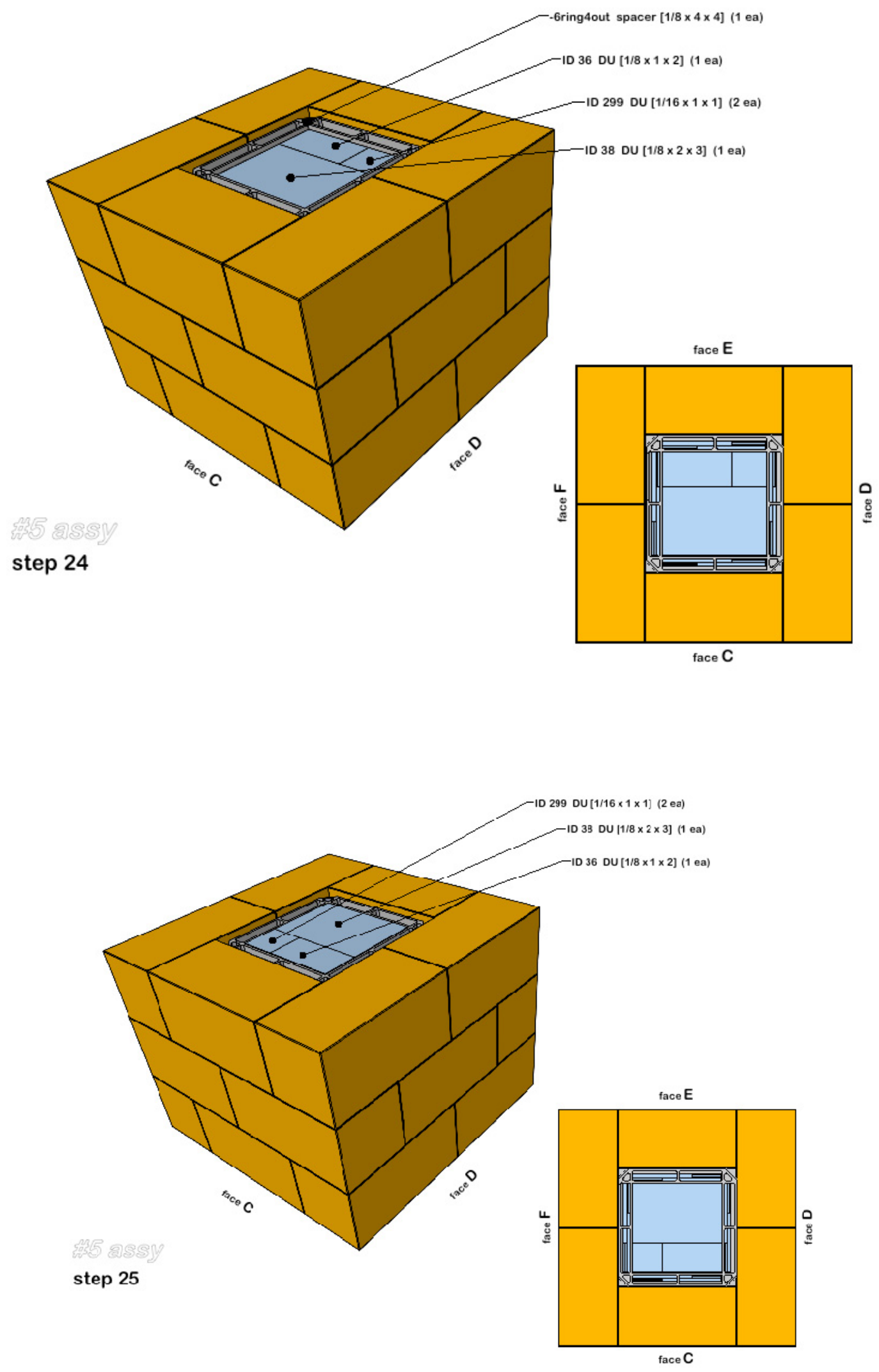


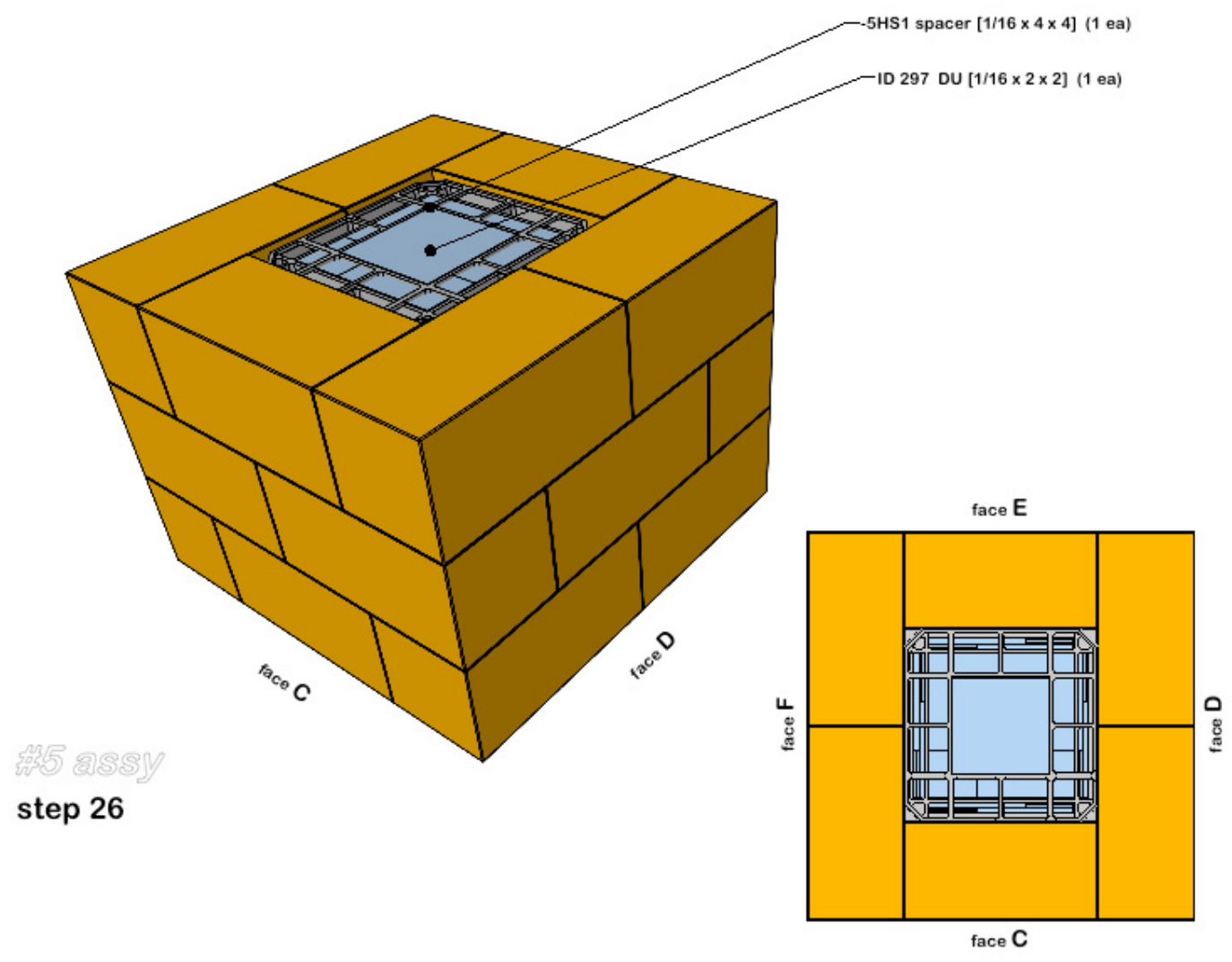



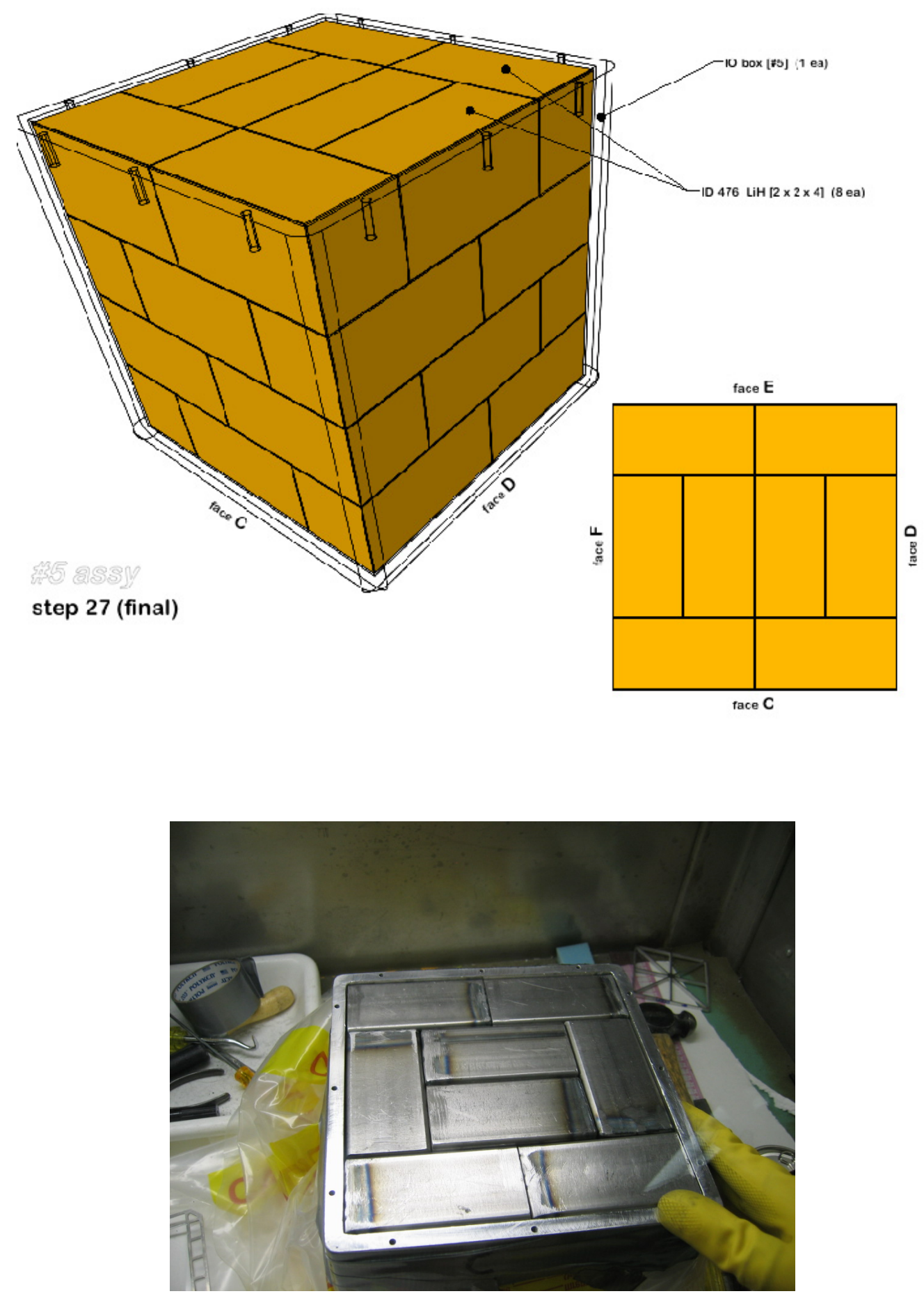
Appendix B

Composite Shielding of DU (IO\#6) 


\section{Appendix B}

\section{Composite Shielding of DU (IO\#6)}

This appendix presents an inspection object (IO\#6) that was designed to assess the effect of a multicomponent shield around a DU sample. The relative position of the aluminum IO Box is also shown to visually assist the reader. It begins with an exploded view of all components and then presents the key steps in the assembly of the IO. For further clarification, assembly photos are included at selected steps in the assembly process. The upper left table below identifies the material parts with the "ID\#" being a specific ZPPR material identification (see Ref. 1), the "part names" provides the material type (with plate thickness, width, and length in inches within parenthesis), and the number of plates used ("qty"). Items not having a unique ID\# for this IO indicate custom-made aluminum components required for the final assembly. The lower left table presents the elemental mass $(\mathrm{kg})$ for each material component ("Mele") [U238 for $\mathrm{DU}$, and $\mathrm{Li}-7$ for $\mathrm{LiH}$ ], the total mass of that material component ("Mtot"), and the total mass of the assembled IO (with the aluminum IO Box). LiH had a density of $0.34 \mathrm{~g} / \mathrm{cc}$ and a lithium composition of $6.38 \mathrm{wt} \% \mathrm{Li}-6$ and $80.91 \mathrm{wt} \% \mathrm{Li}-7$. All spacers are made of standard 6061-T6 aluminum.
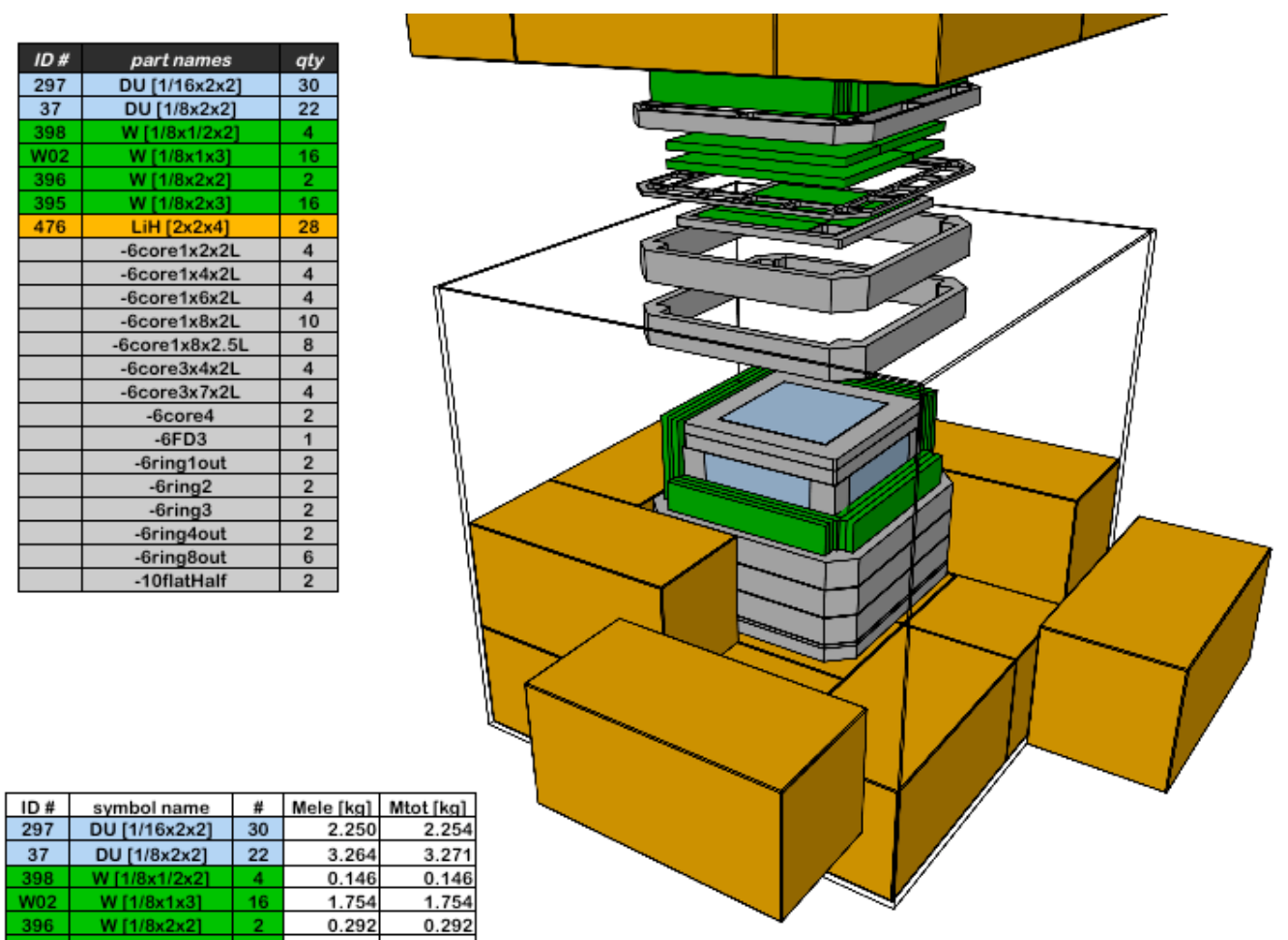

\begin{tabular}{|c|c|c|c|c|}
\hline ID \# & symbol name & \# & Mele $[\mathrm{kg}]$ & Mtot [kg] \\
\hline 297 & DU $[1 / 16 \times 2 \times 2]$ & 30 & 2.250 & 2.254 \\
\hline 37 & $\mathrm{DU}[1 / 8 \times 2 \times 2]$ & 22 & 3.264 & 3.271 \\
\hline 398 & $W[1 / 8 \times 1 / 2 \times 2]$ & 4 & 0.146 & 0.146 \\
\hline W02 & $W[1 / 8 \times 1 \times 3]$ & 16 & 1.754 & 1.754 \\
\hline 396 & $W[1 / 8 \times 2 \times 2]$ & 2 & 0.292 & 0.292 \\
\hline 395 & $W[1 / 8 \times 2 \times 3]$ & 16 & 3.507 & 3.507 \\
\hline 476 & $\operatorname{LiH}[2 \times 2 \times 4]$ & 28 & 2.453 & 10.998 \\
\hline \multirow[t]{2}{*}{-} & 10 box \& spacers & - & 7.936 & 7.936 \\
\hline & & otals & 19.352 & 27.904 \\
\hline
\end{tabular}



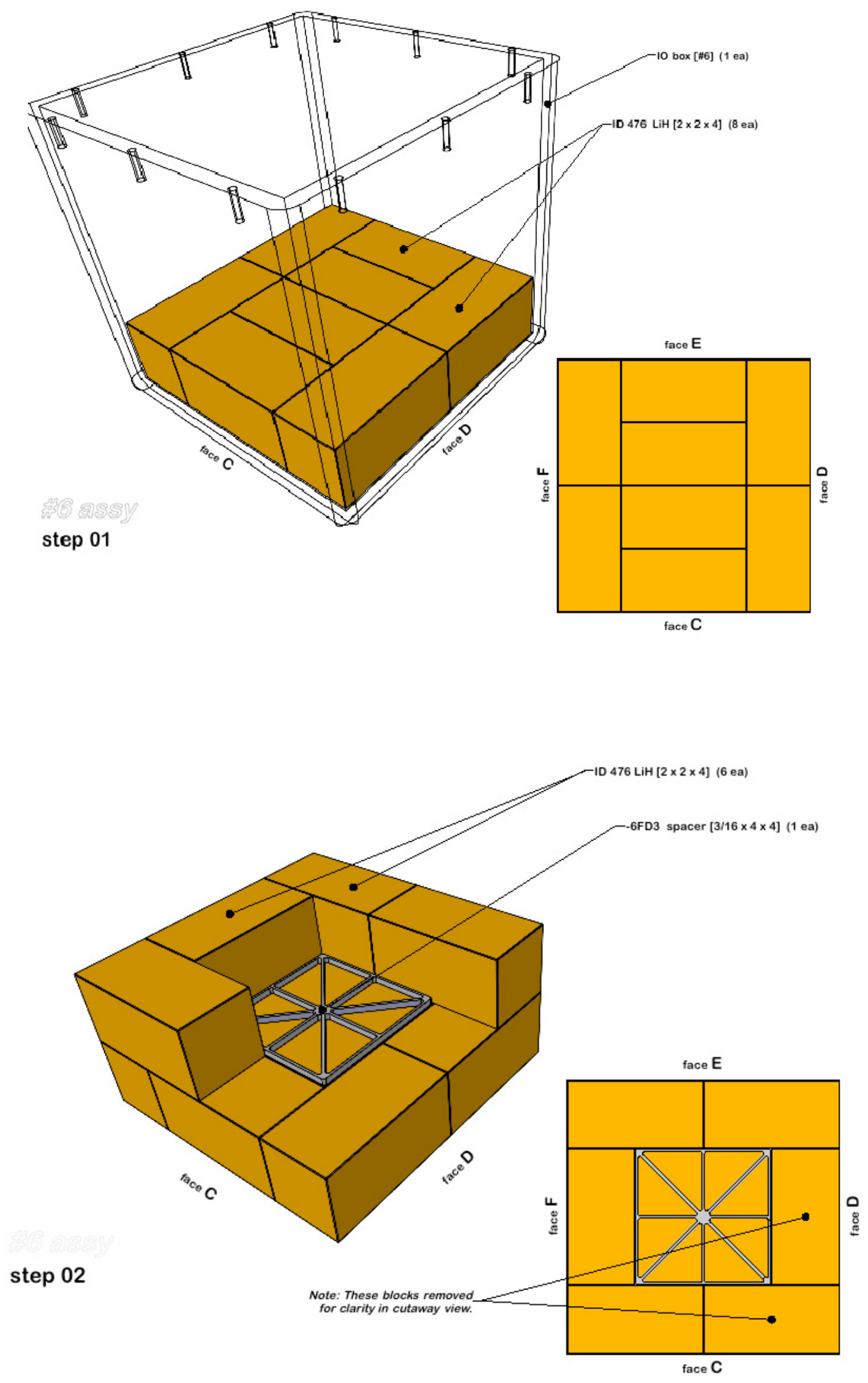

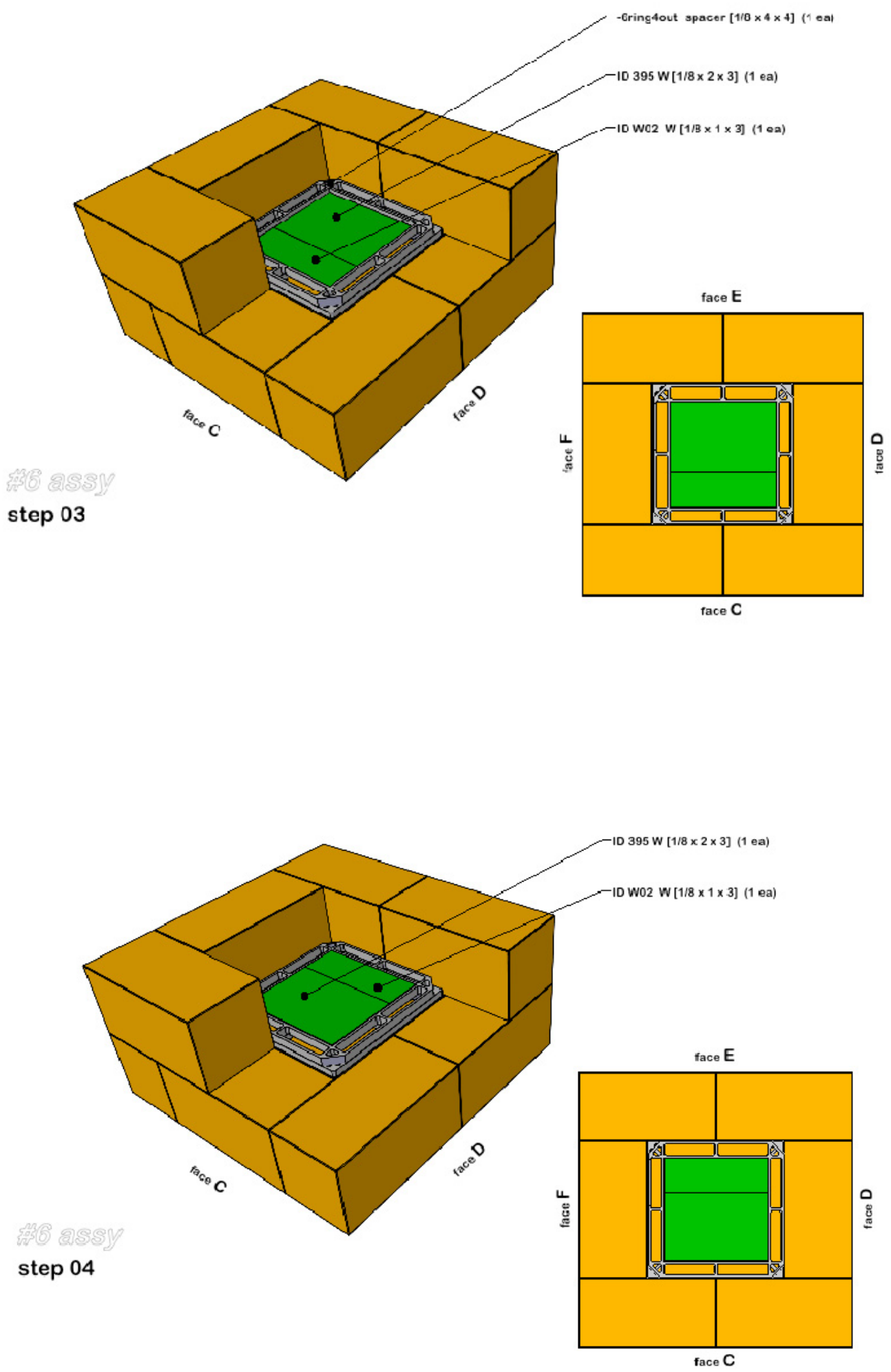

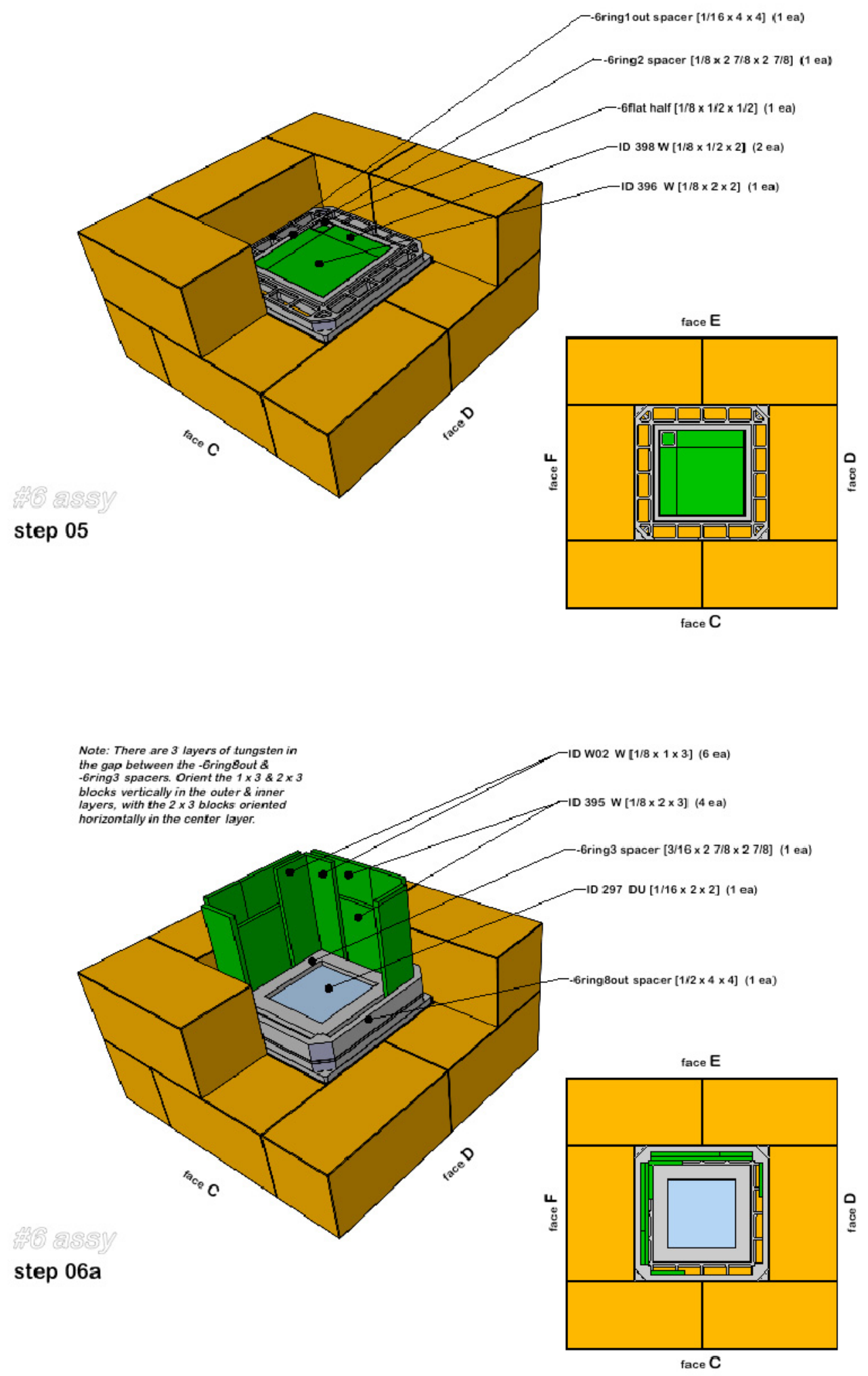

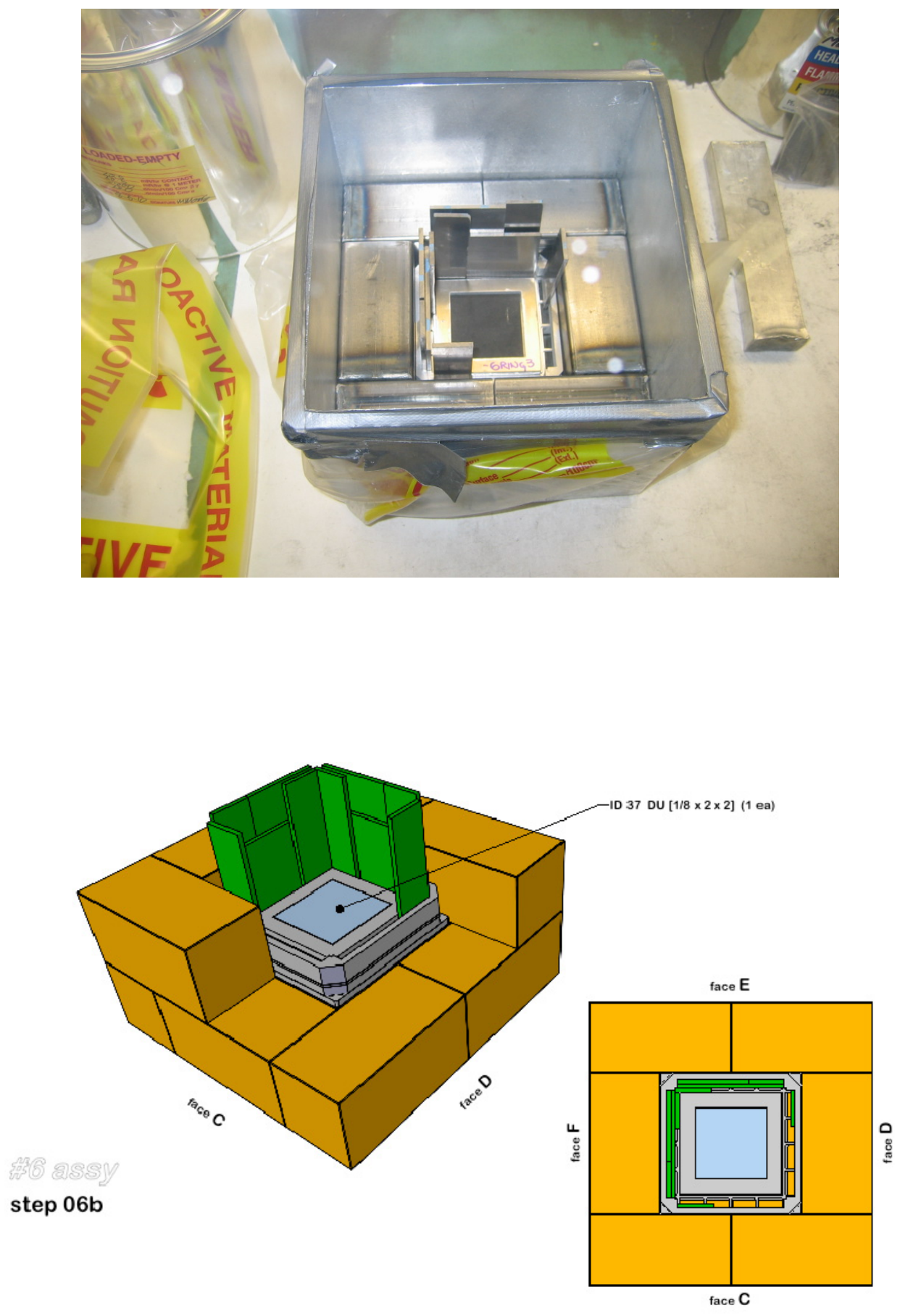

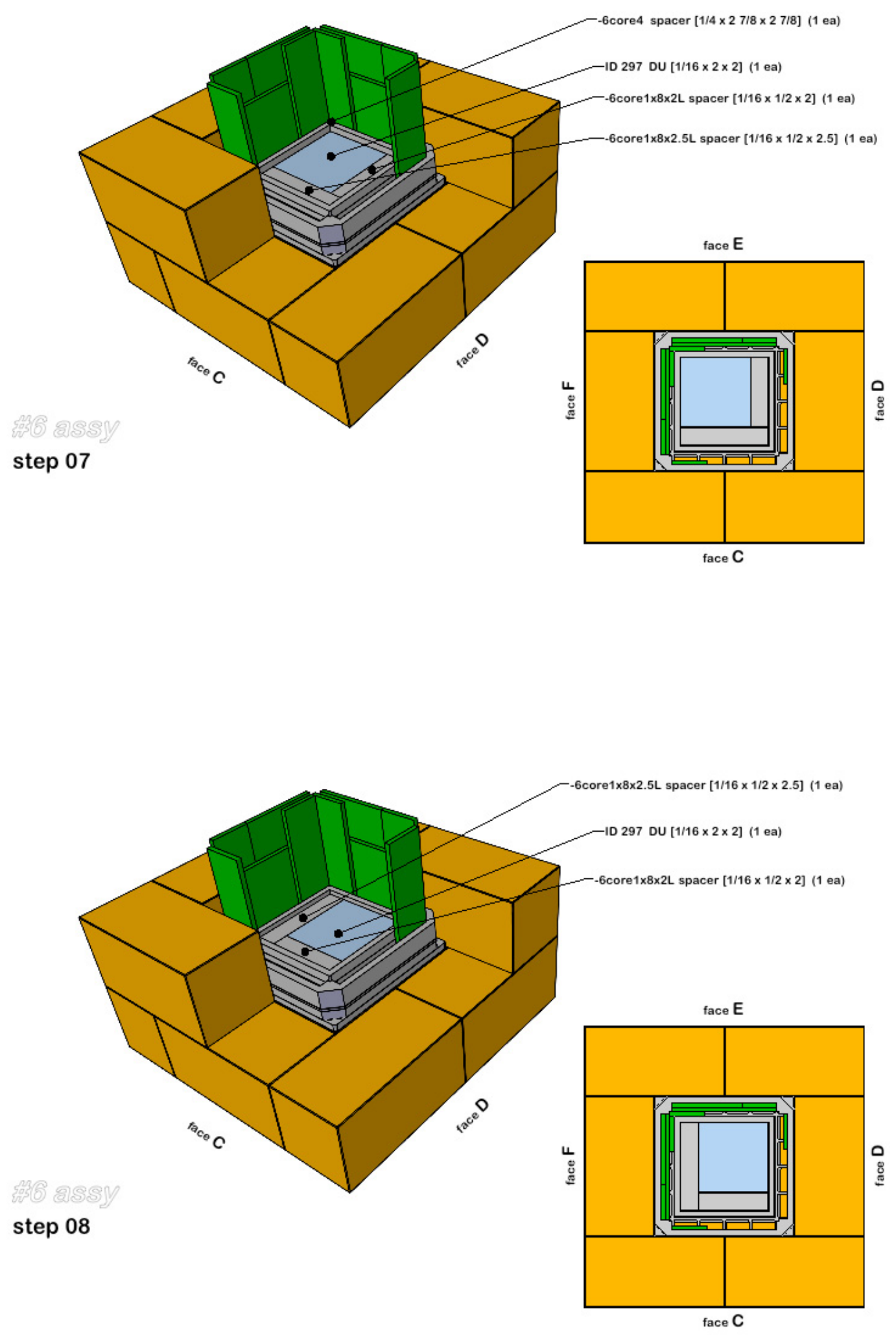

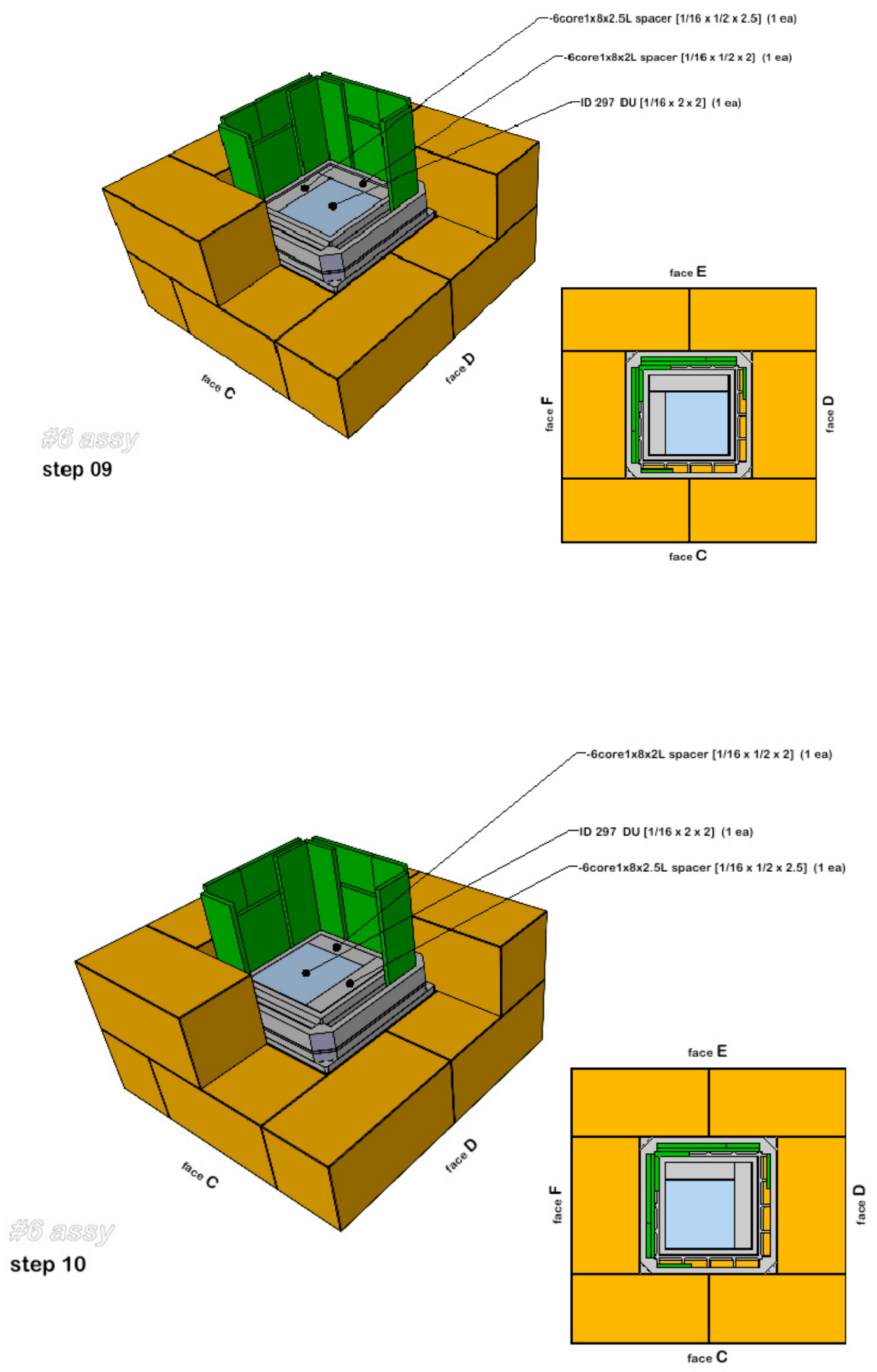

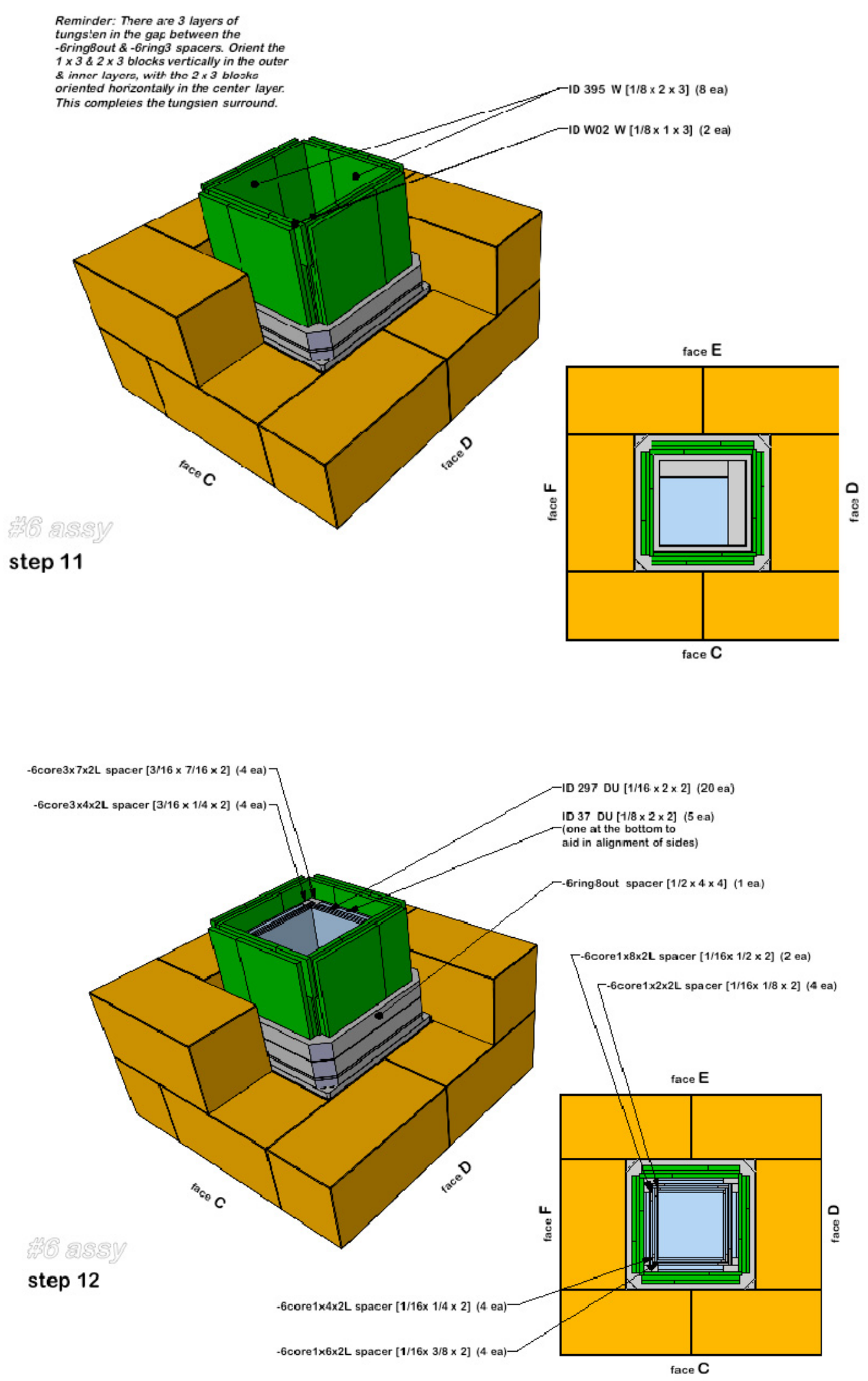

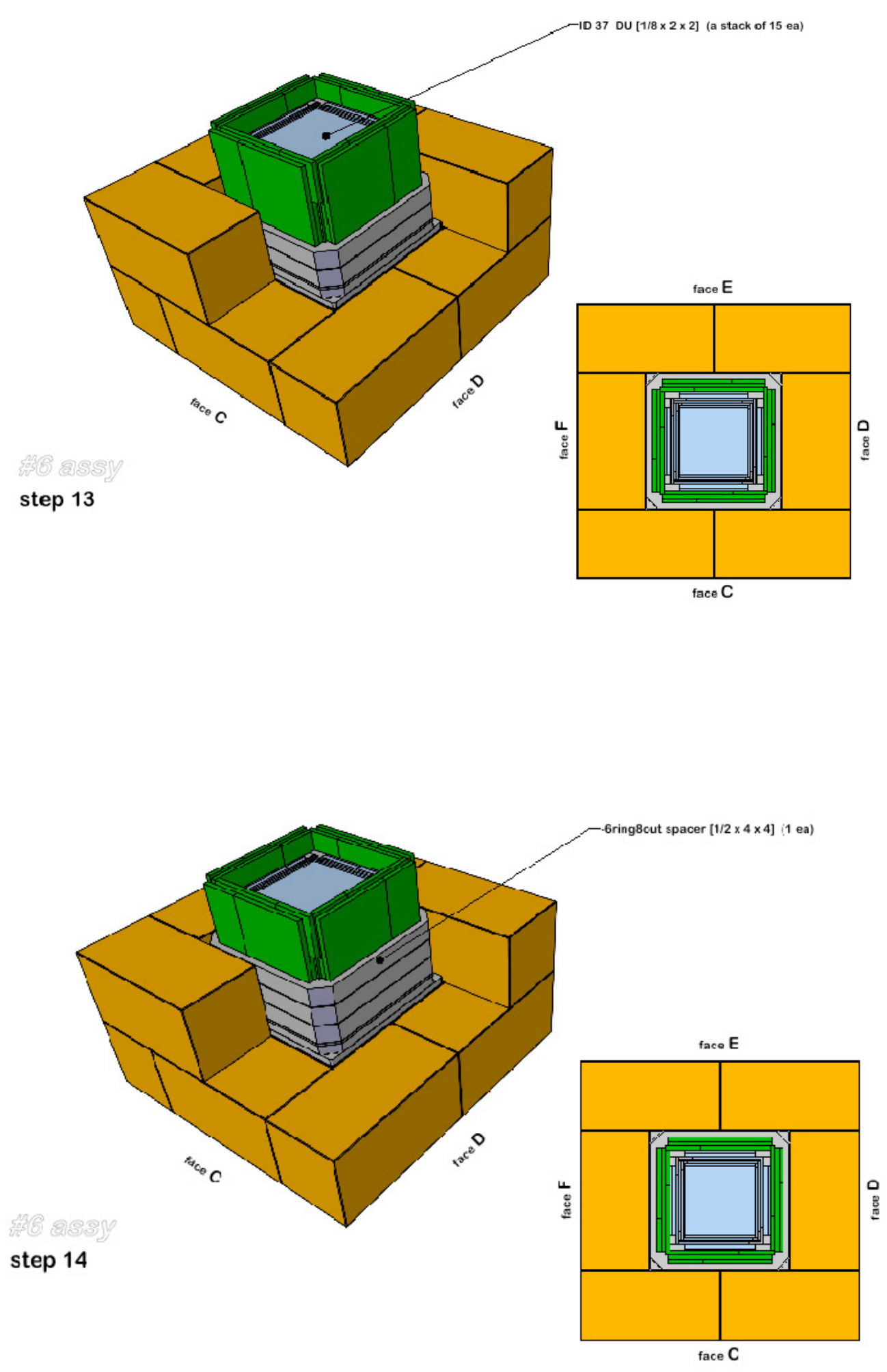

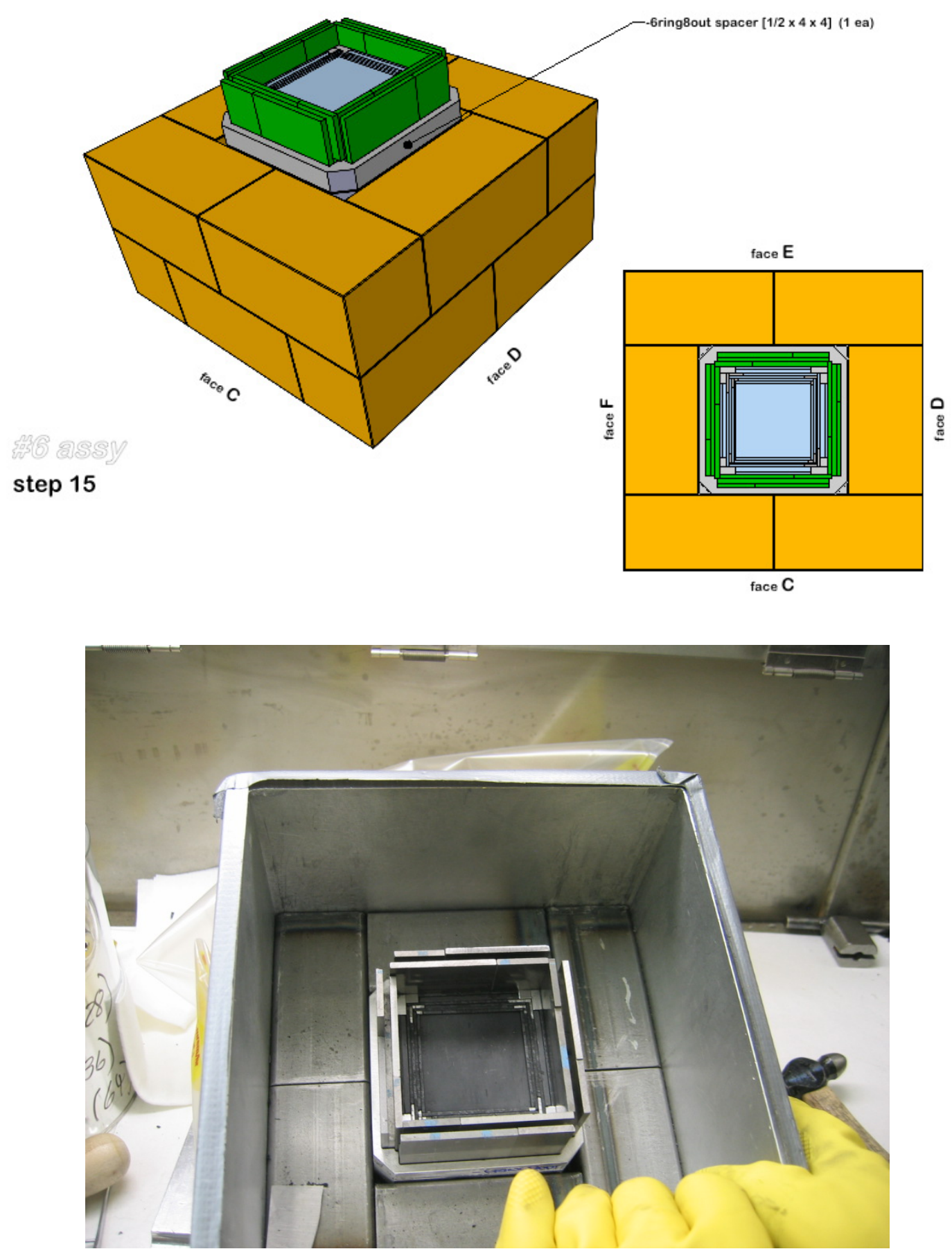

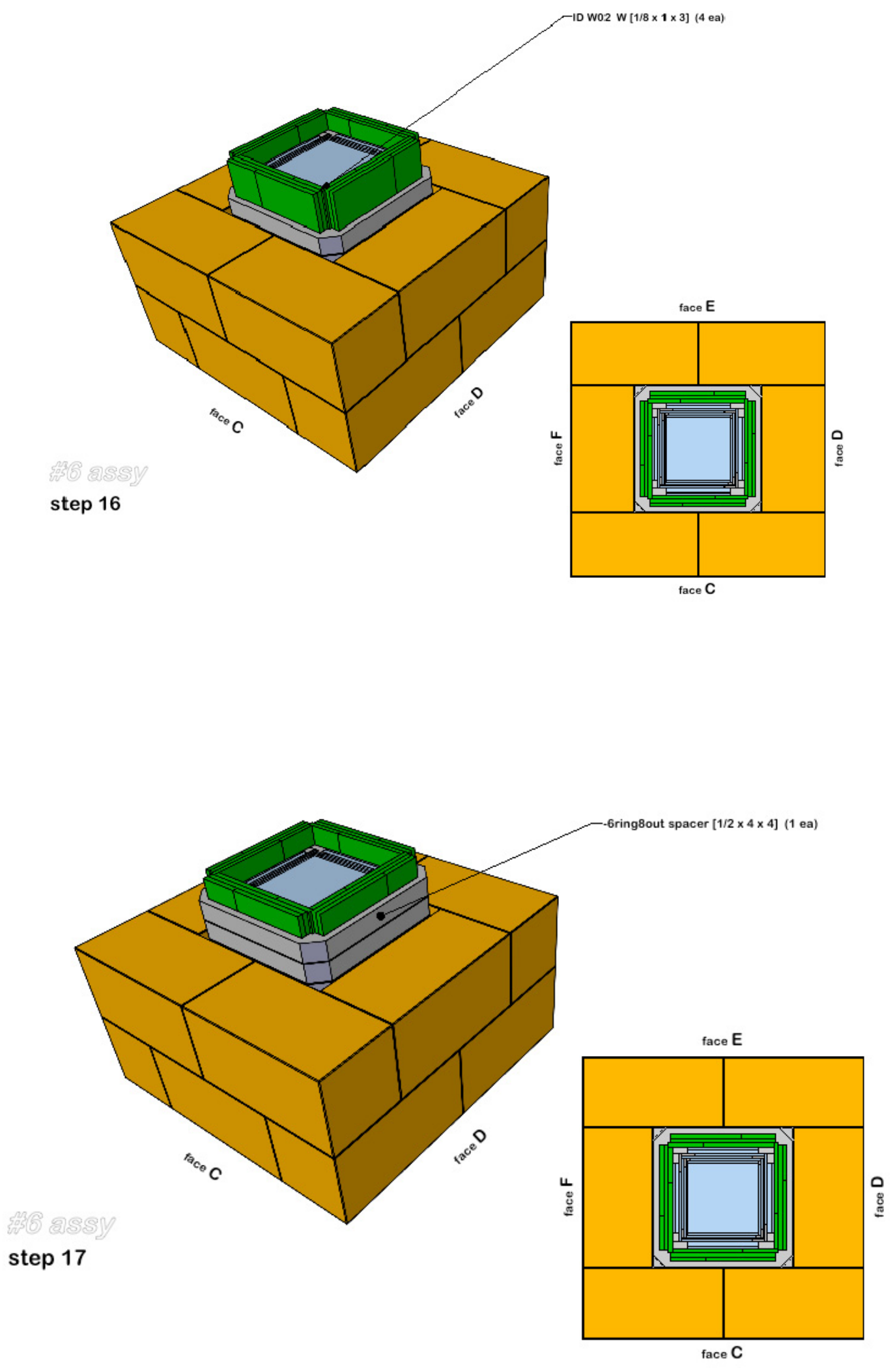

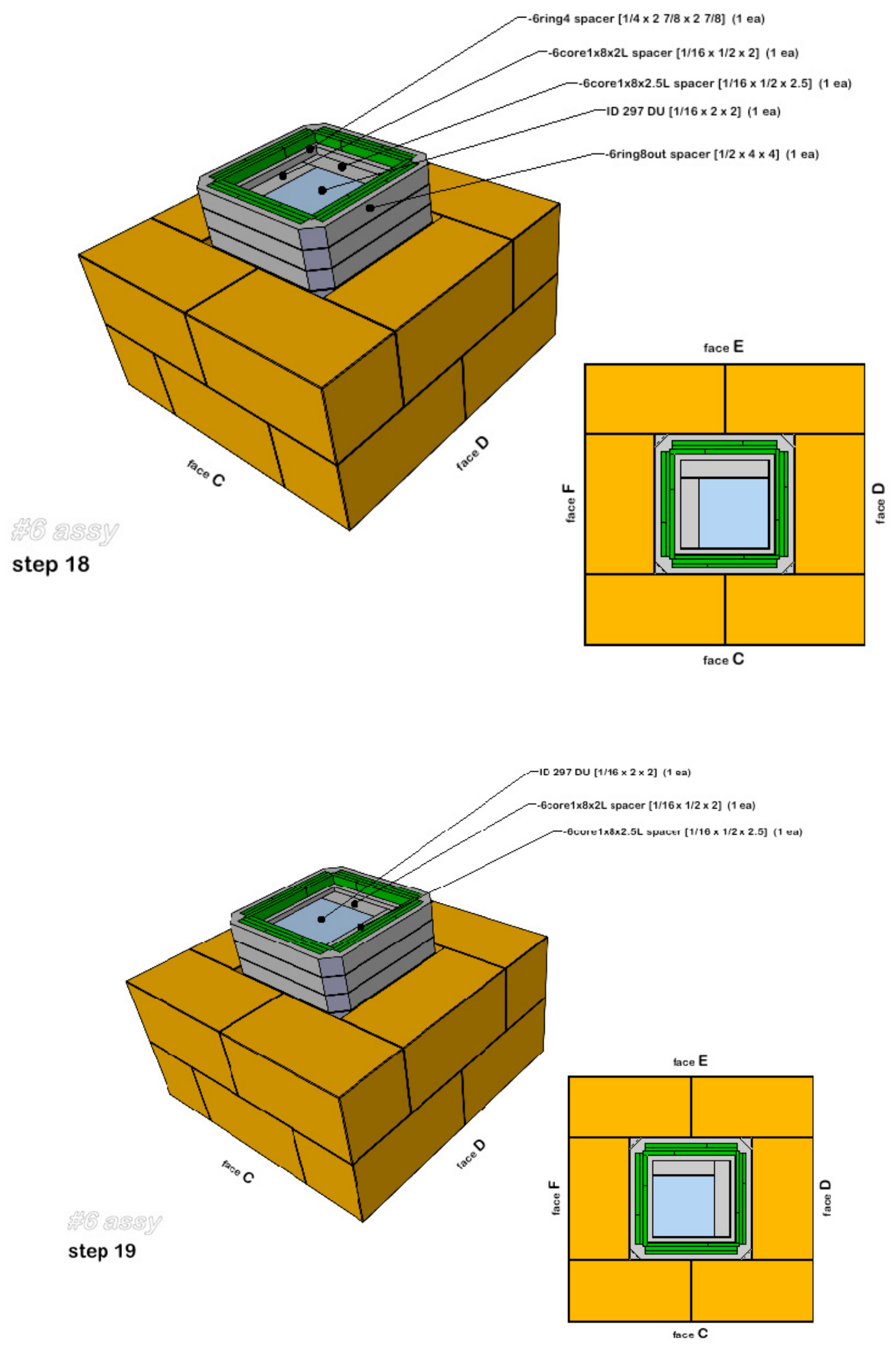

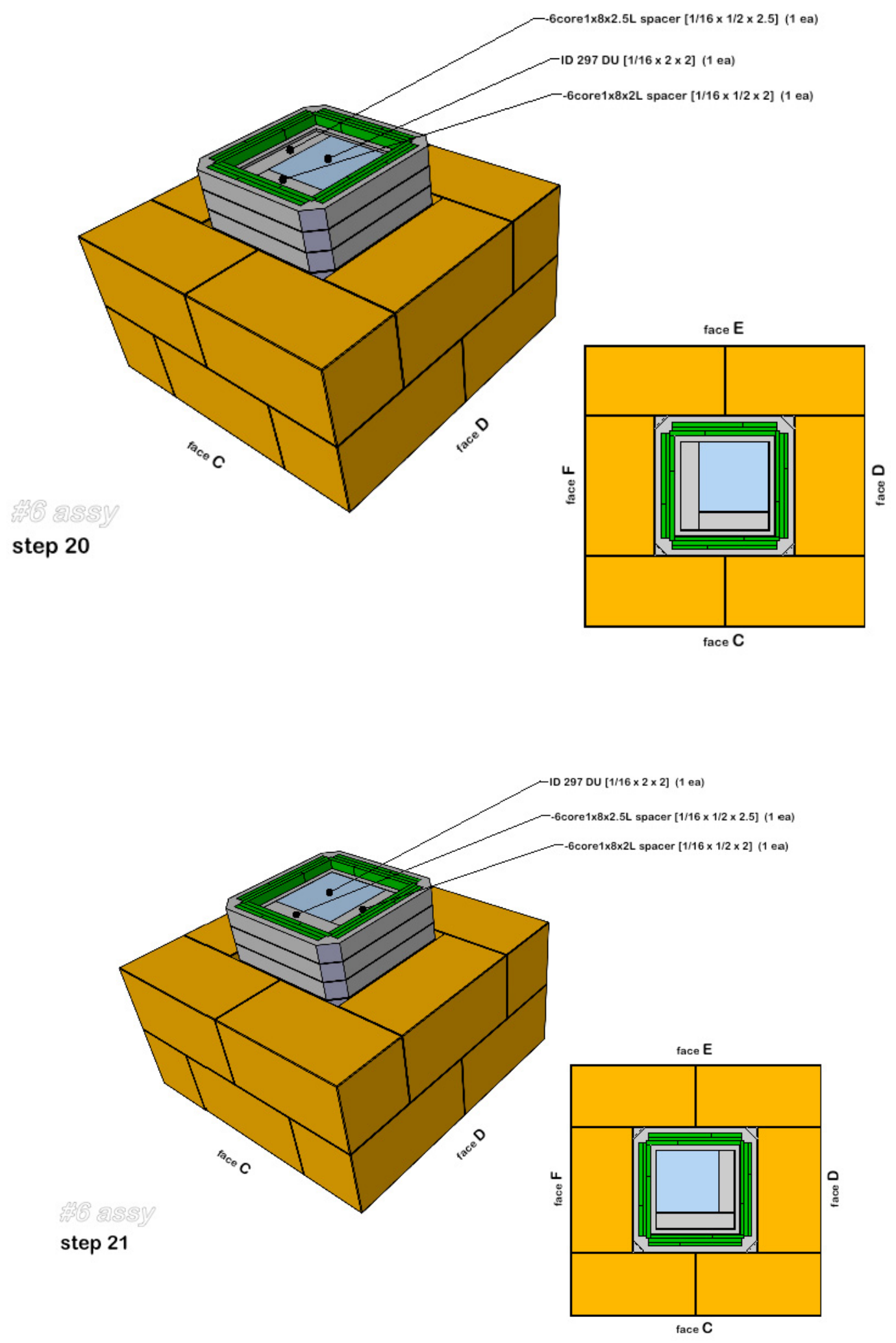

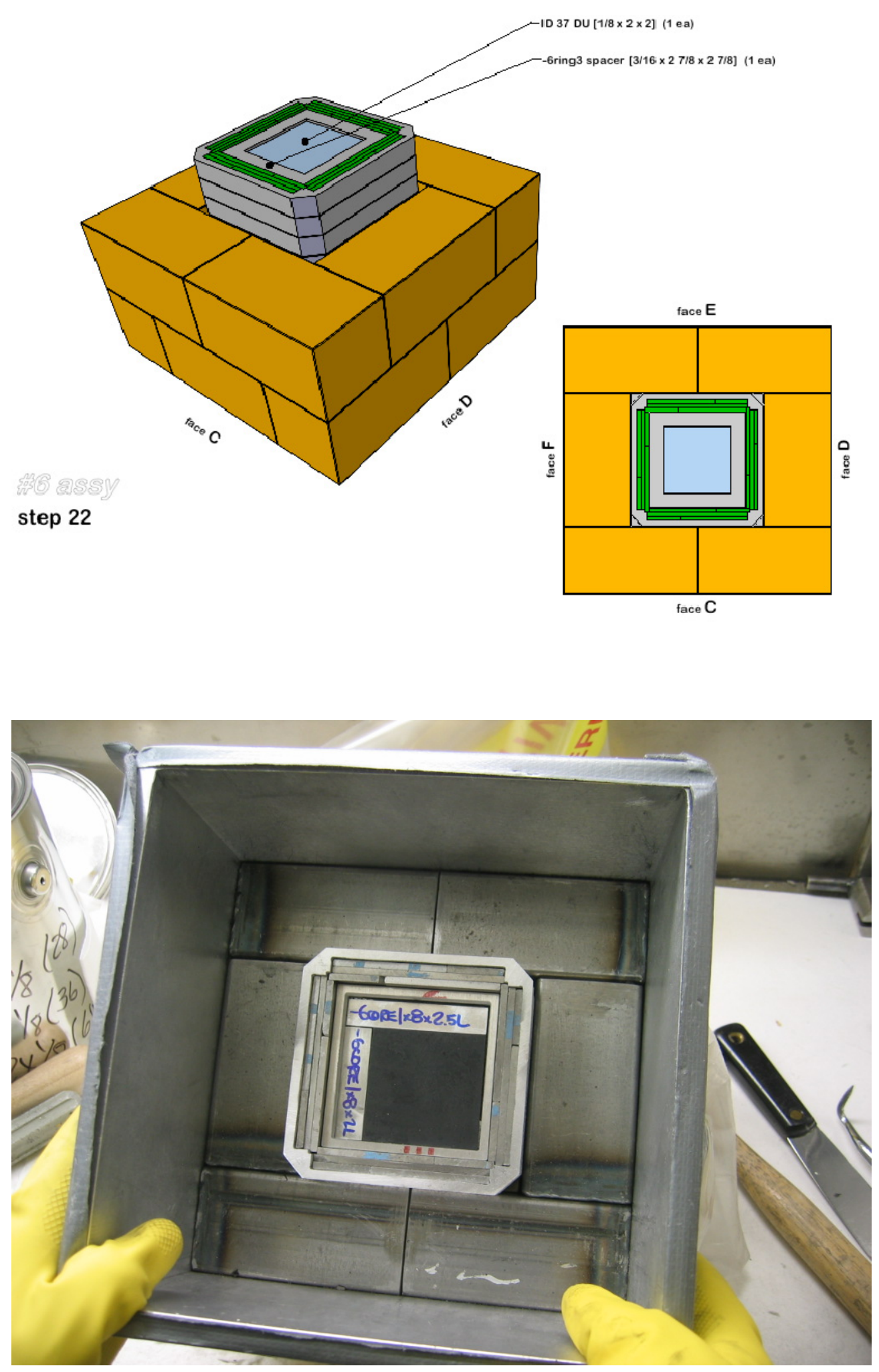

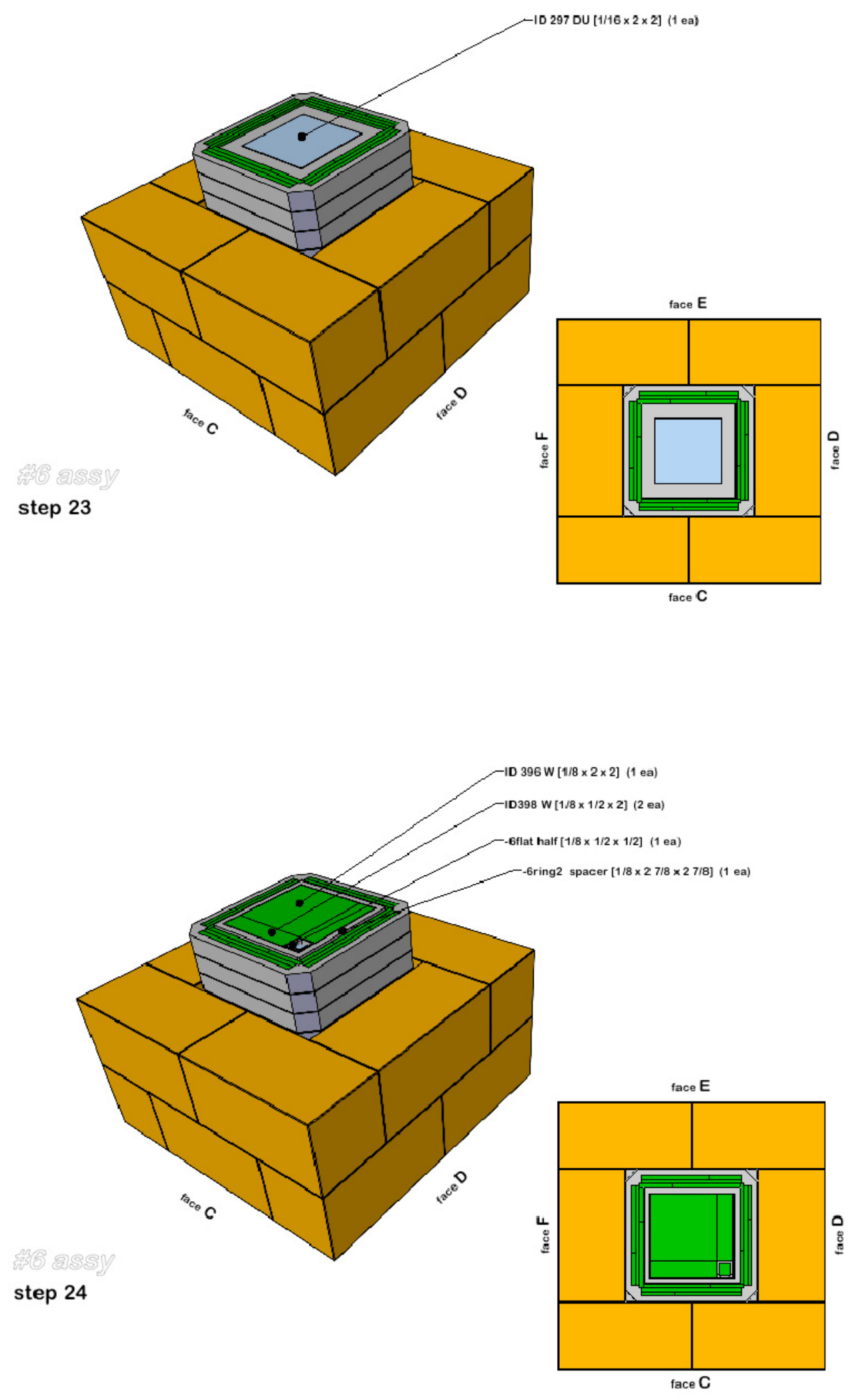

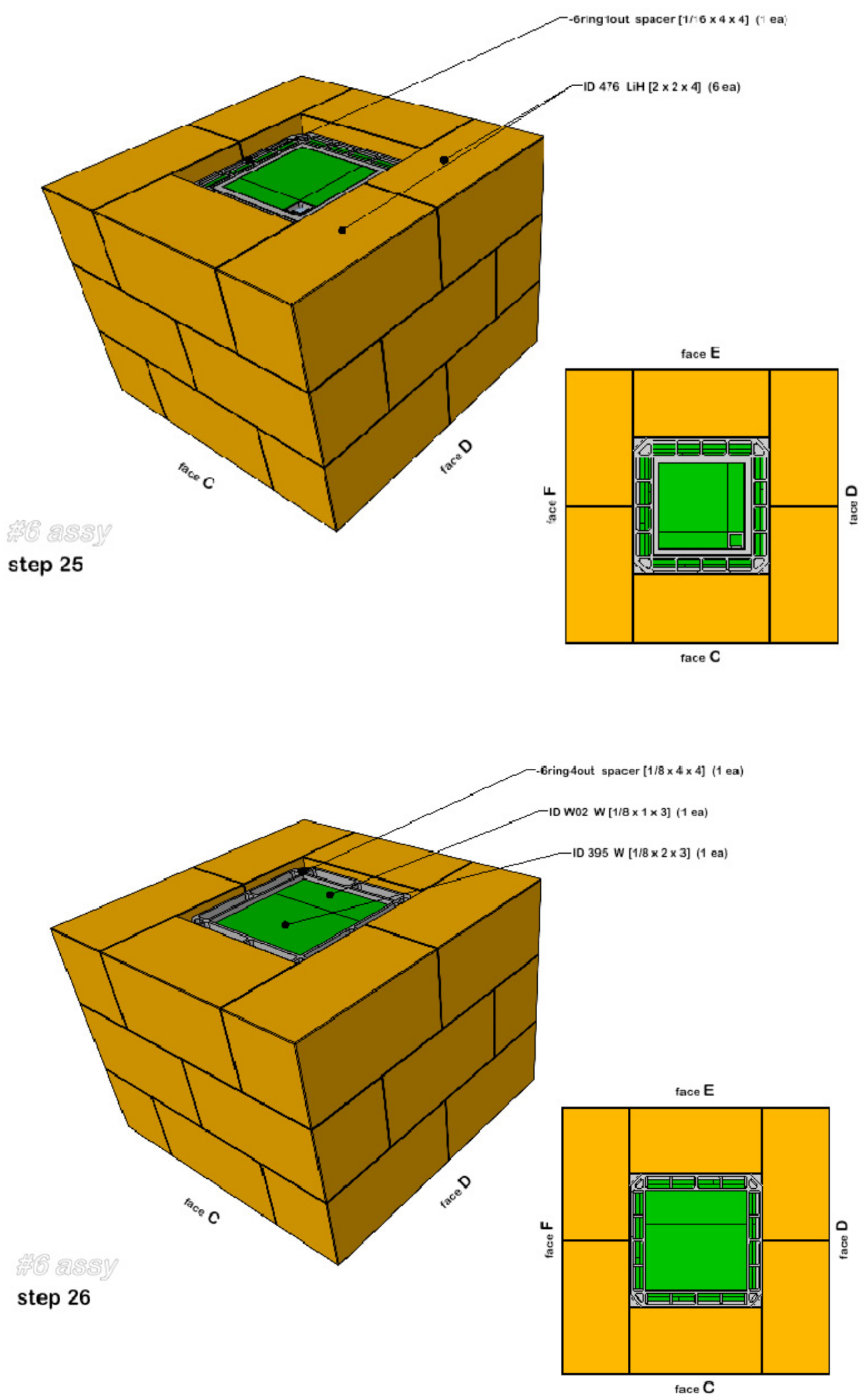

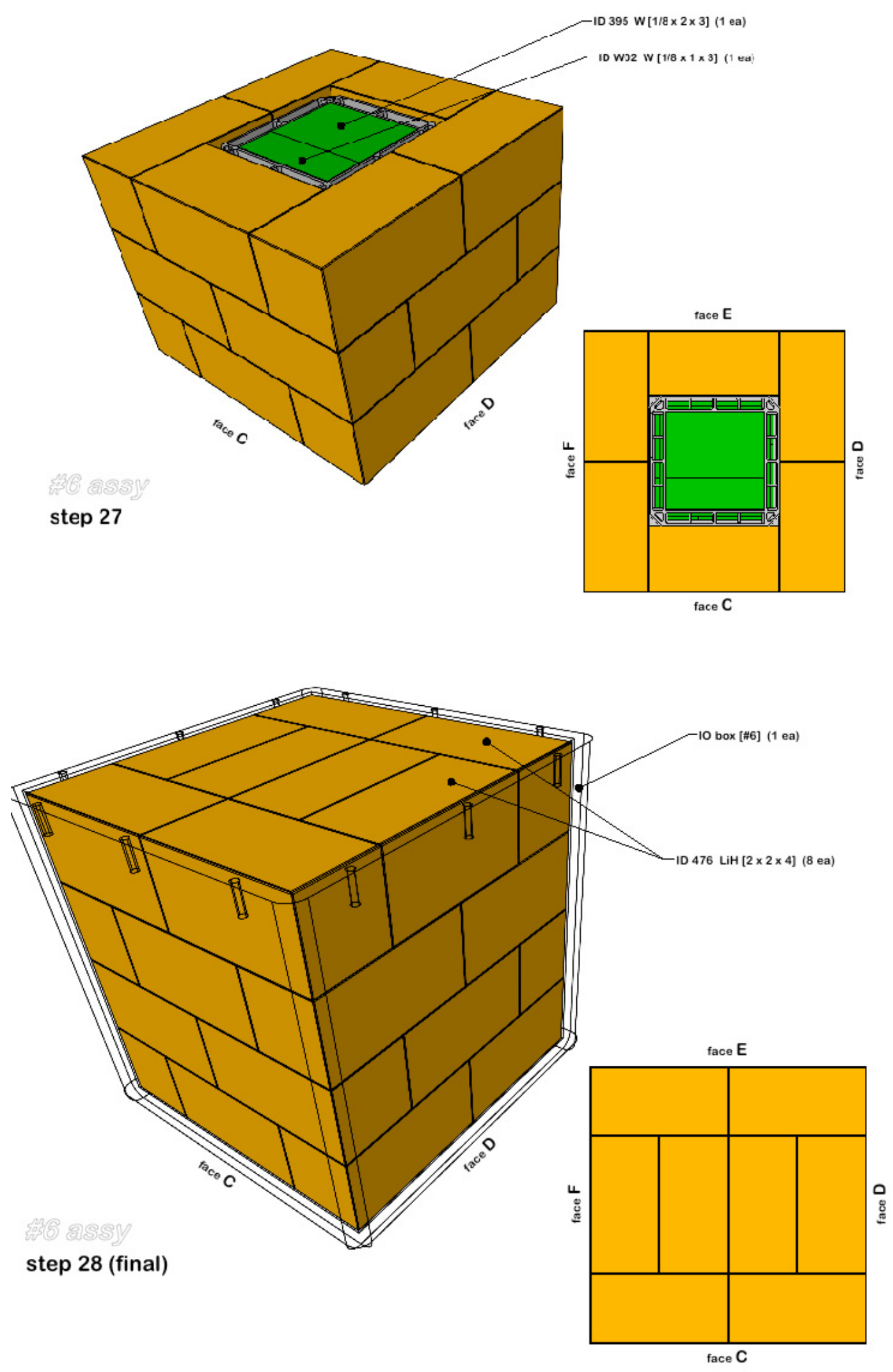


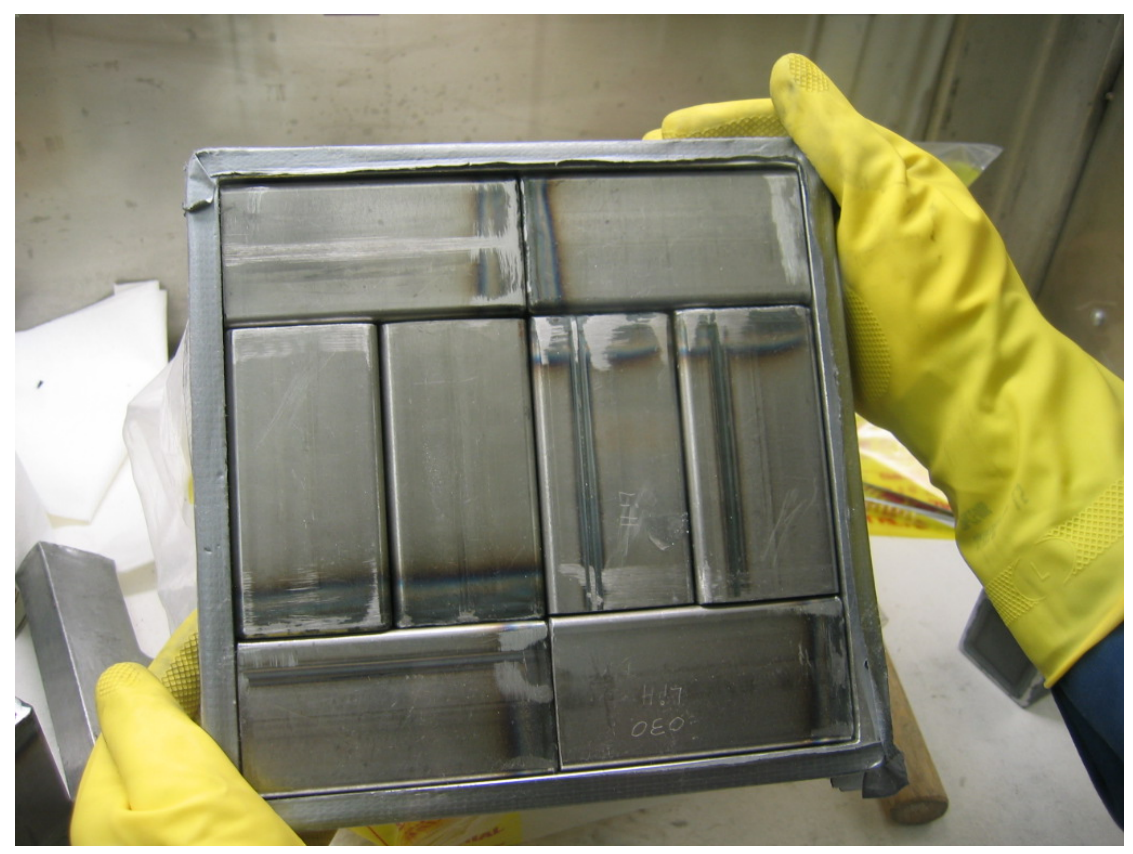




\section{Appendix C}

\section{DU Shielding of HEU (IO\#7)}




\section{Appendix C}

\section{DU Shielding of HEU (IO\#7)}

This appendix presents an inspection object (IO\#7) that was designed to assess the effect of a DU shield around a HEU sample. The relative position of the aluminum IO Box is also shown to visually assist the reader. It begins with an exploded view of all components and then presents the key steps in the assembly of the IO. For further clarification, assembly photos are included at selected steps in the assembly process. The upper left table below identifies the material parts with the "ID\#" being a specific ZPPR material identification (see Ref. 1), the "part names" provides the material type (with plate thickness, width, and length in inches within parenthesis), and the number of plates used ("qty"). Items not having a unique ID\# for this IO indicate custom-made aluminum components required for the final assembly. The lower left table presents the elemental mass (kg) for each material component ("Mele") [U235 for HEU and U-238 for DU], the total mass of that material component ("Mtot"), and the total mass of the assembled IO (with the aluminum IO Box). All spacers are made of standard 6061-T6 aluminum.

\begin{tabular}{|c|c|c|}
\hline ID\# & part names & qty \\
\hline 521 & HEU $[1 / 16 \times 2 \times 2]$ & 74 \\
\hline 297 & $\mathrm{DU}[1 / 16 \times 2 \times 2]$ & 24 \\
\hline 294 & DU $[1 / 8 \times 1 / 2 \times 2]$ & 4 \\
\hline 299 & $D U[1 / 16 \times 1 \times 1]$ & 40 \\
\hline 36 & DU $[1 / 8 \times 1 \times 2]$ & 24 \\
\hline 37 & $\mathrm{DU}[1 / 8 \times 2 \times 2]$ & 6 \\
\hline 38 & DU $[1 / 8 \times 2 \times 3]$ & 16 \\
\hline \multirow[t]{21}{*}{39} & $\mathrm{DU}[1 / 8 \times 2 \times 4]$ & 28 \\
\hline & -6 core $1 \times 2 \times 2 L$ & 2 \\
\hline & -6 core $1 \times 4 \times 2 L$ & 2 \\
\hline & -6 core $1 \times 6 \times 2 L$ & 3 \\
\hline & -6 core $1 \times 8 \times 2 L$ & 10 \\
\hline & -6 core $1 \times 8 \times 2.5 L$ & 8 \\
\hline & -6 core $3 \times 4 \times 2 L$ & 4 \\
\hline & -6 core $3 \times 7 \times 2 L$ & 4 \\
\hline & -6 core4 & 2 \\
\hline & -6 ring3 & 2 \\
\hline & -6ring3 & 2 \\
\hline & -7 corner5 & 4 \\
\hline & $-7 F D 4$ & 2 \\
\hline & $-7 F D 8$ & 2 \\
\hline & $-7 F S 8$ & 3 \\
\hline & $-7 \mathrm{HD} 1$ & 2 \\
\hline & $-7 \mathrm{HD} 3$ & 2 \\
\hline & $-7 \mathrm{HD} 8$ & 2 \\
\hline & $-7 \mathrm{HS} 8$ & 3 \\
\hline & -7 ring8 & 2 \\
\hline & -10flatHalf & 2 \\
\hline
\end{tabular}

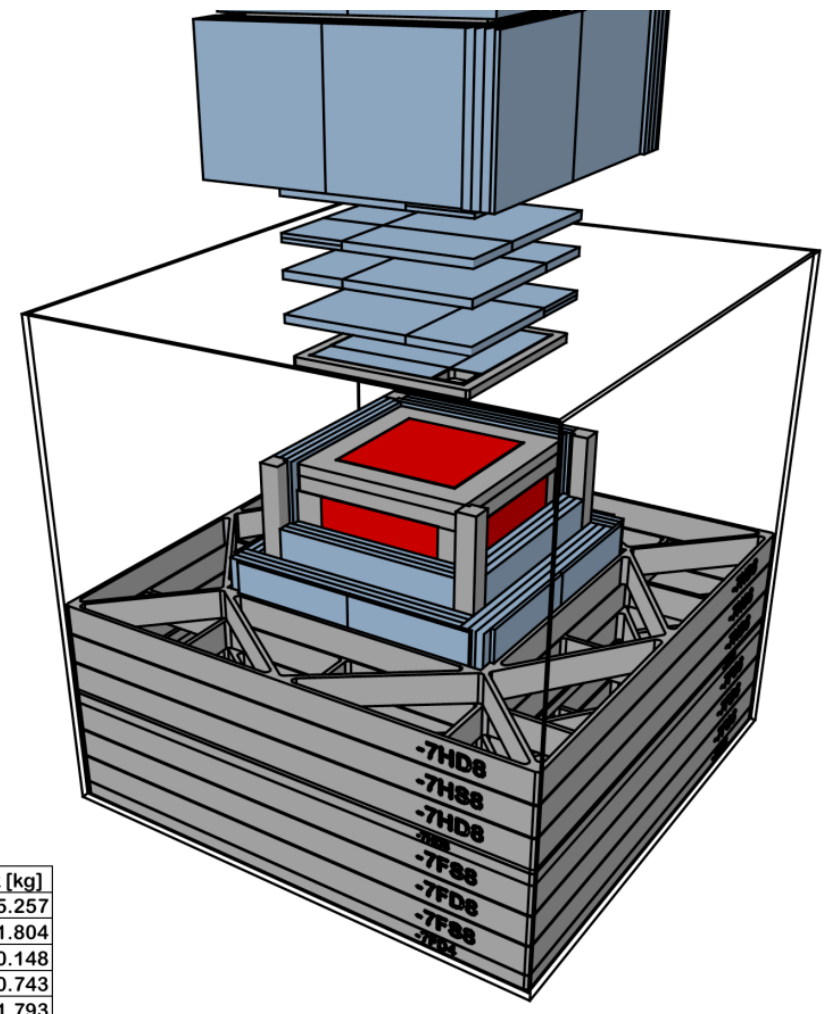

\begin{tabular}{|c|c|c|c|c|}
\hline ID \# & symbol name & \# & Mele [kg] & Mtot [kg] \\
\hline 521 & HEU [1/16×2×2] & 74 & 4.898 & 5.257 \\
\hline 297 & $\mathrm{DU}[1 / 16 \times 2 \times 2]$ & 24 & 1.800 & 1.804 \\
\hline 294 & DU $[1 / 8 \times 1 / 2 \times 2]$ & 4 & 0.148 & 0.148 \\
\hline 299 & $D U[1 / 16 \times 1 \times 1]$ & 40 & 0.742 & 0.743 \\
\hline 36 & DU $[1 / 8 \times 1 \times 2]$ & 24 & 1.789 & 1.793 \\
\hline 37 & DU $[1 / 8 \times 2 \times 2]$ & 6 & 0.890 & 0.892 \\
\hline 38 & DU $[1 / 8 \times 2 \times 3]$ & 16 & 3.576 & 3.584 \\
\hline 39 & DU $[1 / 8 \times 2 \times 4]$ & 28 & 8.315 & 8.333 \\
\hline \multirow[t]{2}{*}{-} & 10 box \& spacers & - & 10.133 & 10.133 \\
\hline & & tals & 32.290 & 32.687 \\
\hline
\end{tabular}



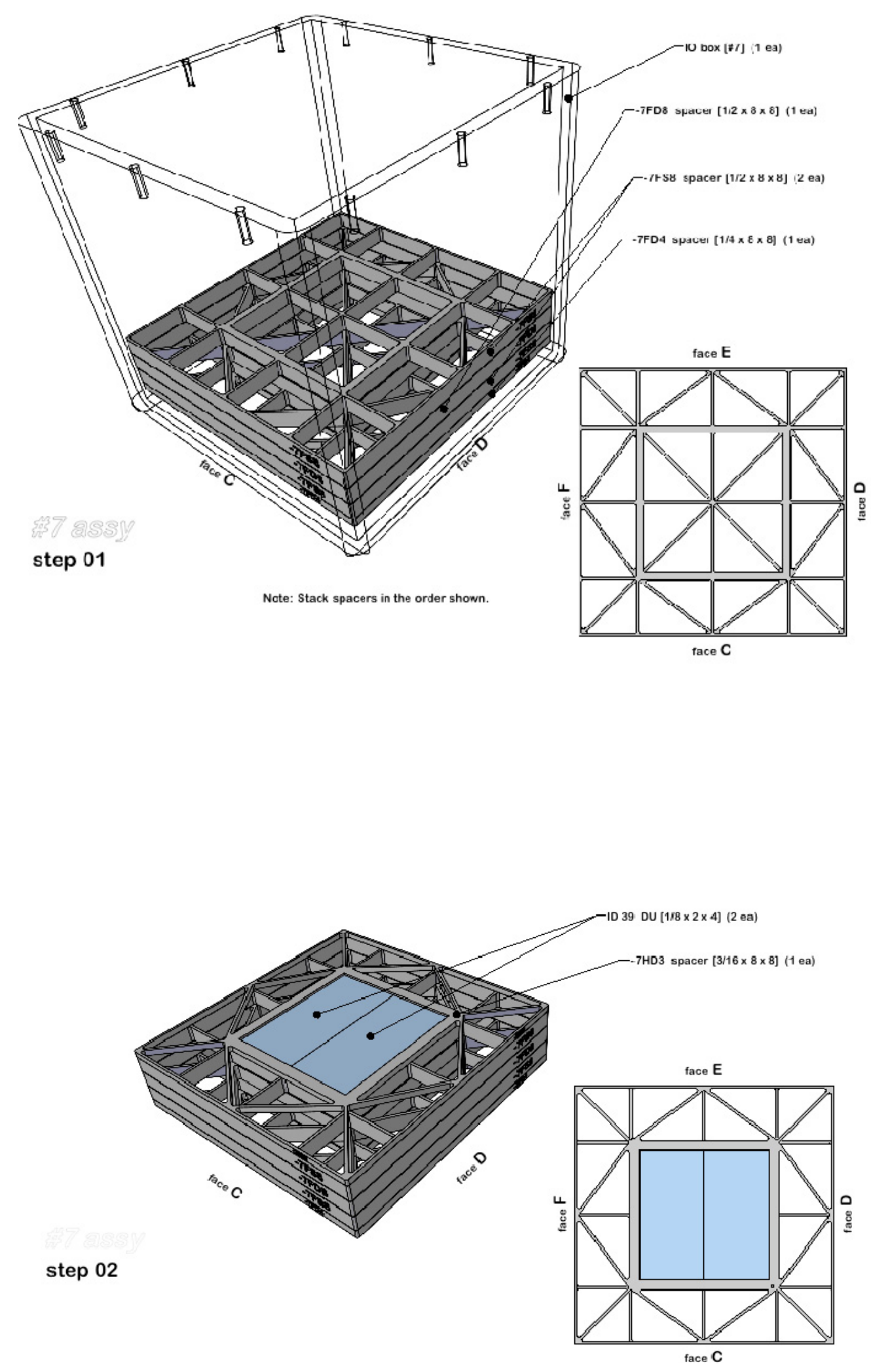

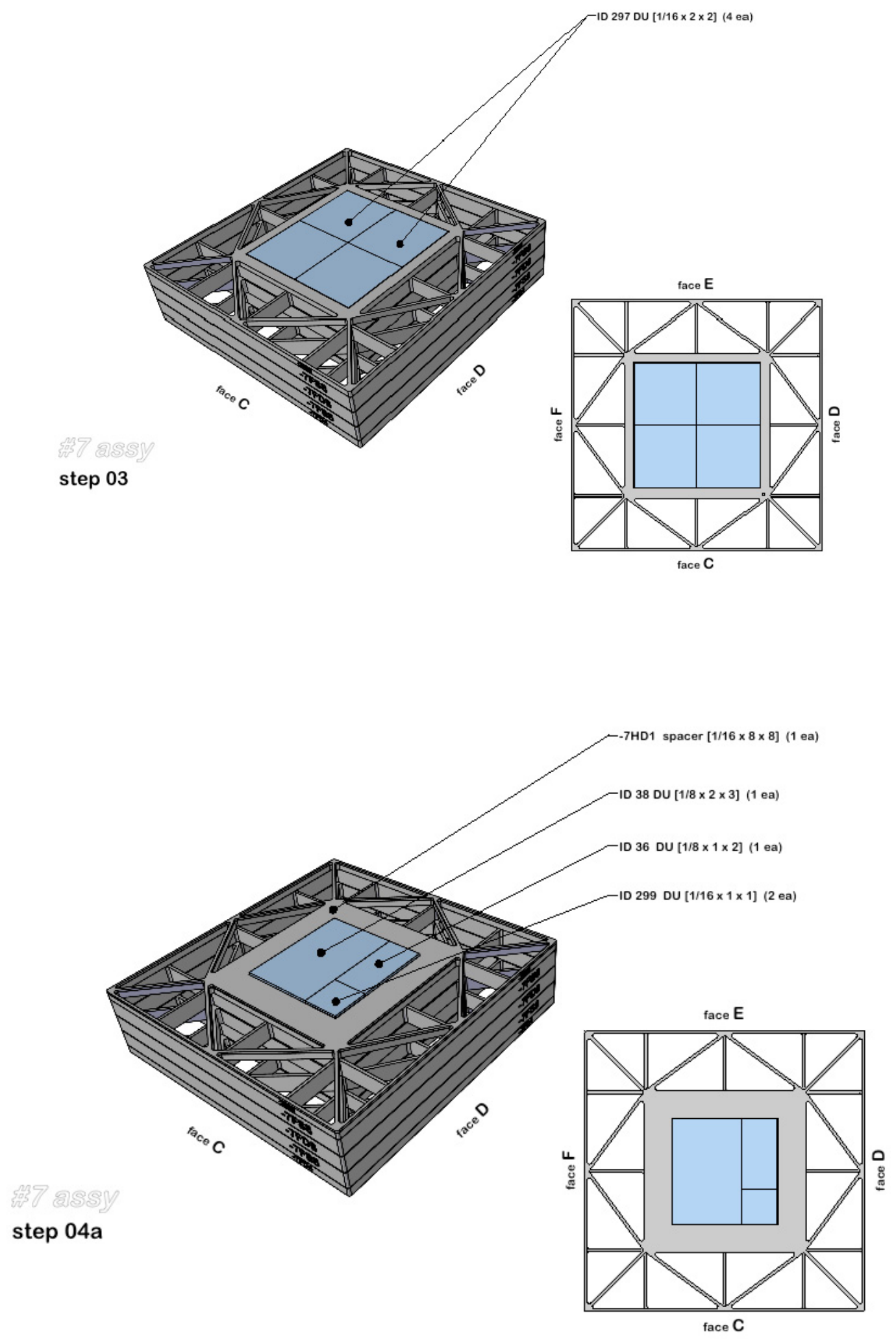

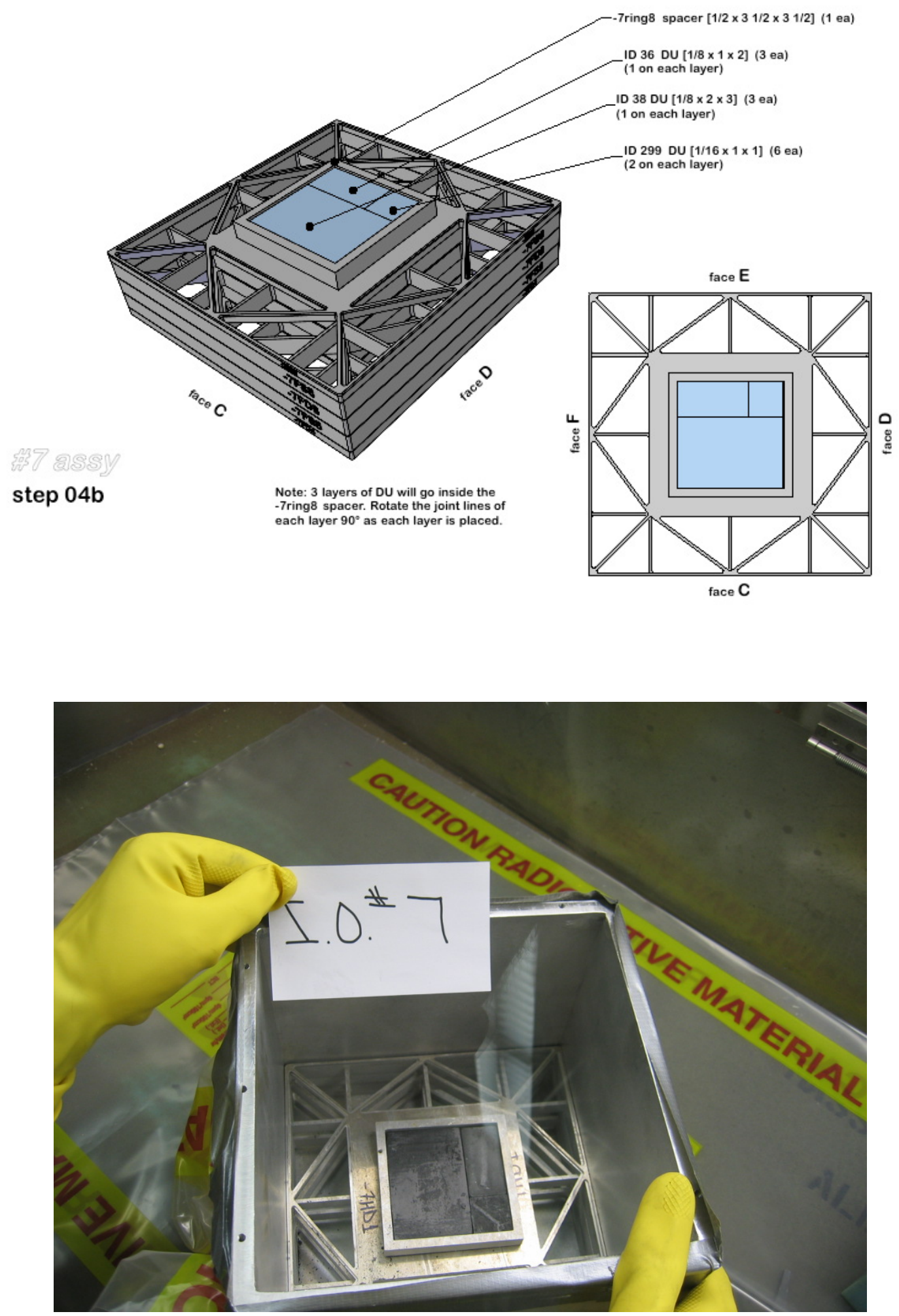

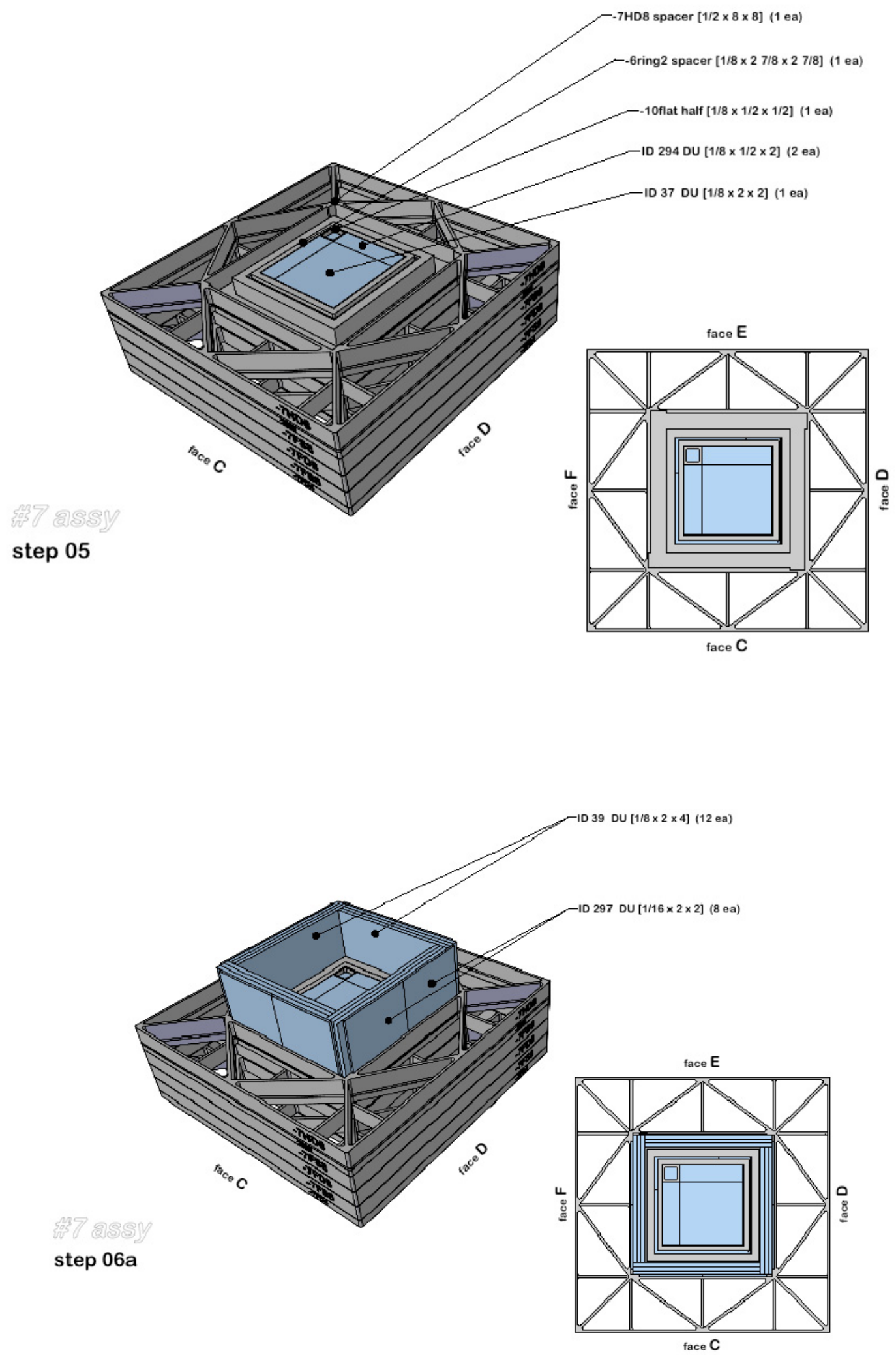

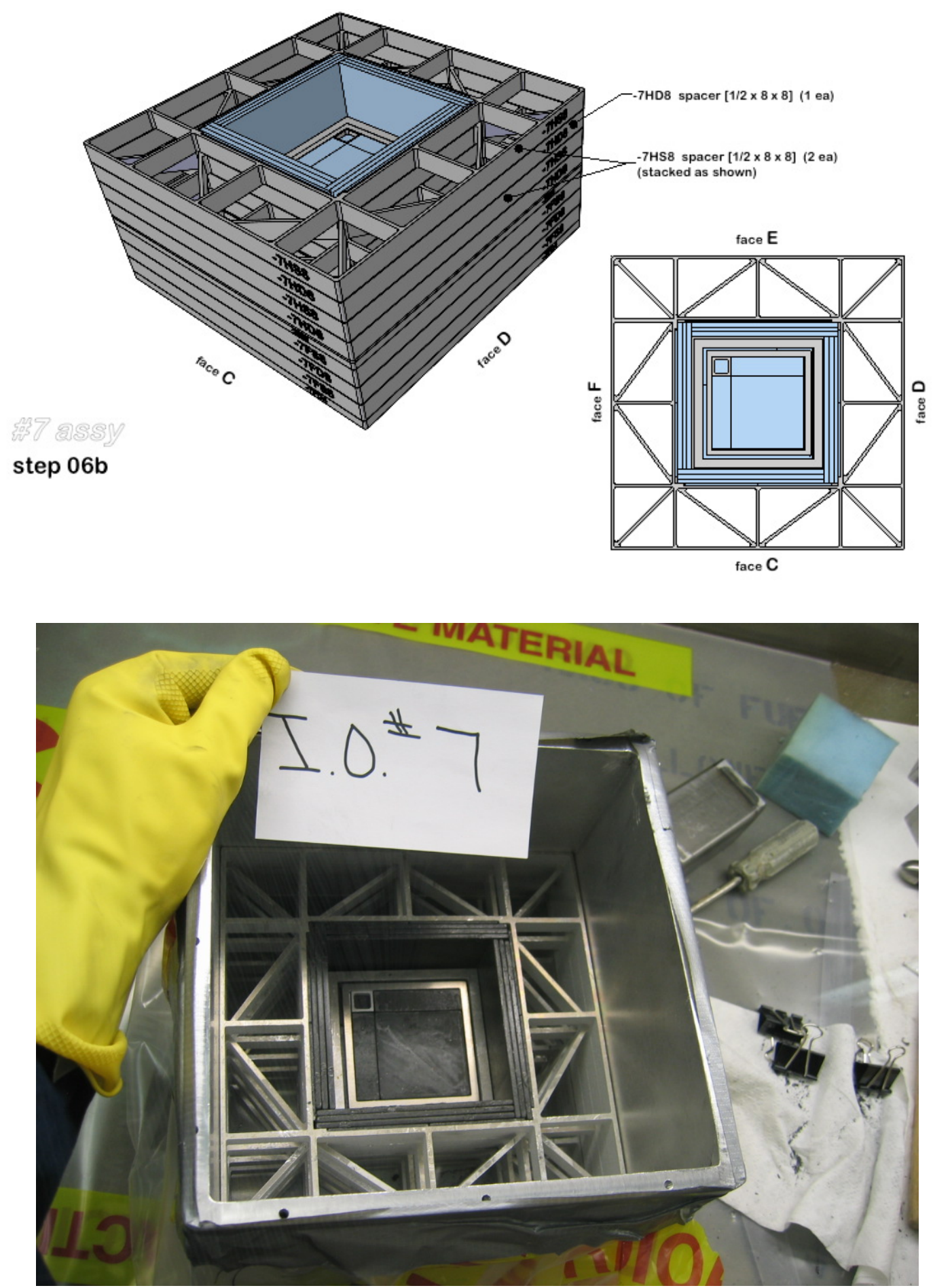


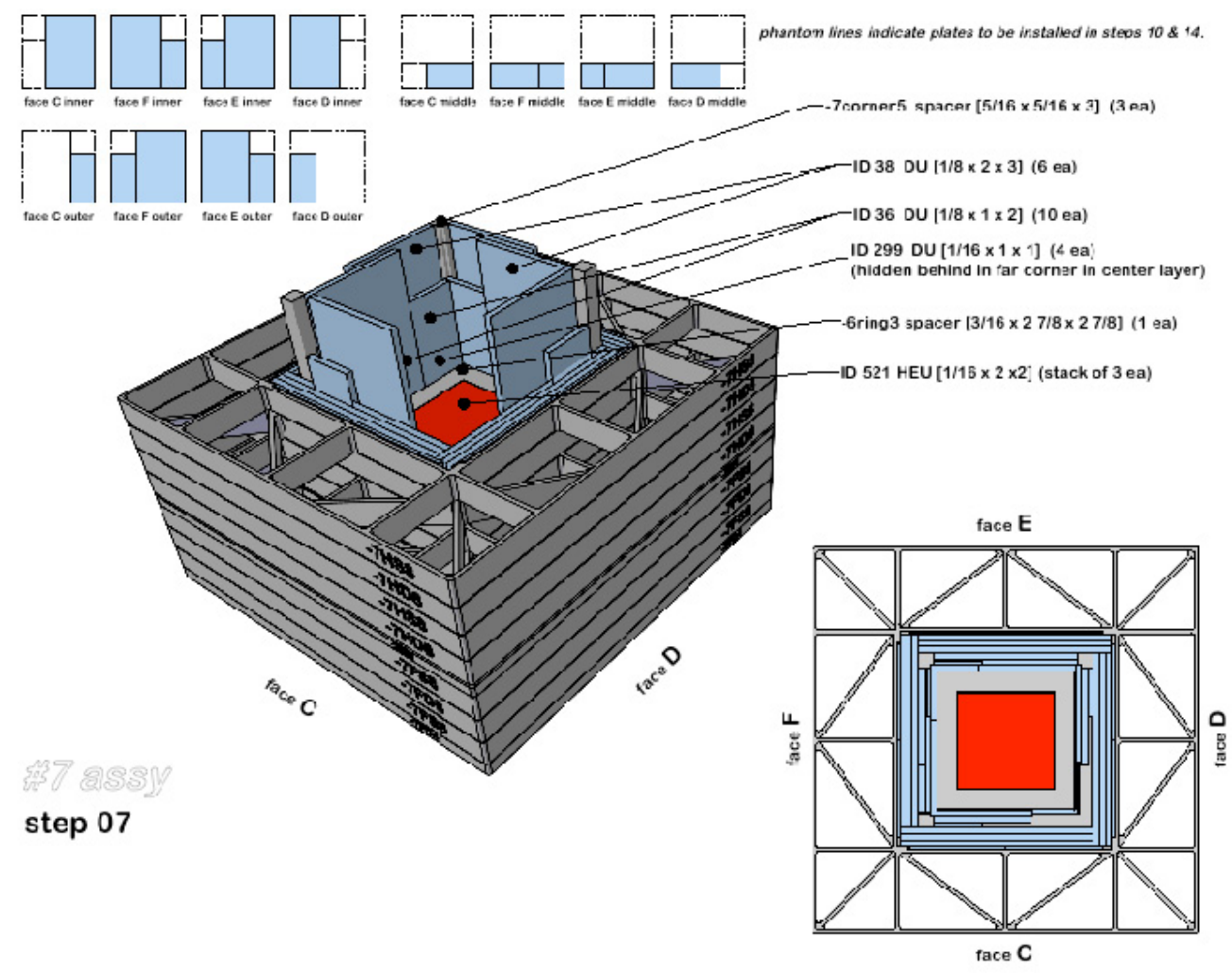

Note: 4 layers of HEU \& spacers will go inside the -6 core 4 spacer. Rotate the joint lines of each layer $90^{\circ}$ as each layer is placed within the spacer.

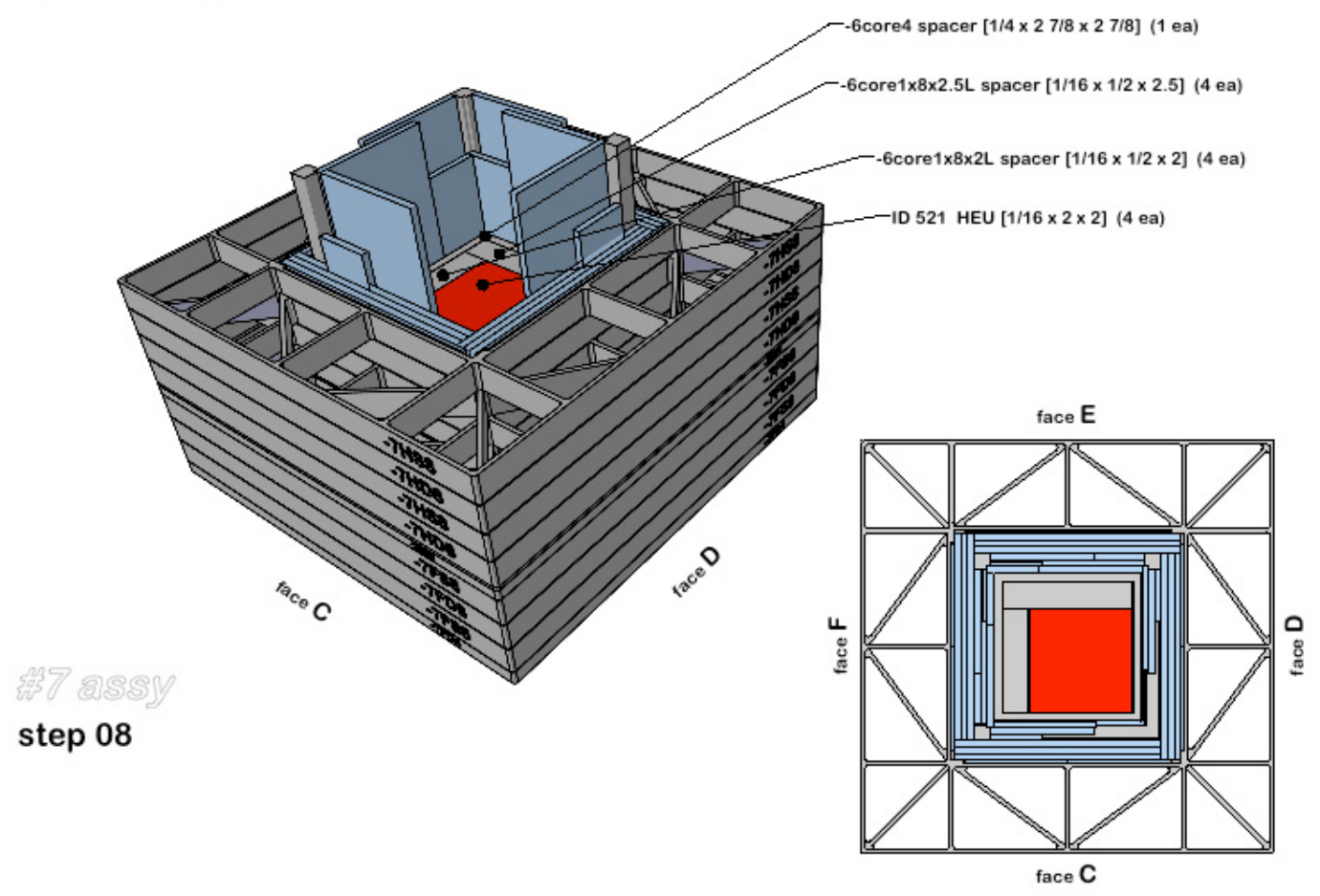



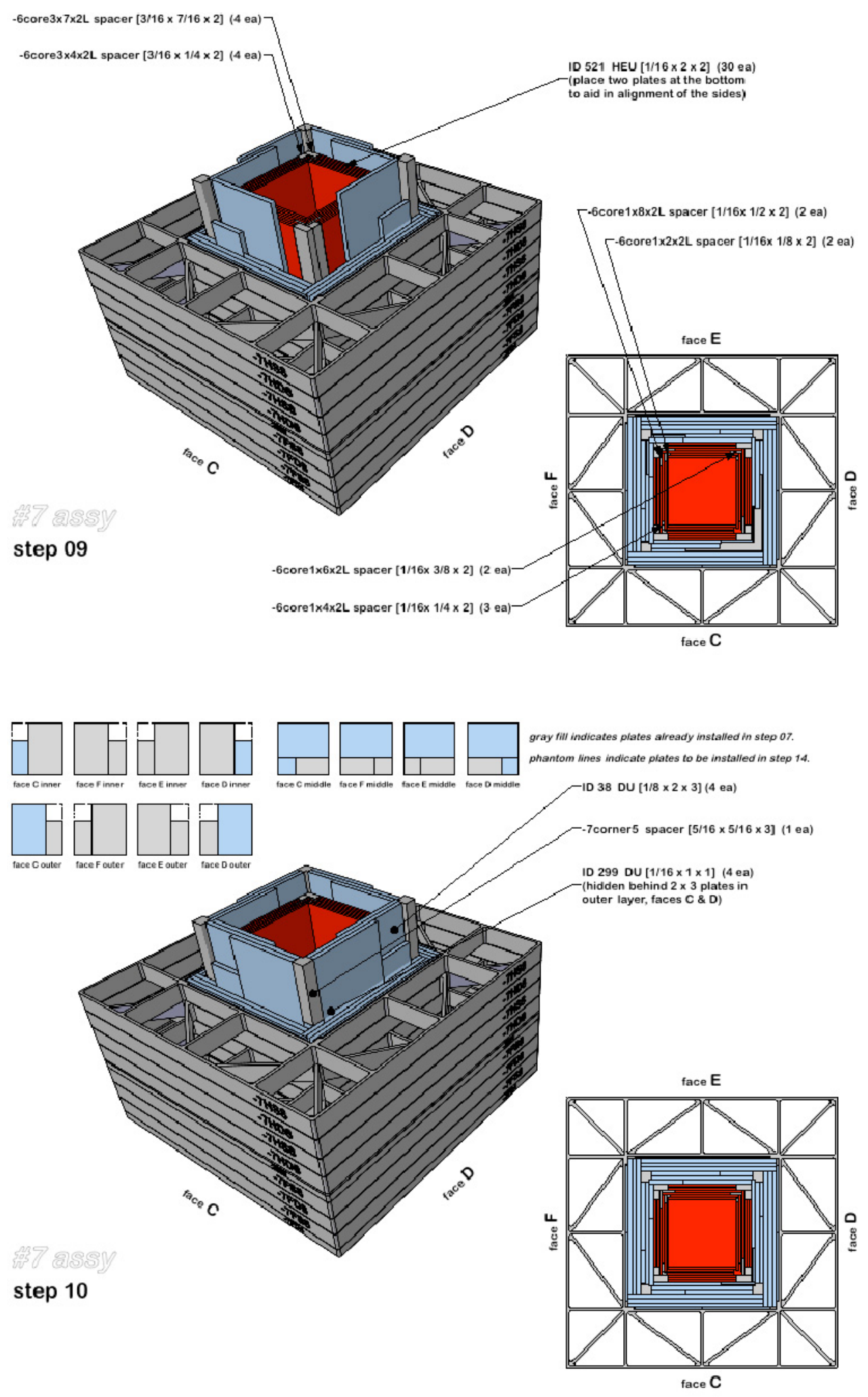


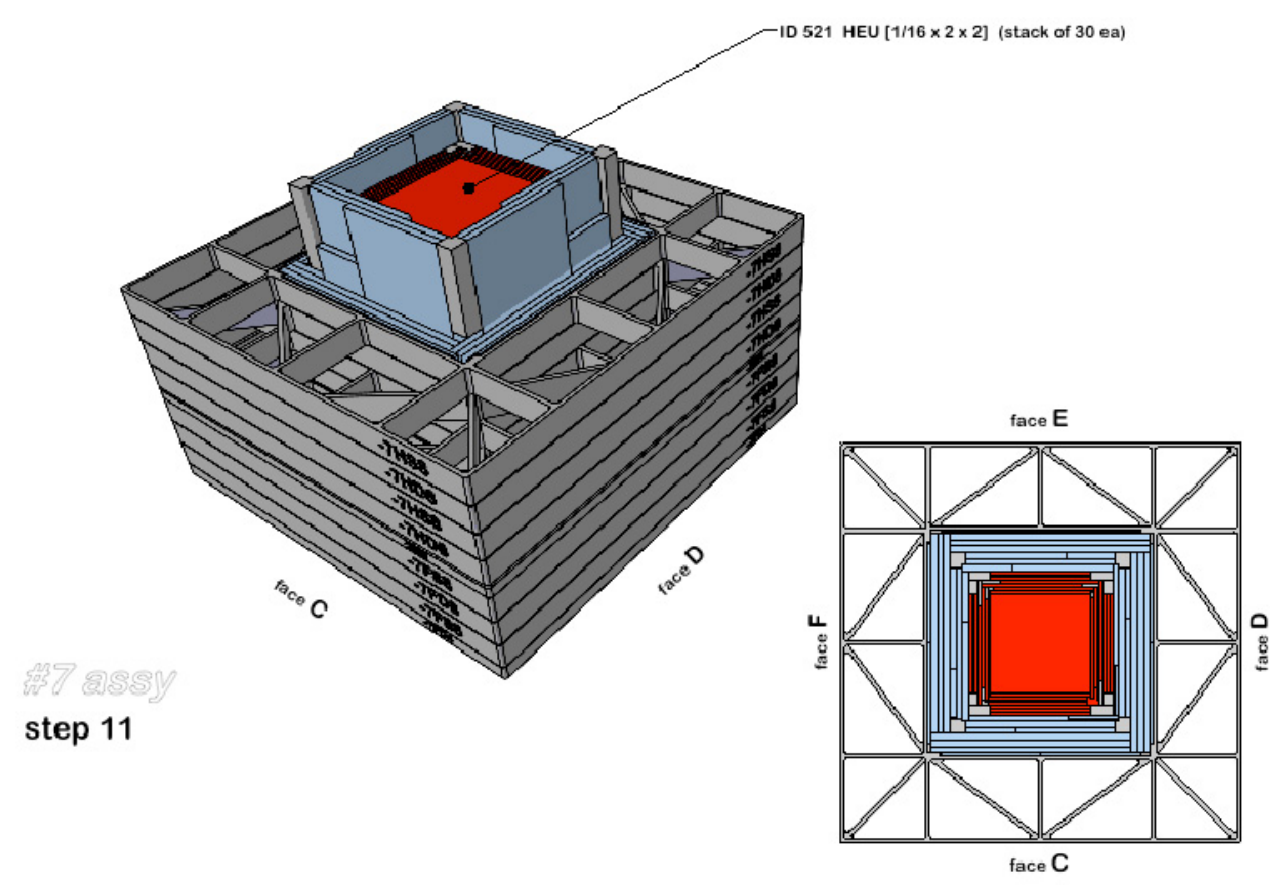

Note: 4 layers of HEU \& spacers will go

inside the -6core 4 spacer. $R$

lines of each layer $90^{\circ}$ as each layer is

placed within the spacer.

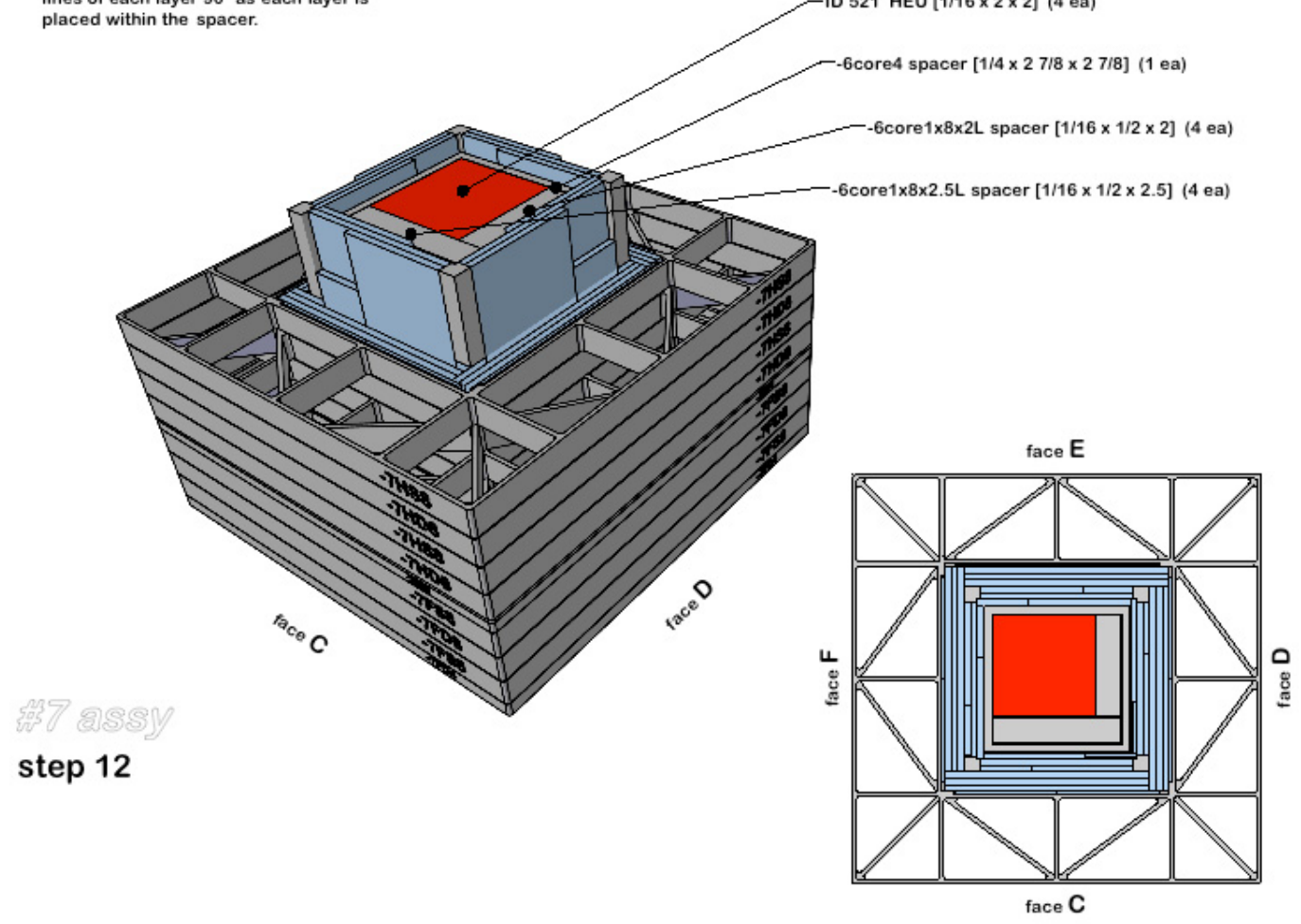



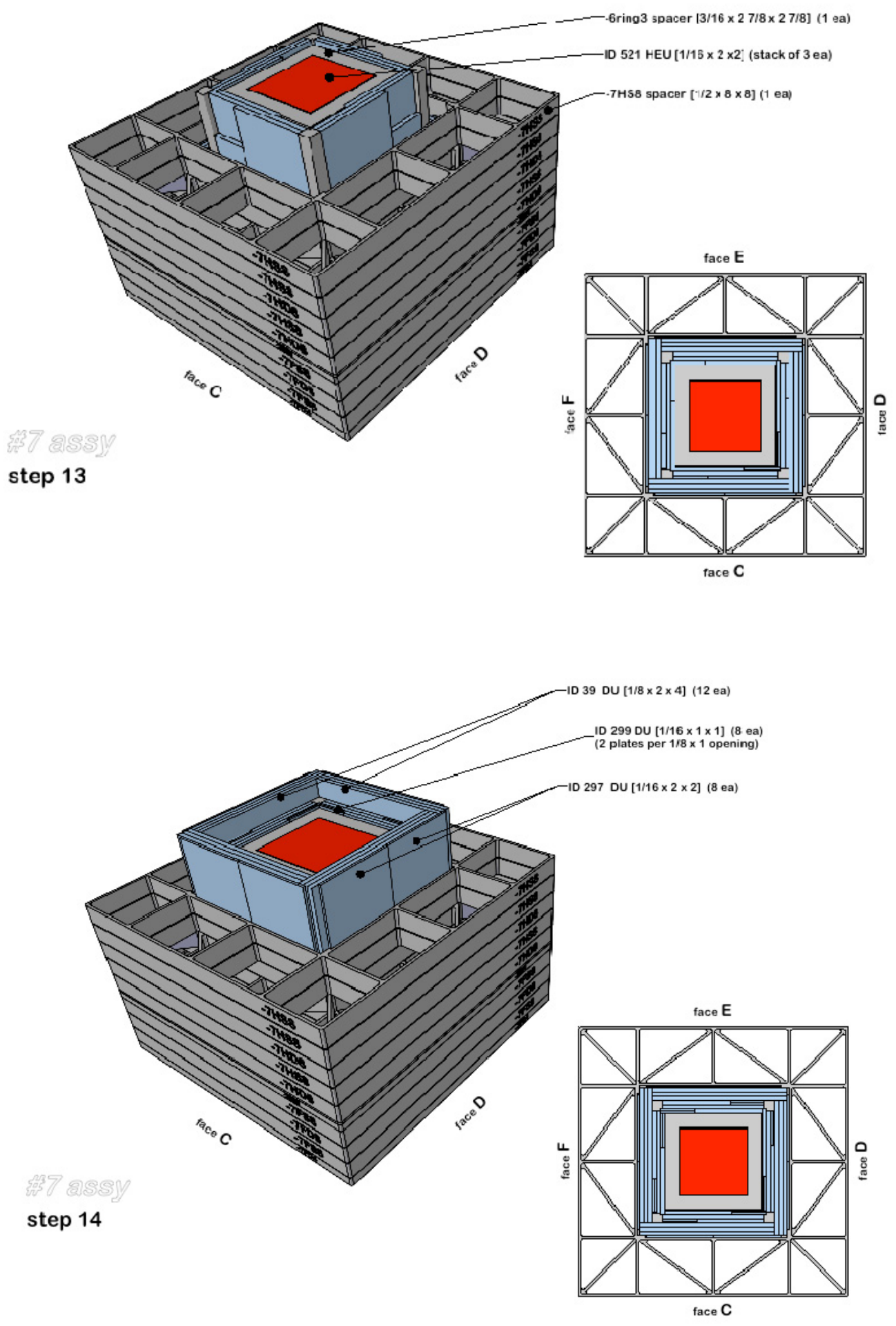

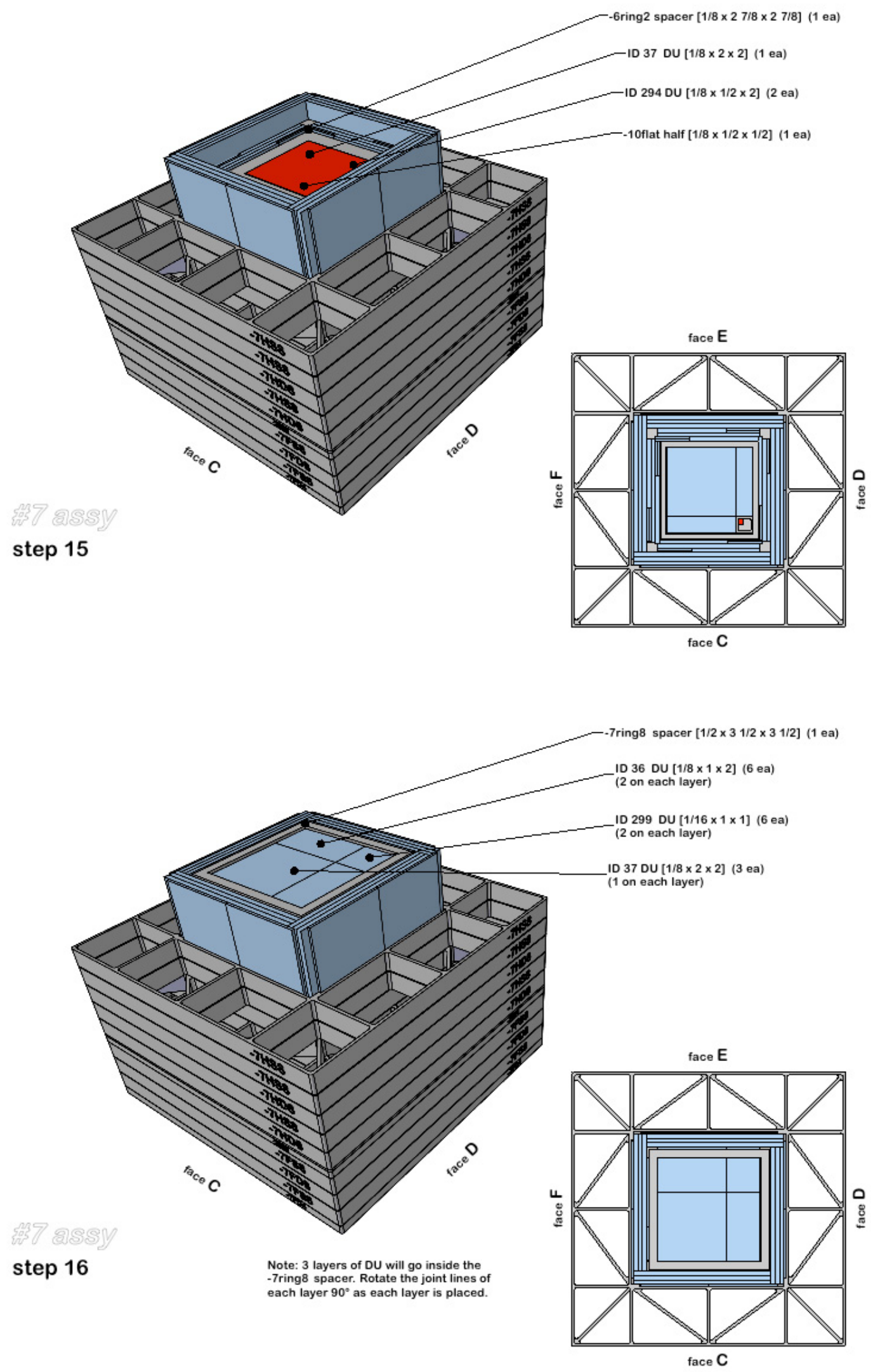

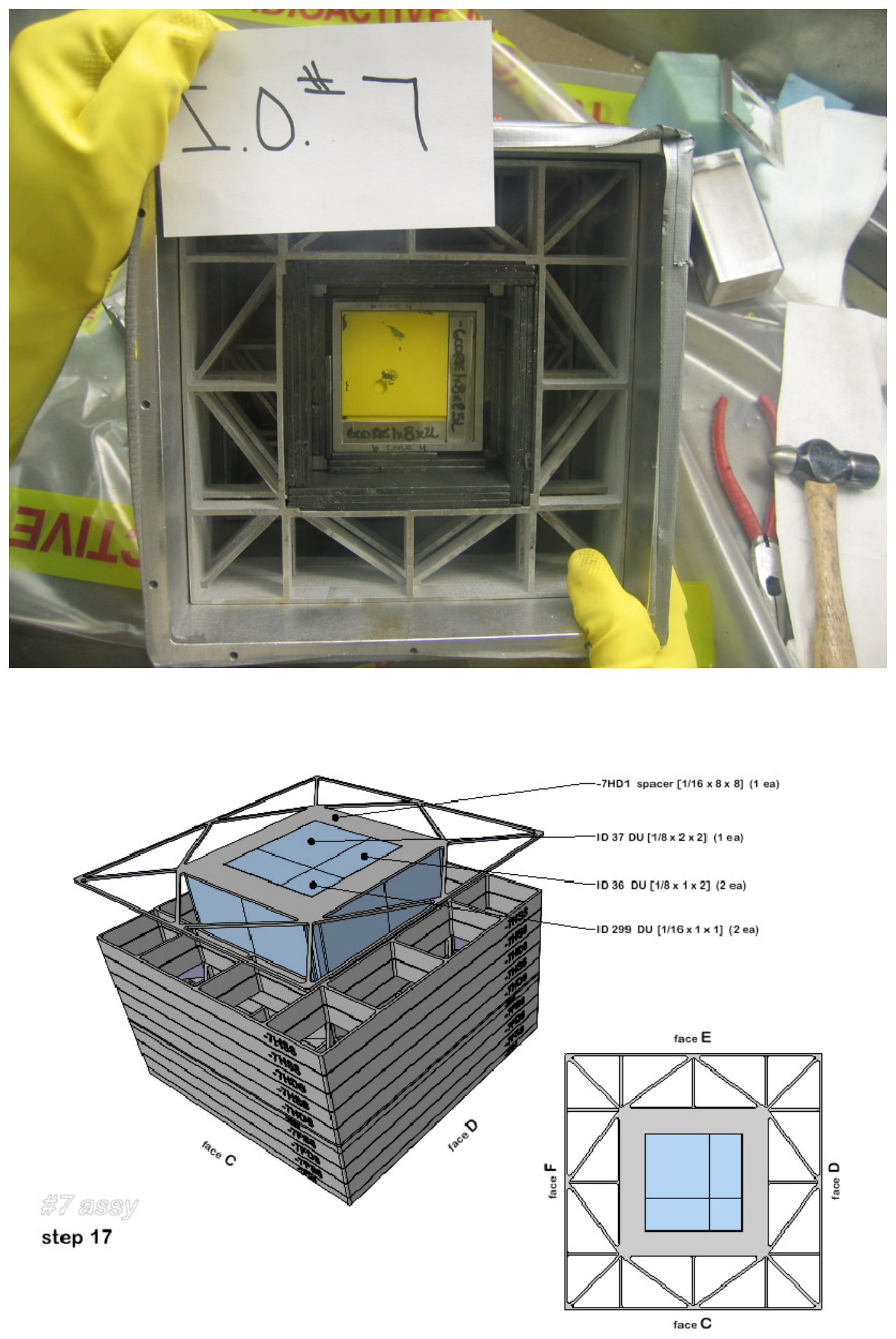

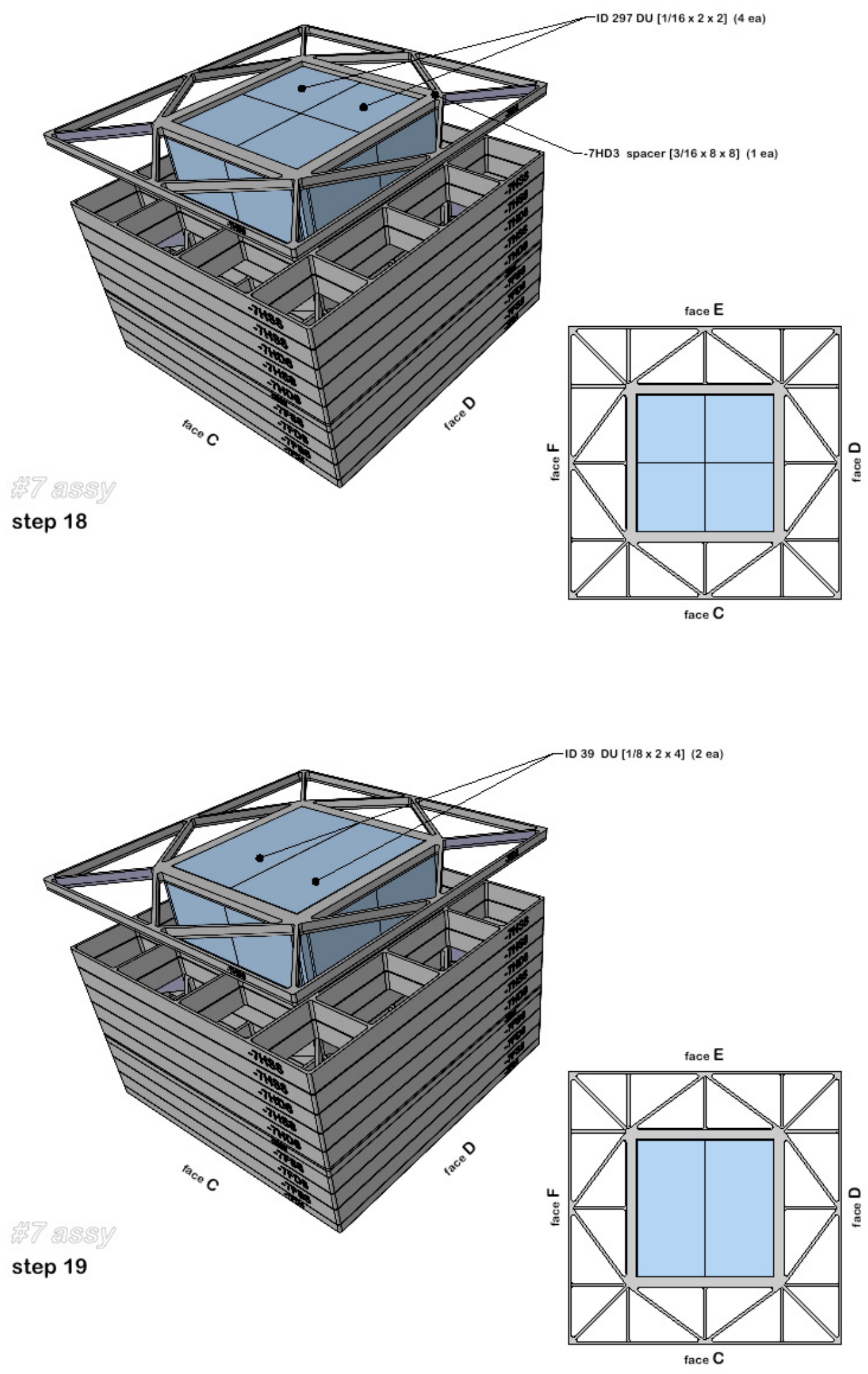

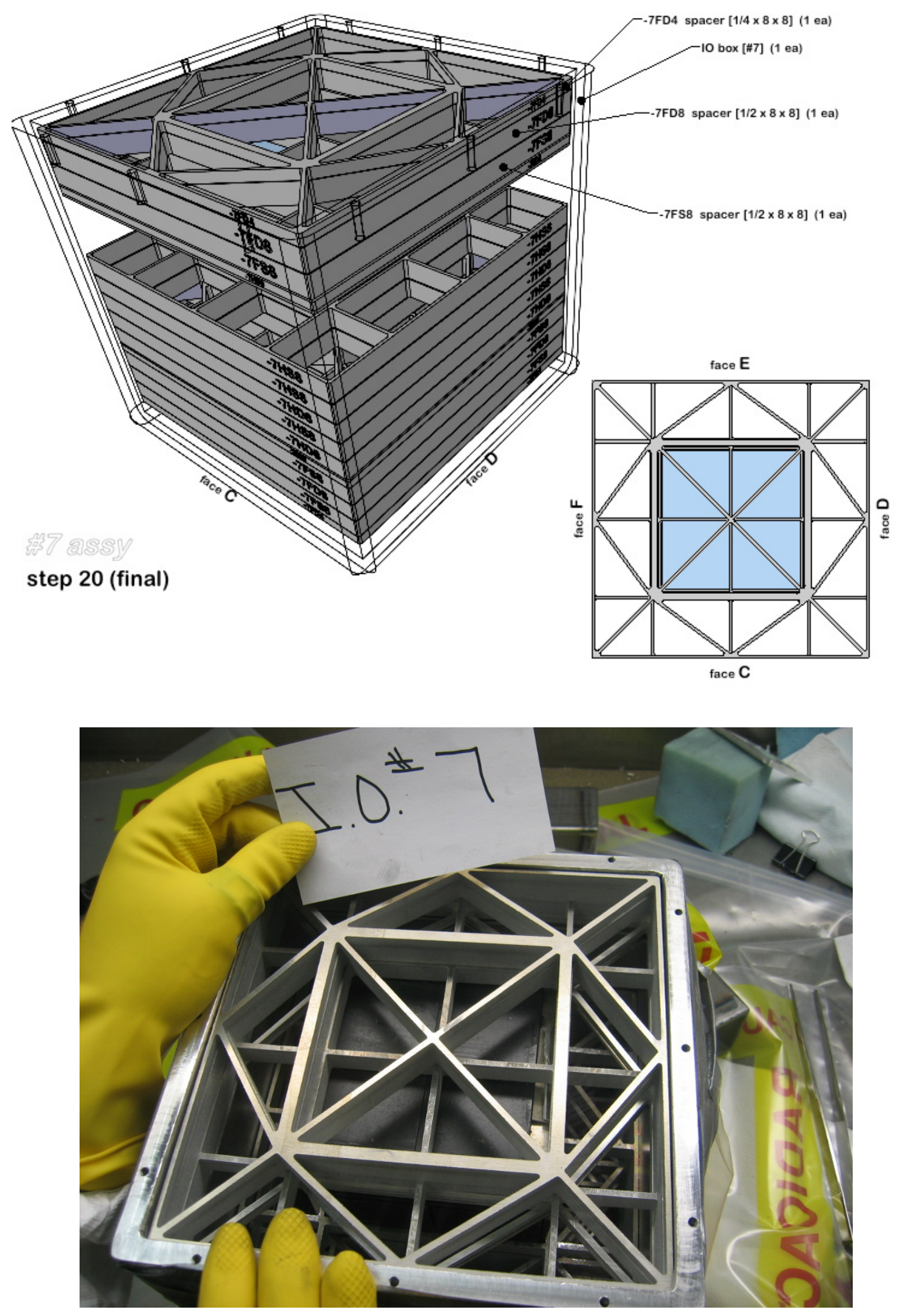
Appendix D

\section{DU Shielding of Plutonium (IO\#8)}




\section{Appendix D}

\section{DU Shielding of Plutonium (IO\#8)}

This appendix presents an inspection object (IO\#8) that was designed to assess the effect of a DU shield around a plutonium sample. The relative position of the aluminum IO Box is also shown to visually assist the reader. It begins with an exploded view of all components and then presents the key steps in the assembly of the IO. For further clarification, assembly photos are included at selected steps in the assembly process. The upper left table below identifies the material parts with the "ID\#" being a specific ZPPR material identification (see Ref. 1), the "part names" provides the material type (with plate thickness, width, and length in inches within parenthesis), and the number of plates used ("qty"). Items not having a unique ID\# for this IO indicate custom-made aluminum components required for the final assembly. The lower left table presents the elemental mass $(\mathrm{kg})$ for each material component ("Mele") [Pu-239 for PuAl and U-238 for DU], the total mass of that material component ("Mtot"), and the total mass of the assembled IO (with the aluminum IO Box). All spacers are made of standard 6061-T6 aluminum.
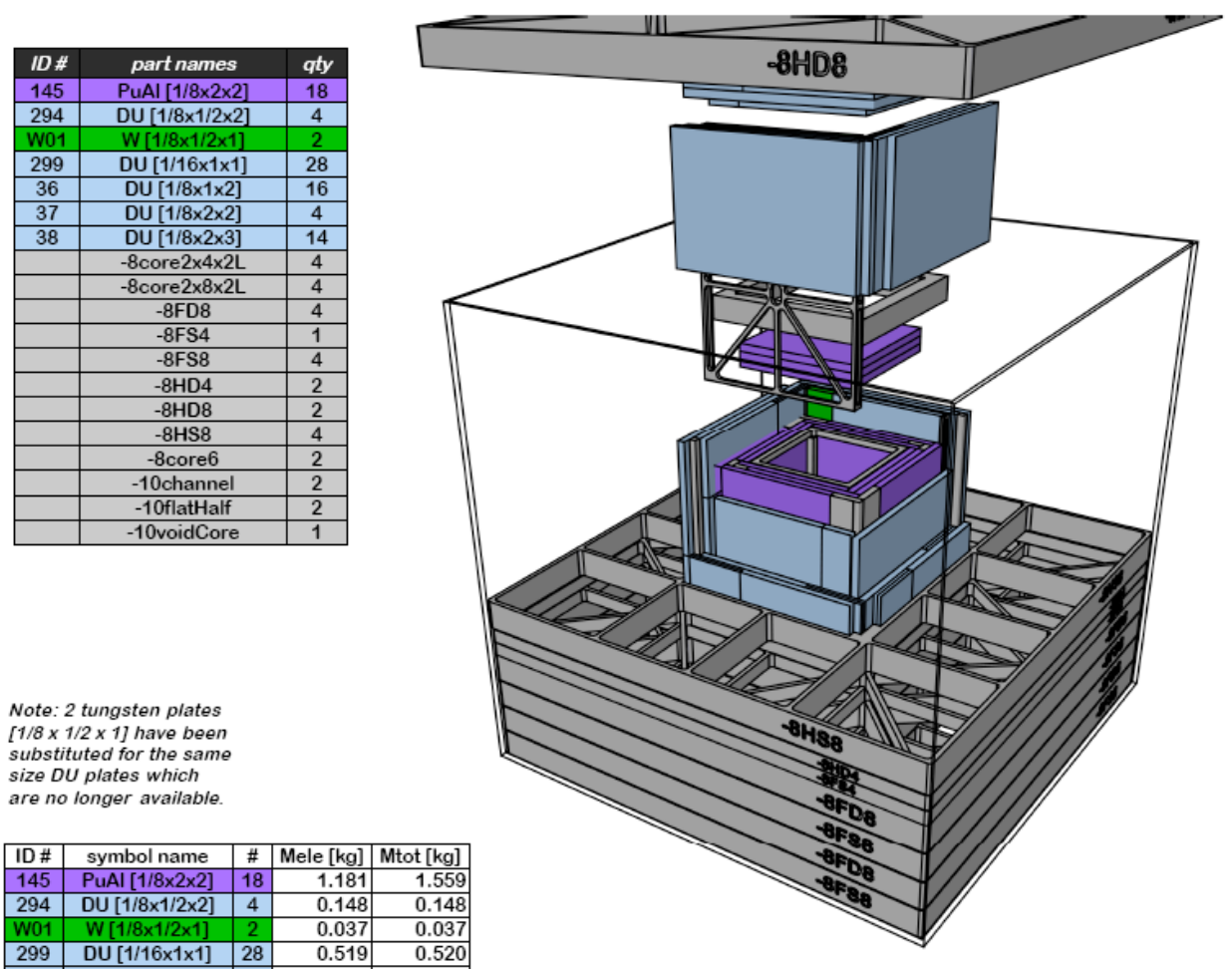

Note: 2 tungsten plates

$[1 / 8 \times 1 / 2 \times 1]$ have been

substituted for the same

size DU plates which

are no longer available.

\begin{tabular}{|c|c|c|c|c|}
\hline ID\# \# & symbol name & \# & Mele $[\mathrm{kg}]$ & Mtot [kg] \\
\hline 145 & PuAl $[1 / 8 \times 2 \times 2]$ & 18 & 1.181 & 1.559 \\
\hline 294 & DU $[1 / 8 \times 1 / 2 \times 2]$ & 4 & 0.148 & 0.148 \\
\hline W01 & $W[1 / 8 \times 1 / 2 \times 1]$ & 2 & 0.037 & 0.037 \\
\hline 299 & DU $[1 / 16 \times 1 \times 1]$ & 28 & 0.519 & 0.520 \\
\hline 36 & DU $[1 / 8 \times 1 \times 2]$ & 16 & 1.193 & 1.196 \\
\hline 37 & DU $[1 / 8 \times 2 \times 2]$ & 4 & 0.593 & 0.595 \\
\hline 38 & DU $[1 / 8 \times 2 \times 3]$ & 14 & 3.129 & 3.136 \\
\hline- & 10 box \& spacers & - & 10.022 & 10.022 \\
\hline & \multicolumn{2}{|c|}{ totals } & 16.822 & 17.213 \\
\hline
\end{tabular}



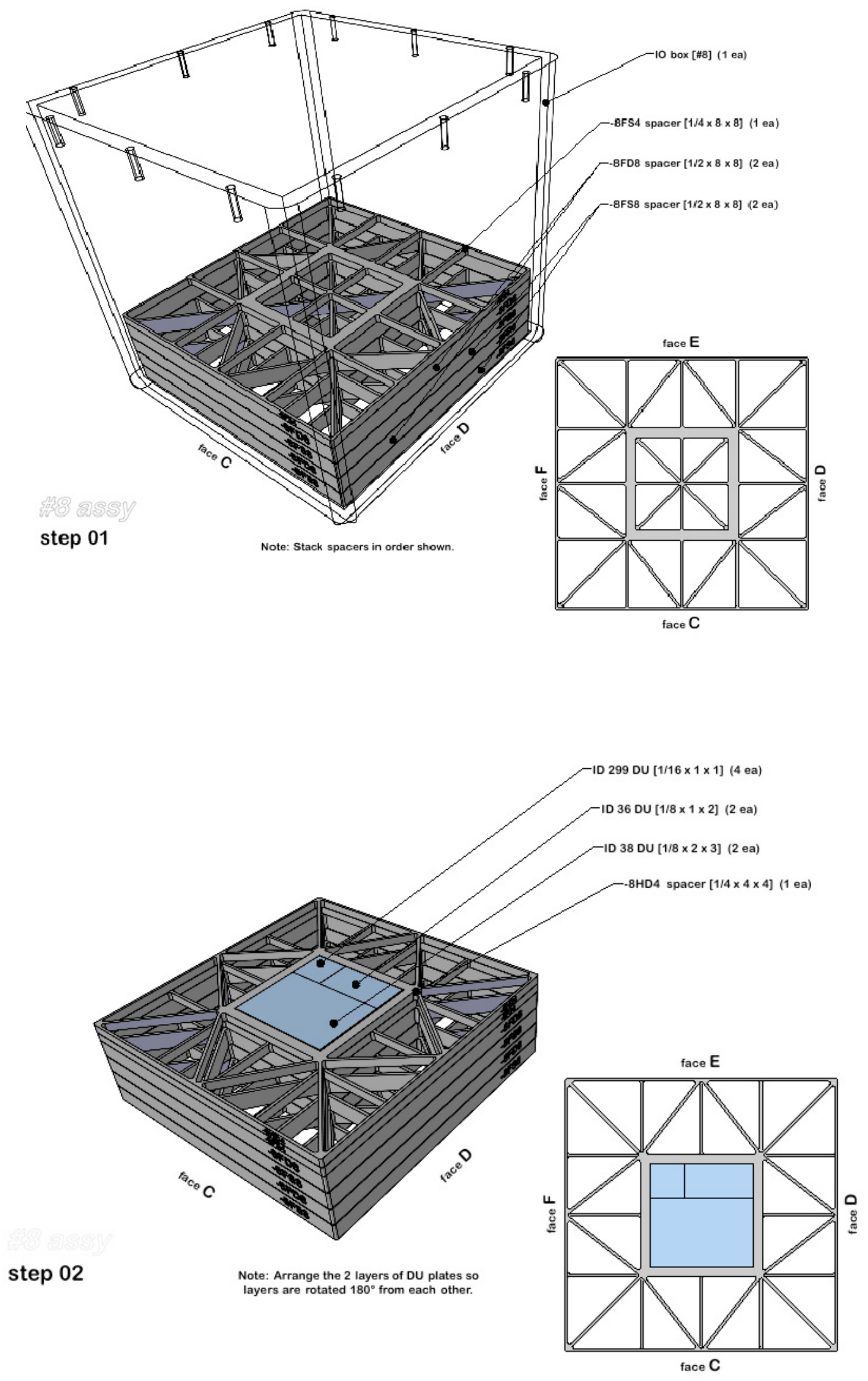

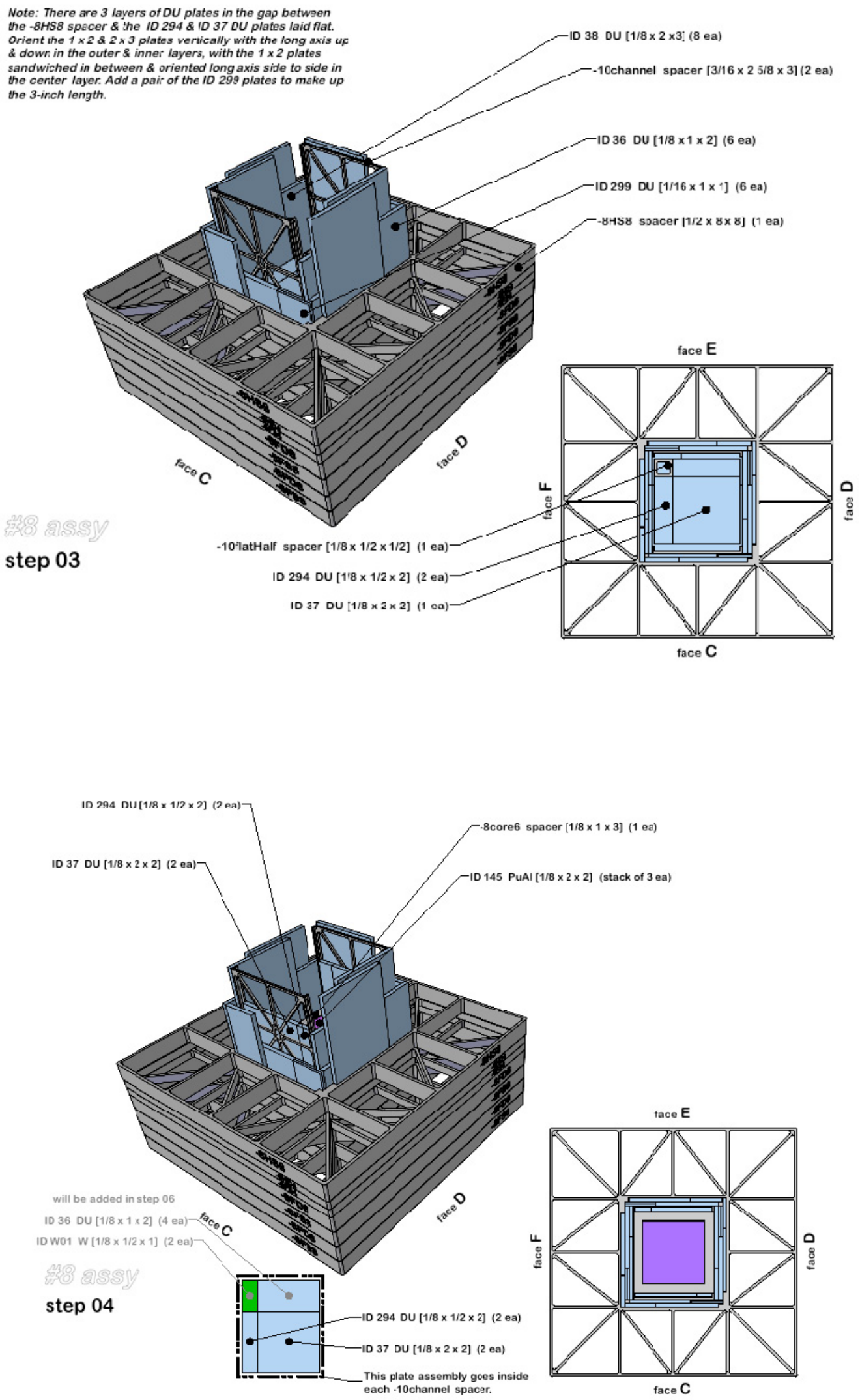

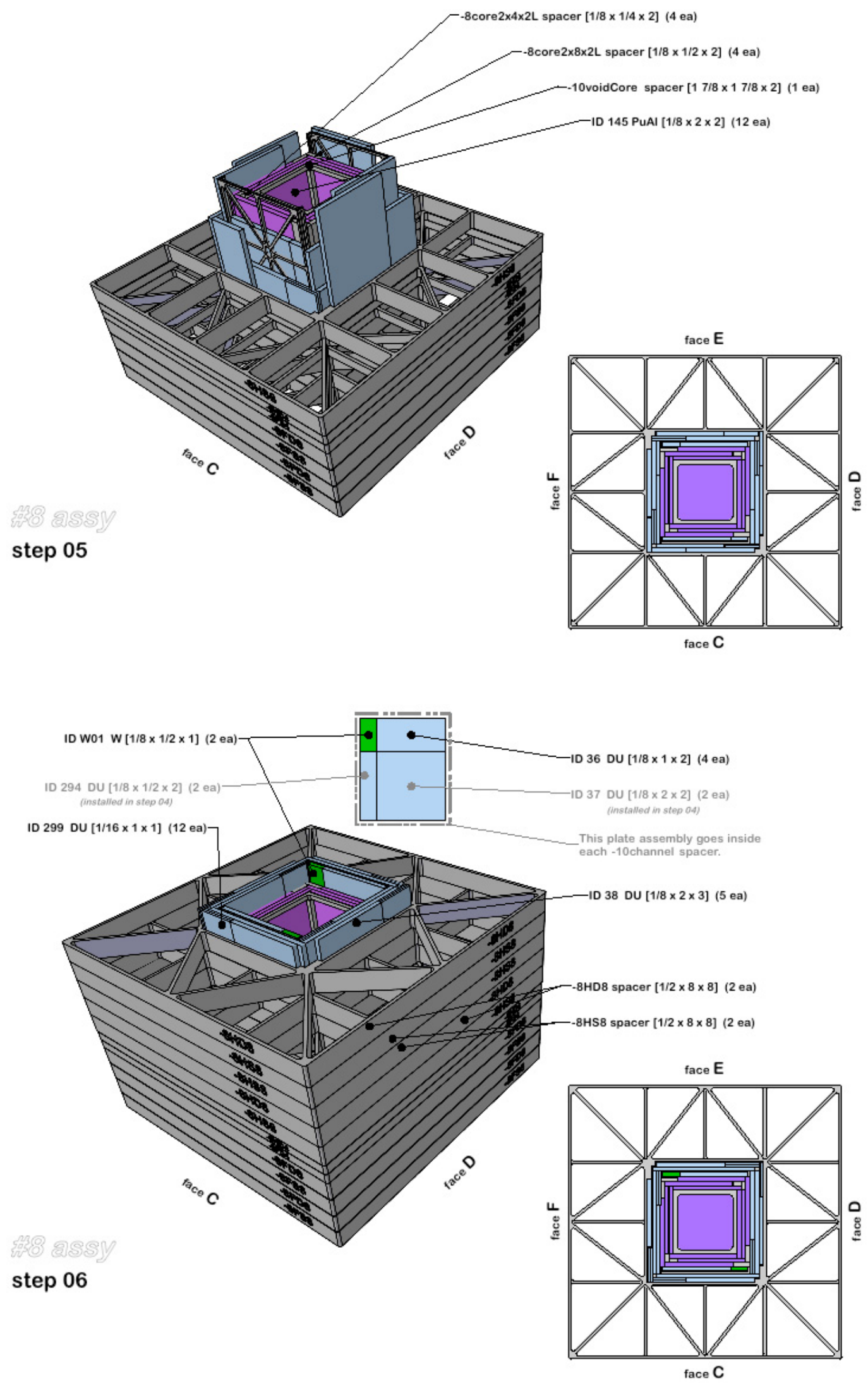

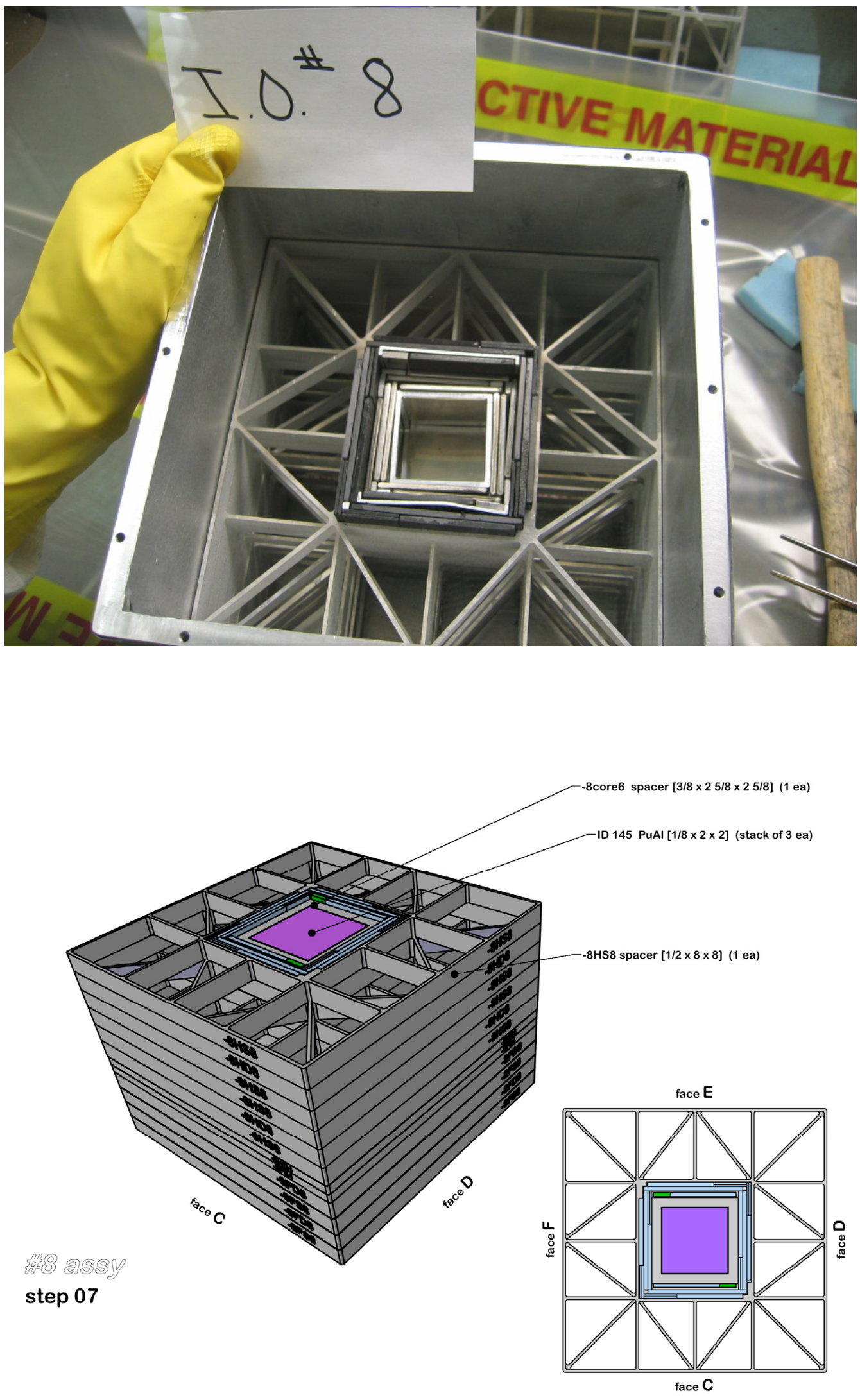

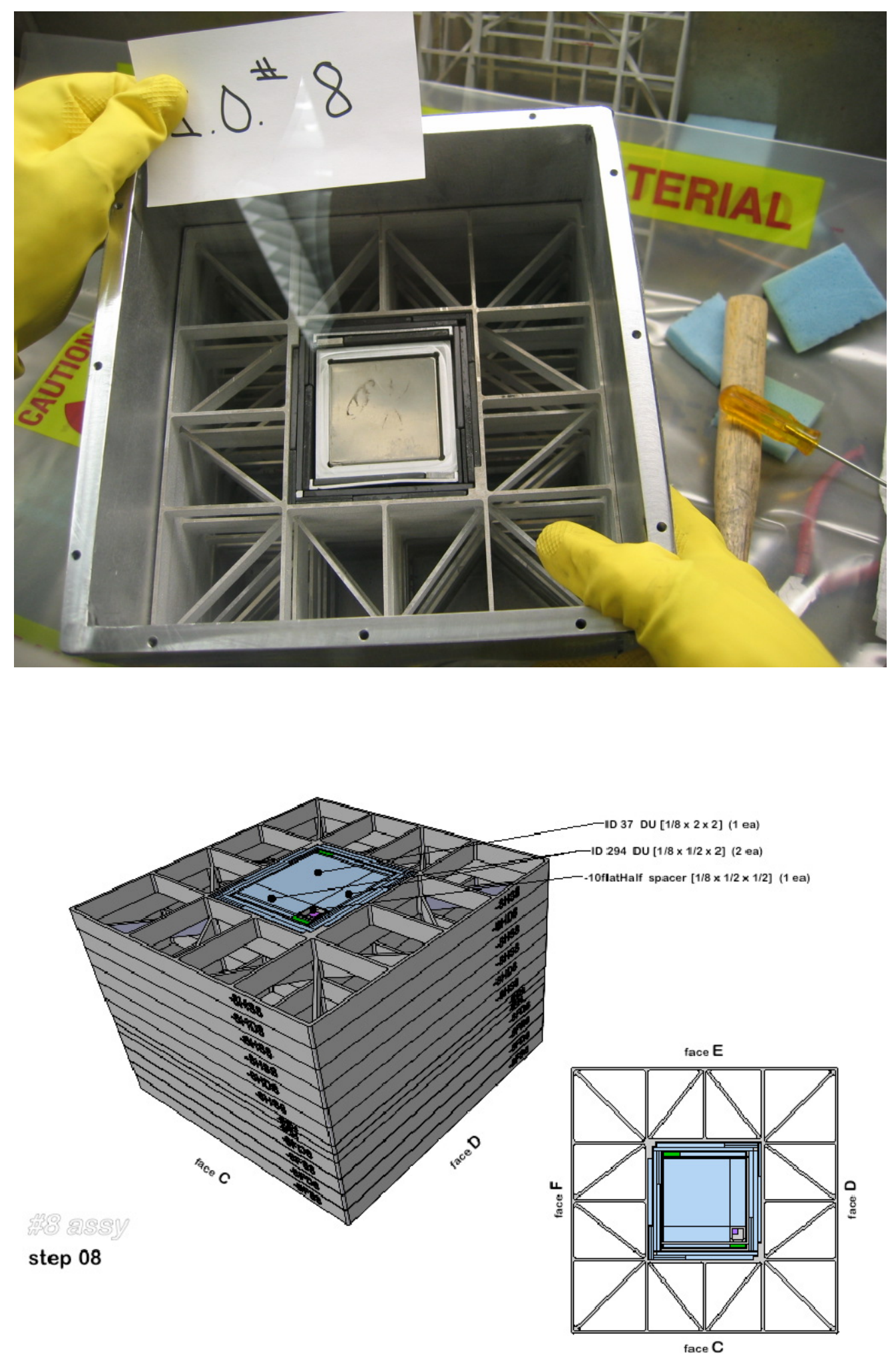

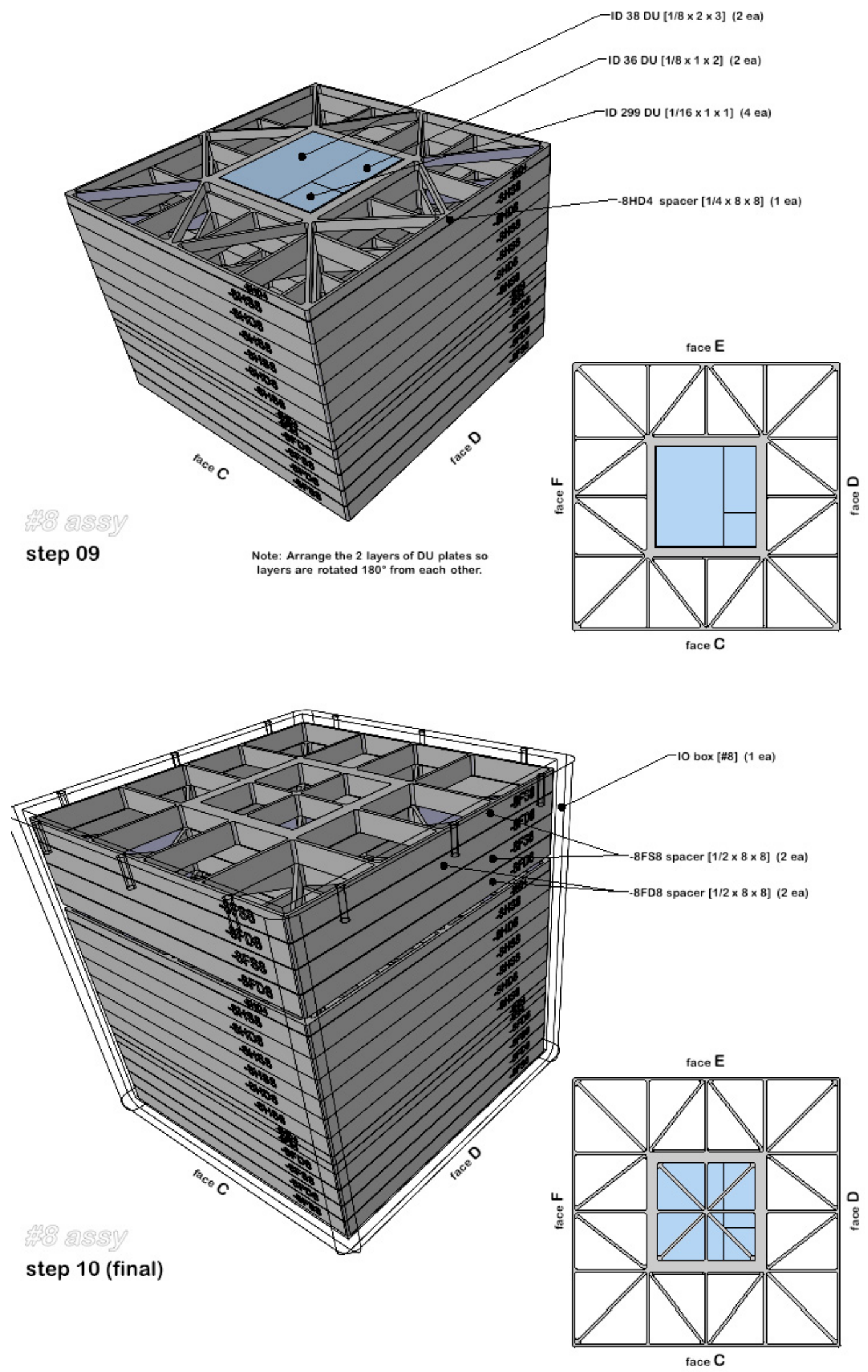


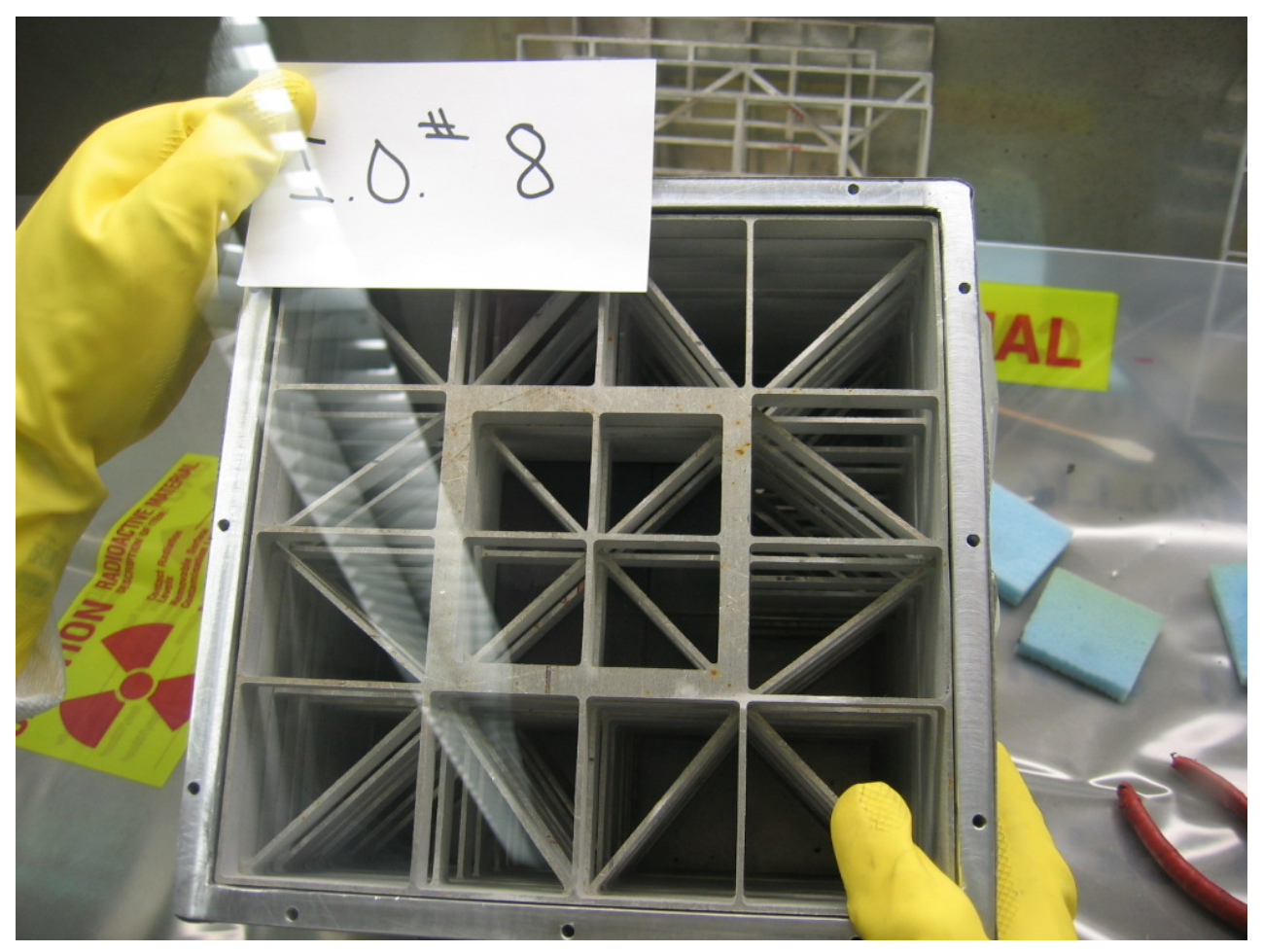


Appendix E

HEU Shielding of Plutonium (IO\#9) 


\section{Appendix E}

\section{HEU Shielding of Plutonium (IO\#9)}

This appendix presents an inspection object (IO\#9) that was designed to assess the effect of an HEU shielding around a plutonium sample. The relative position of the aluminum IO Box is also shown to visually assist the reader. It begins with an exploded view of all components and then presents the key steps in the assembly of the IO. For further clarification, assembly photos are included at selected steps in the assembly process. The upper left table below identifies the material parts with the "ID\#" being a specific ZPPR material identification (see Ref. 1), the "part names" provides the material type (with plate thickness, width, and length in inches within parenthesis), and the number of plates used ("qty"). Items not having a unique ID\# for this IO indicate custom-made aluminum components required for the final assembly. The lower left table presents the elemental mass (kg) for each material component ("Mele") [Pu-239 for PuAl and U-235 for HEU], the total mass of that material component ("Mtot"), and the total mass of the assembled IO (with the aluminum IO Box). All spacers are made of standard 6061-T6 aluminum.
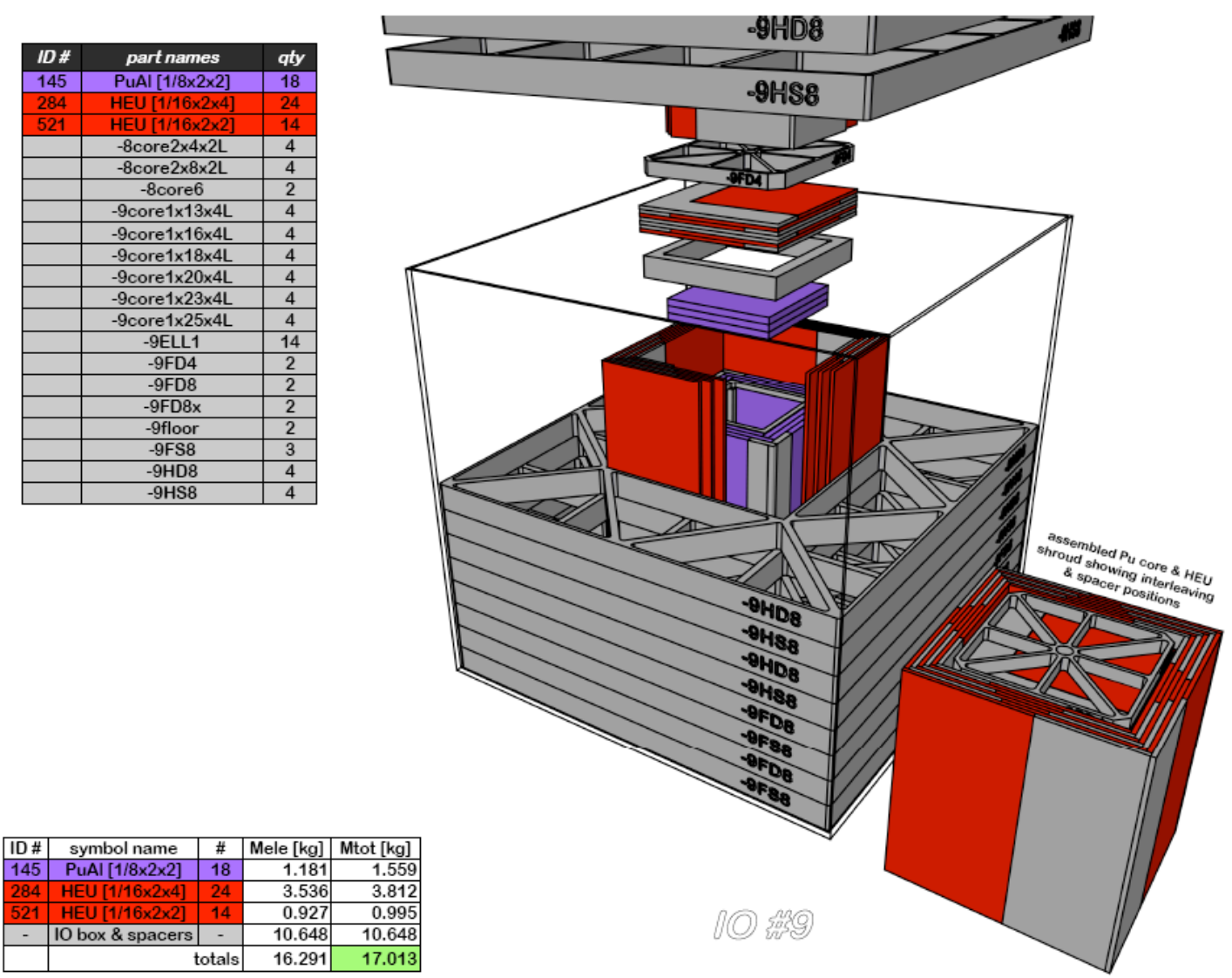

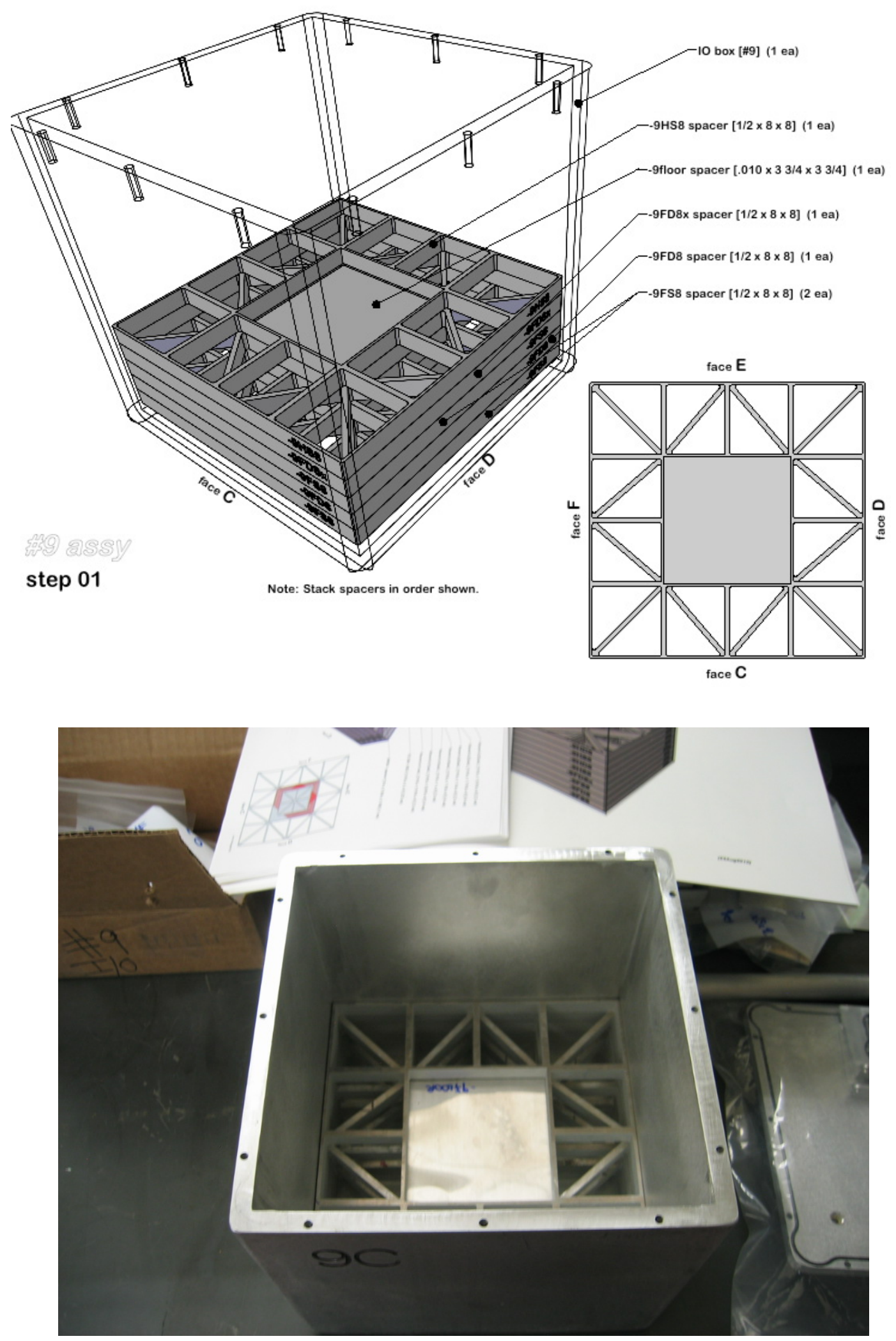

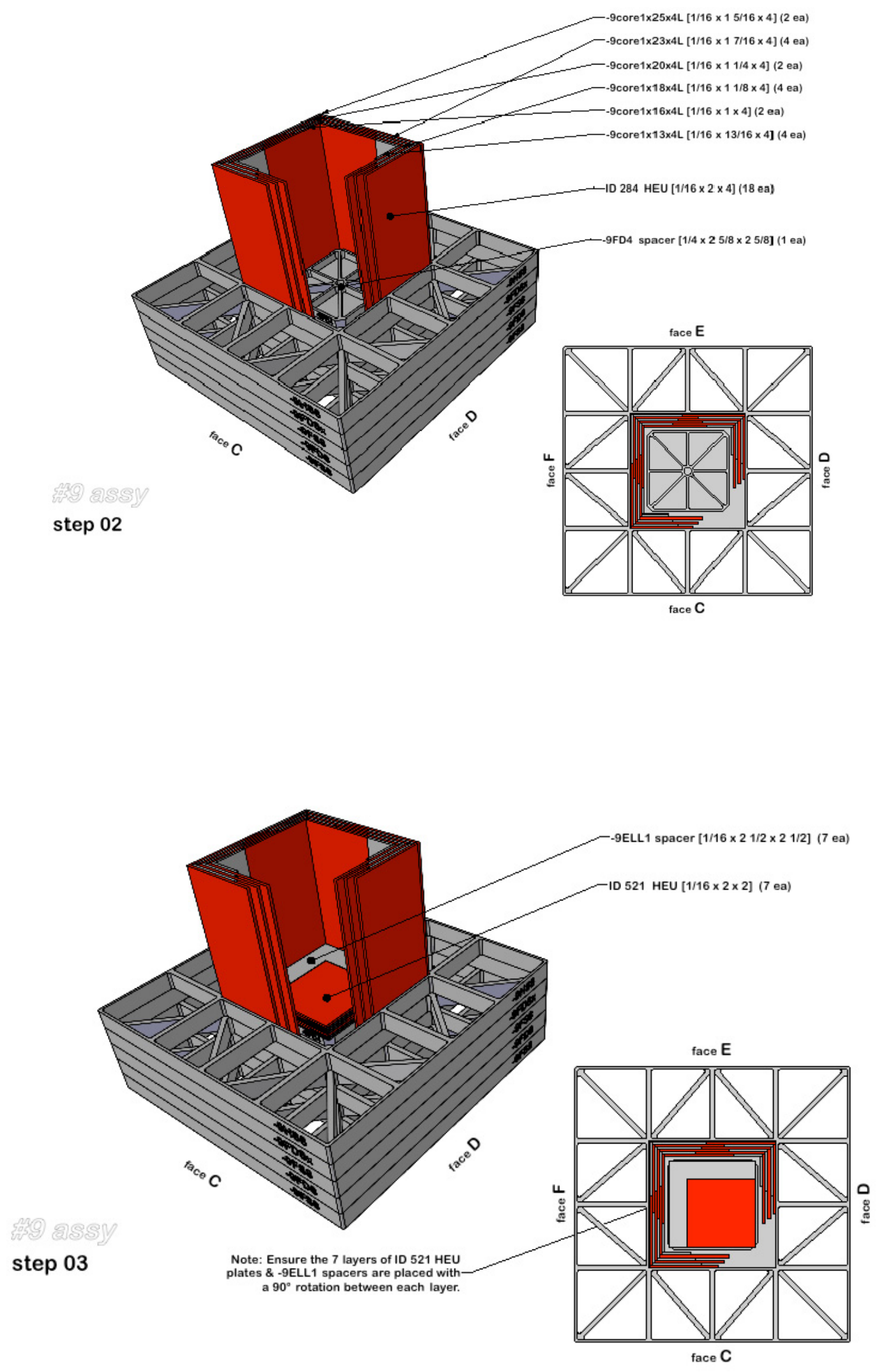

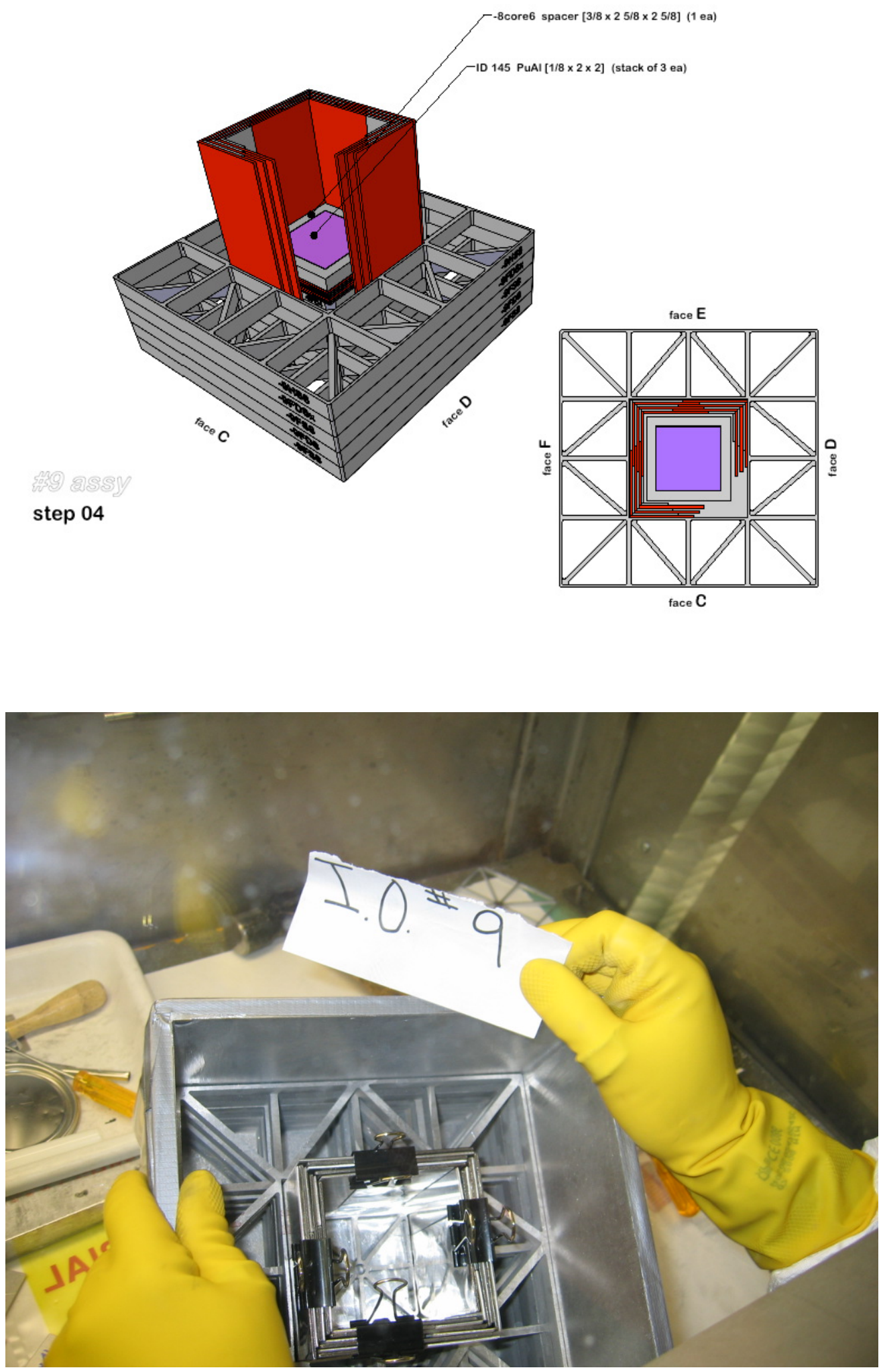

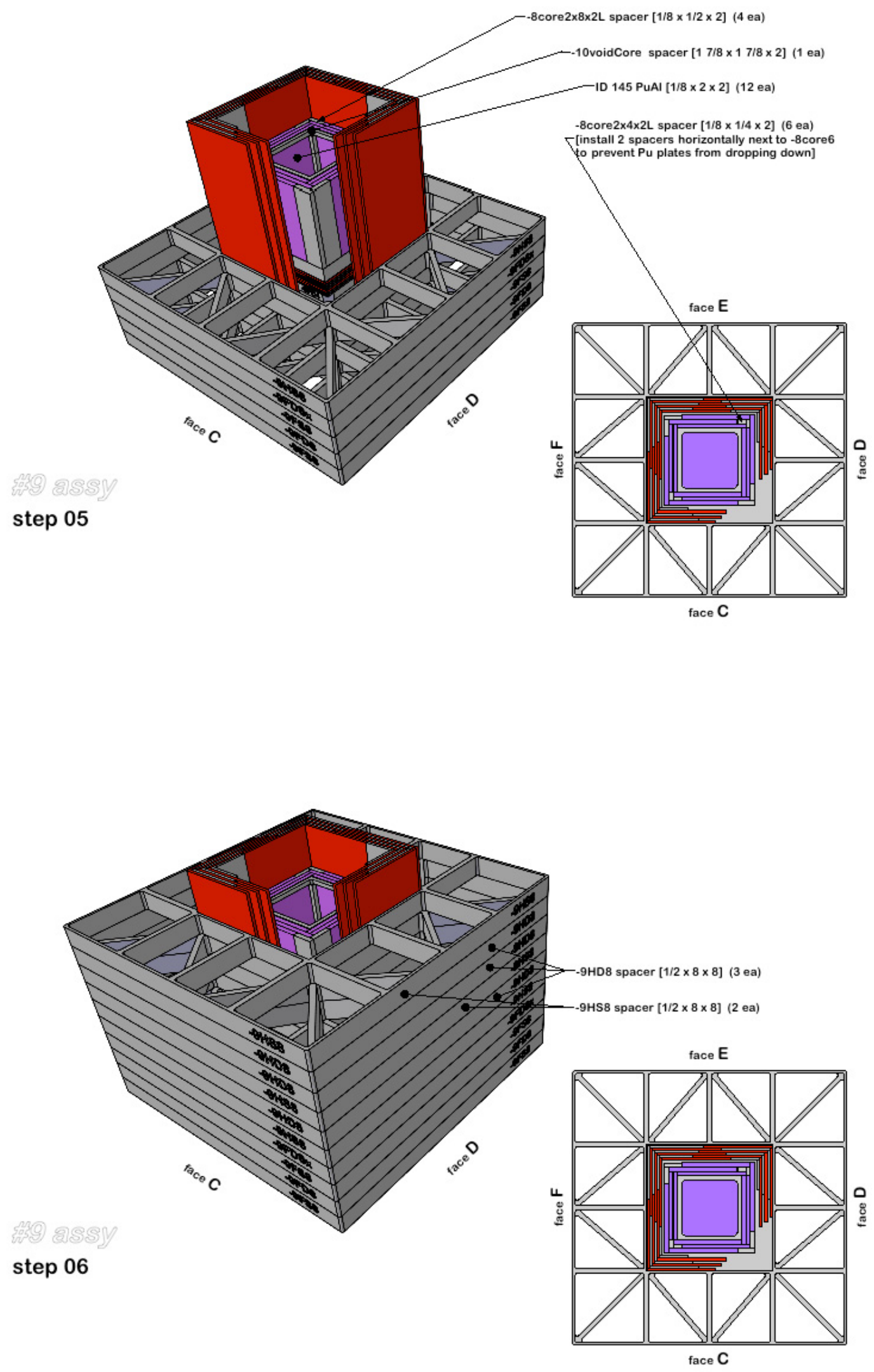

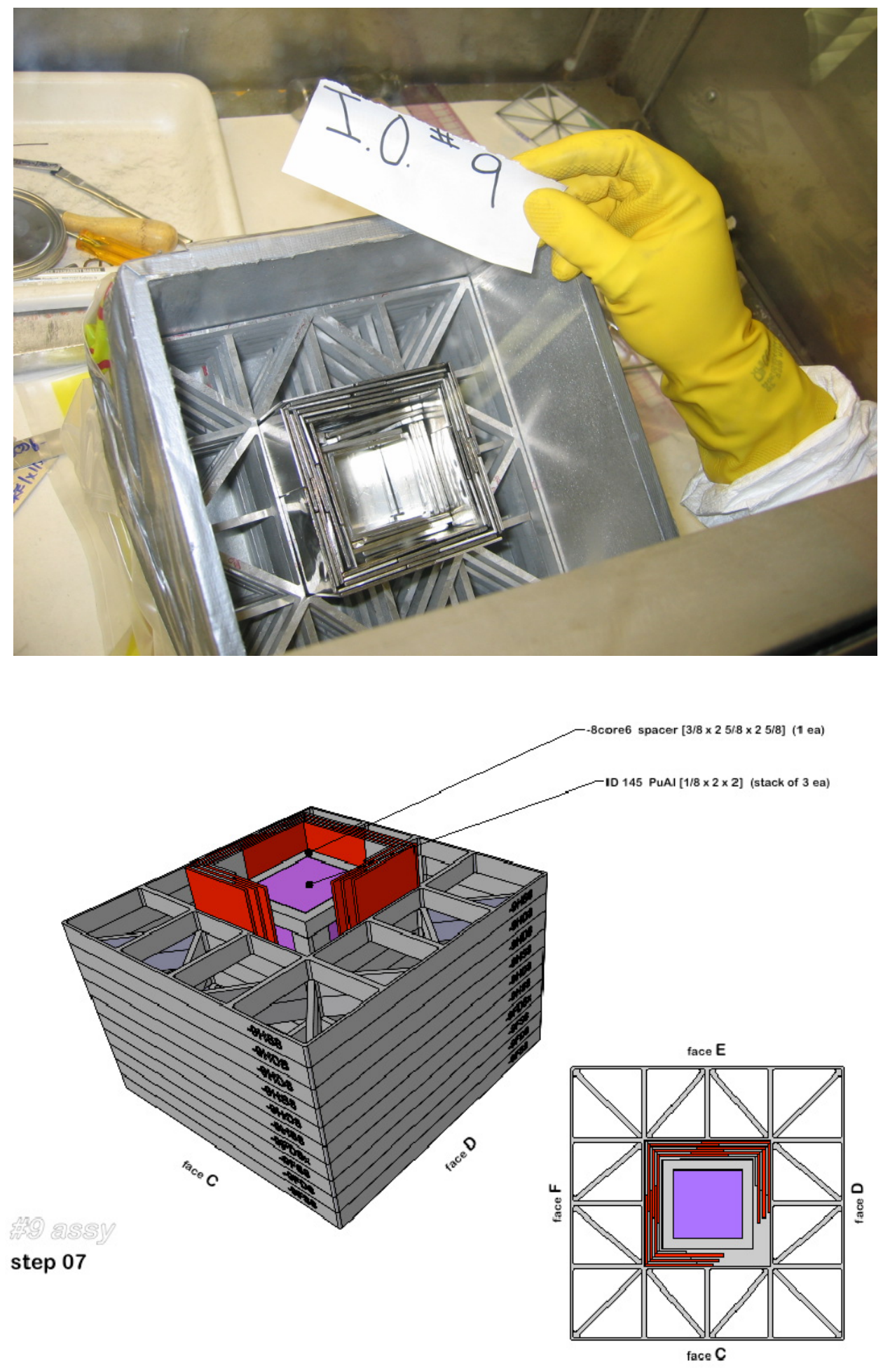

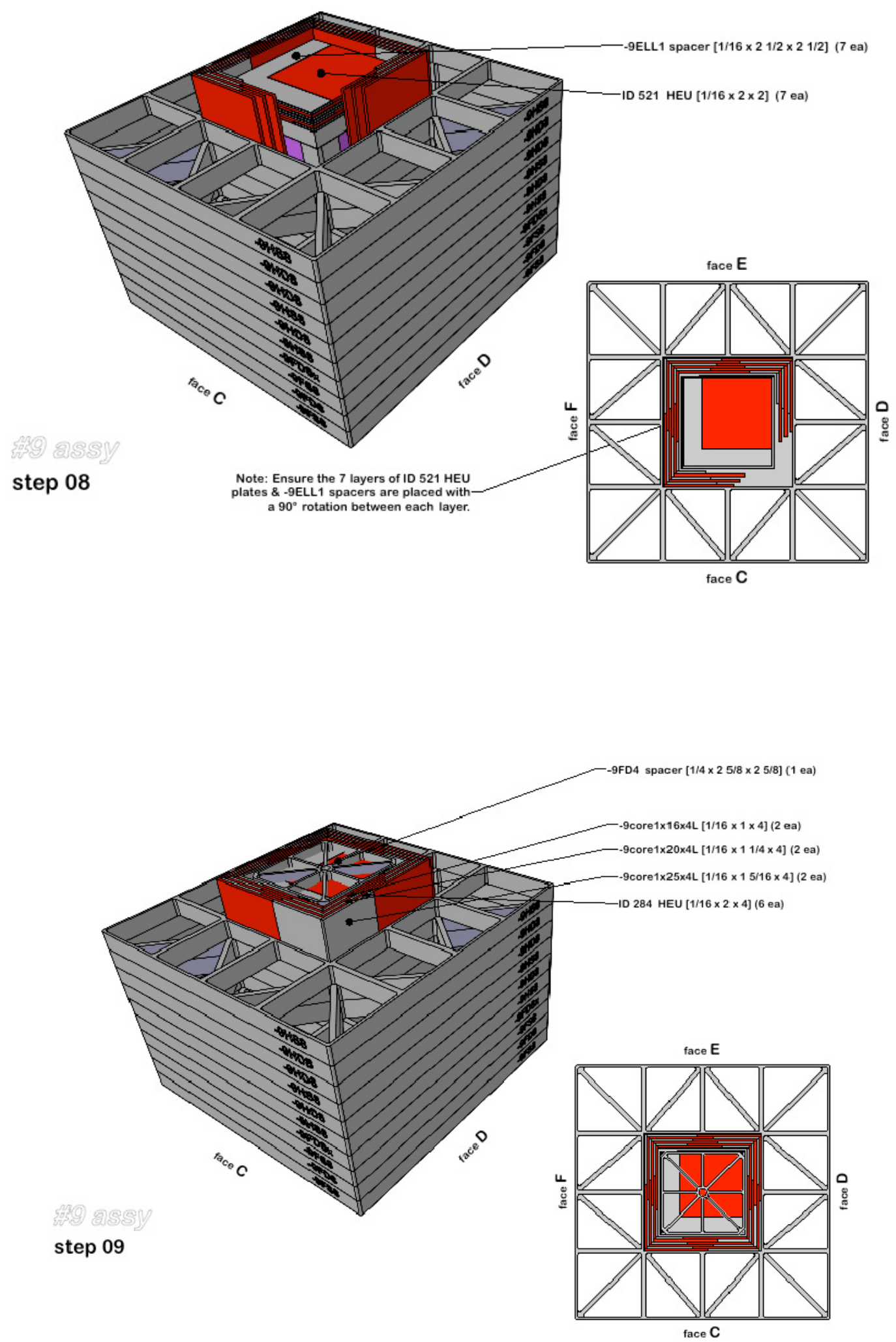

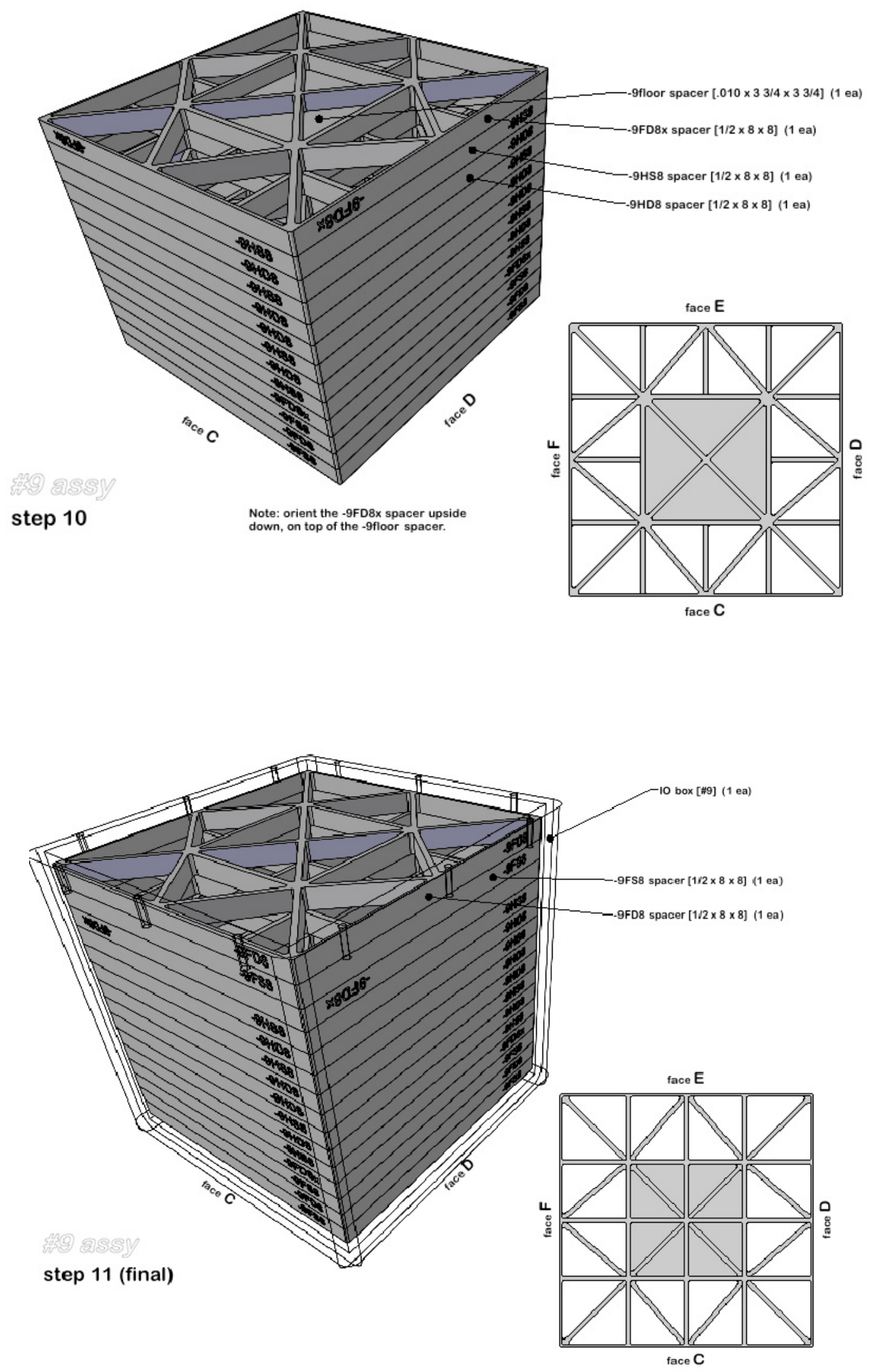


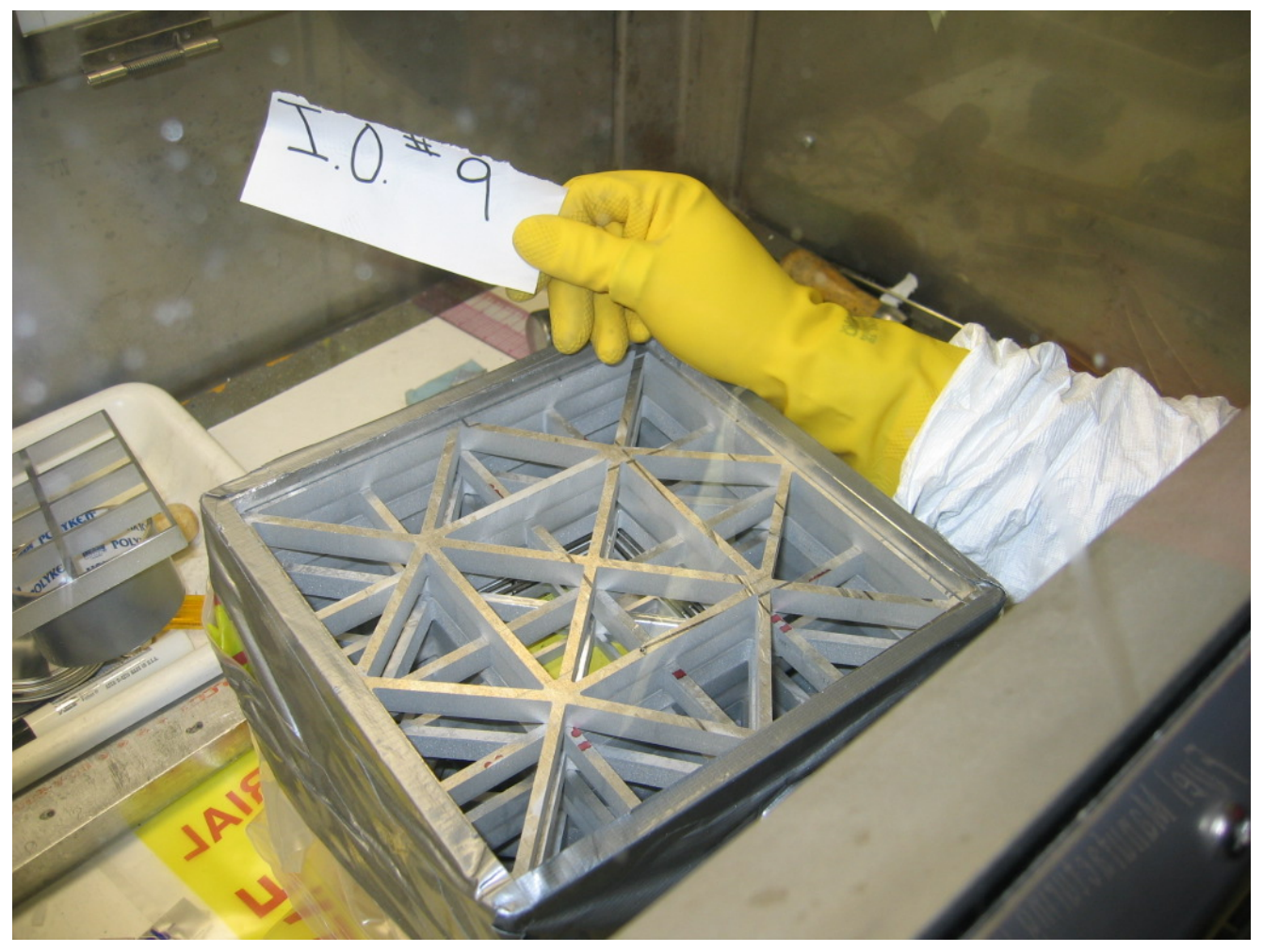




\section{Appendix F}

\section{Composite Shielding of Plutonium (IO\#10)}




\section{Appendix F}

\section{Composite Shielding of Plutonium (IO\#10)}

This appendix presents an inspection object (IO\#10) that was designed to assess the effect of a DU and polyethylene $(0.92 \mathrm{~g} / \mathrm{cc})$ shield around a plutonium sample. The relative position of the aluminum IO Box is also shown to visually assist the reader. It begins with an exploded view of all components and then presents the key steps in the assembly of the IO. For further clarification, assembly photos are included at selected steps in the assembly process. The upper left table below identifies the material parts with the "ID\#" being a specific ZPPR material identification (see Ref. 1), the "part names" provides the material type (with plate thickness, width, and length in inches within parenthesis), and the number of plates used ("qty"). Items not having a unique ID\# for this IO indicate custom-made aluminum components required for the final assembly. The lower left table presents the elemental mass $(\mathrm{kg})$ for each material component ("Mele") [Pu-239 for PuAl and U-238 for DU], the total mass of that material component ("Mtot"), and the total mass of the assembled IO (with the aluminum IO Box). Note the DU shield includes a replacement with two pieces of standard tungsten (relative to Face E). All spacers are made of standard 6061-T6 aluminum.
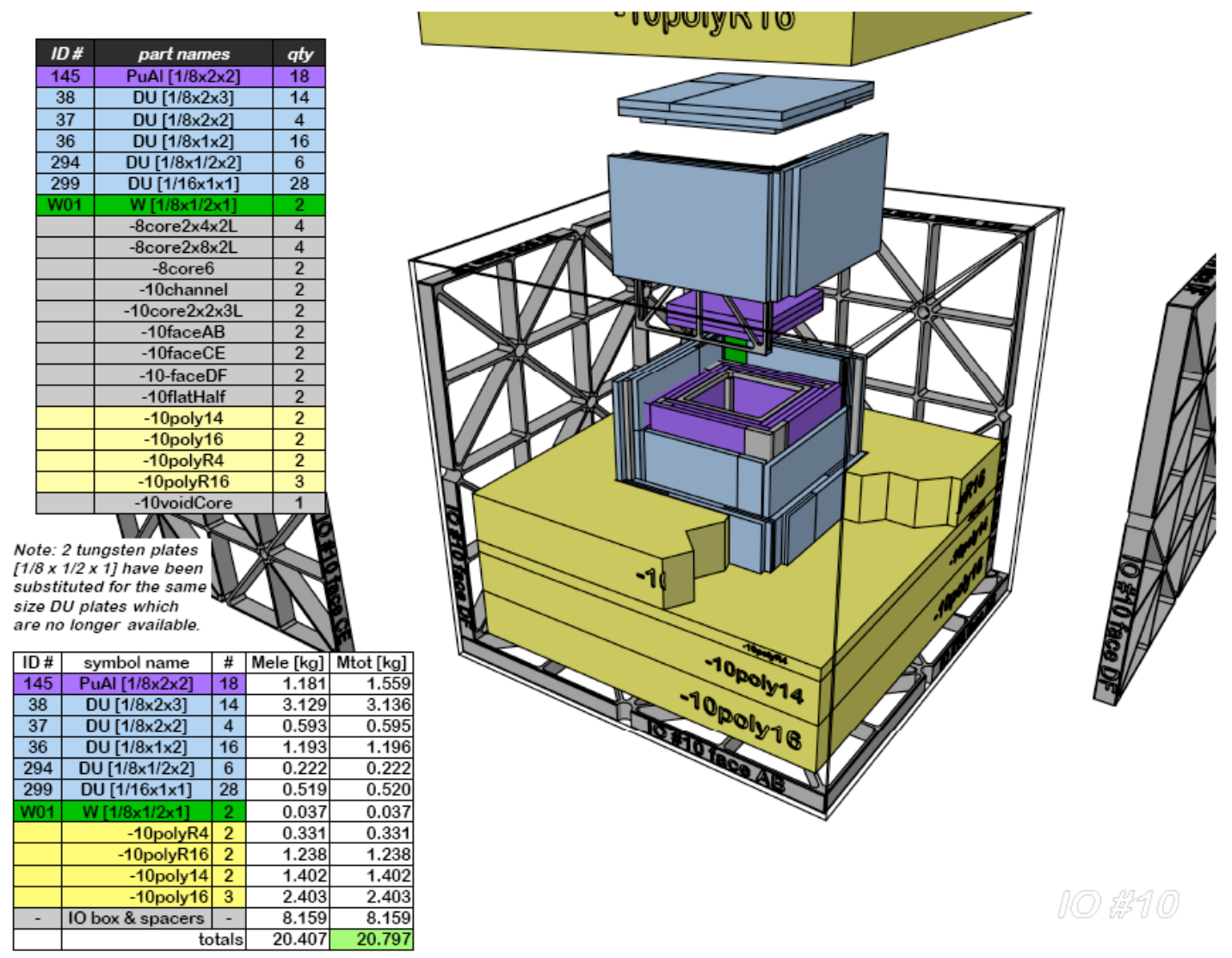

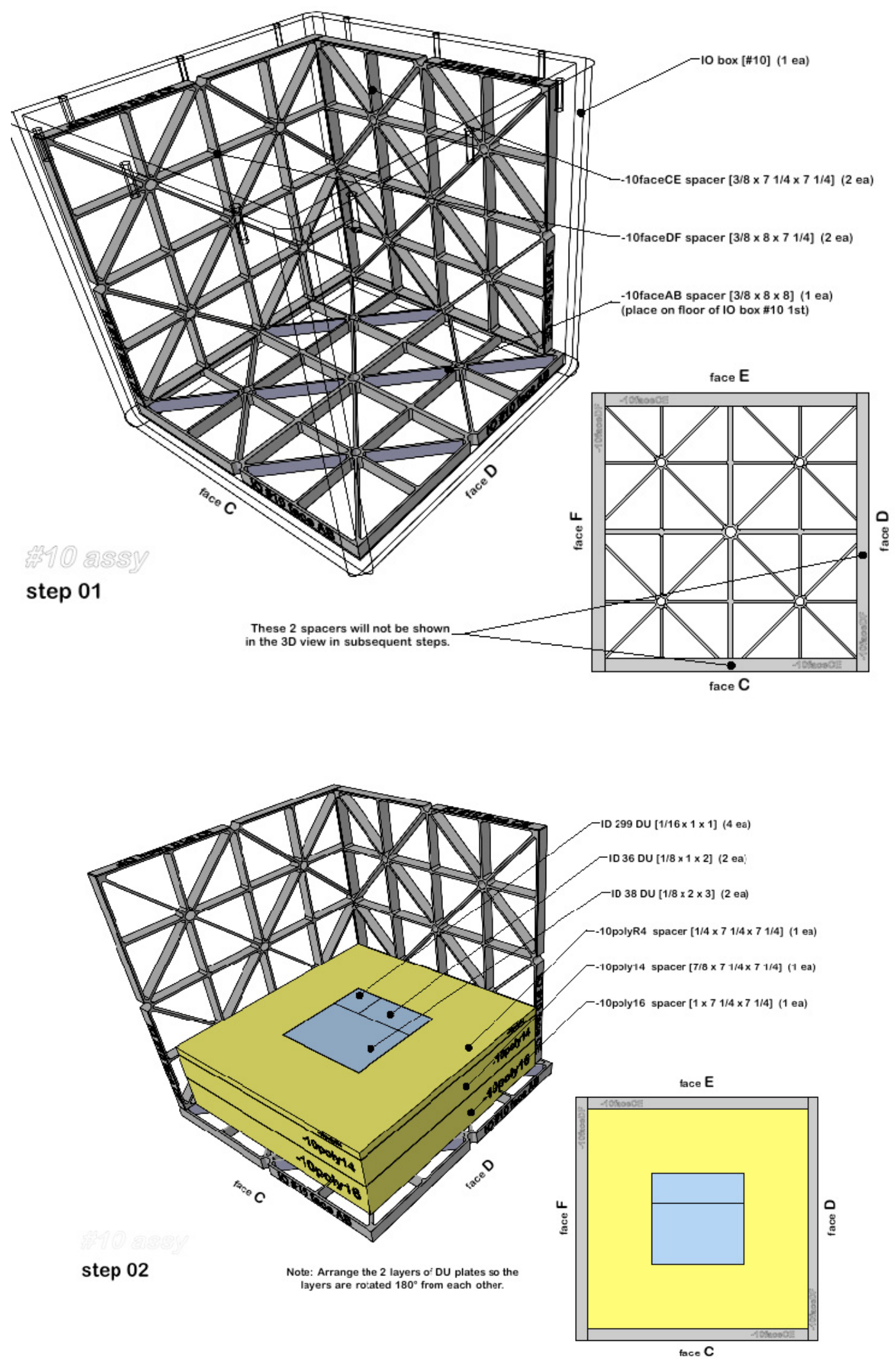

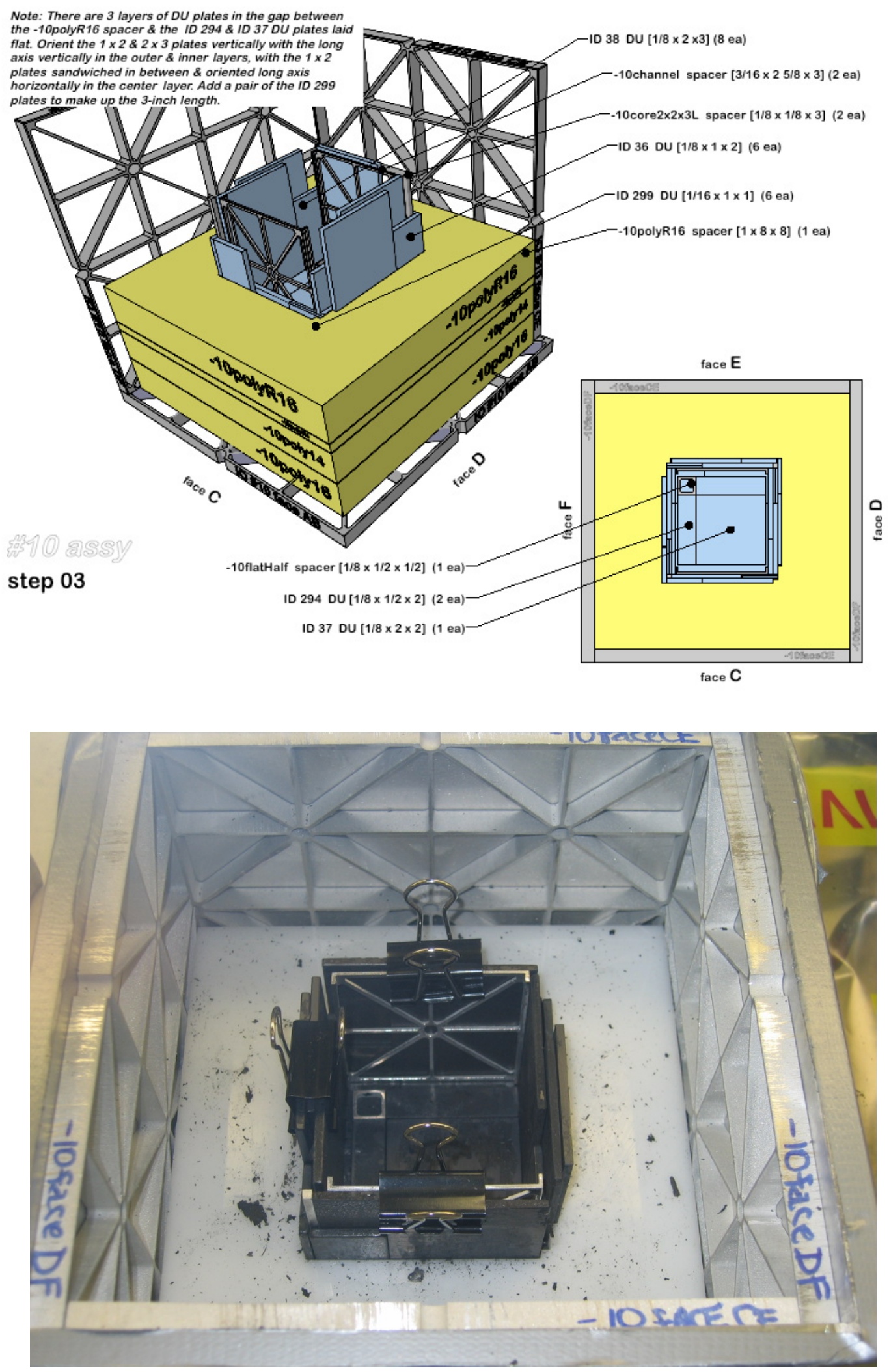

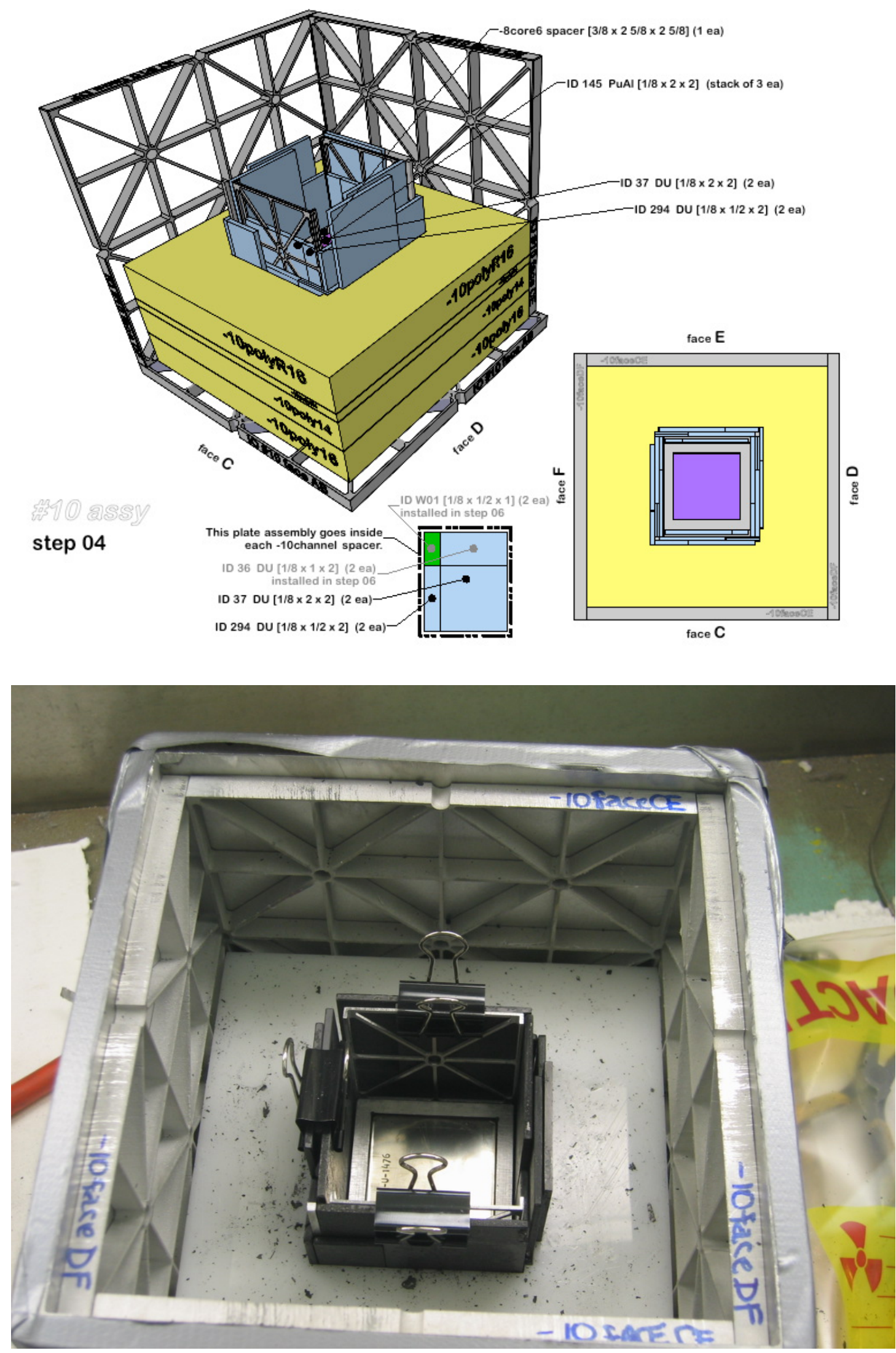

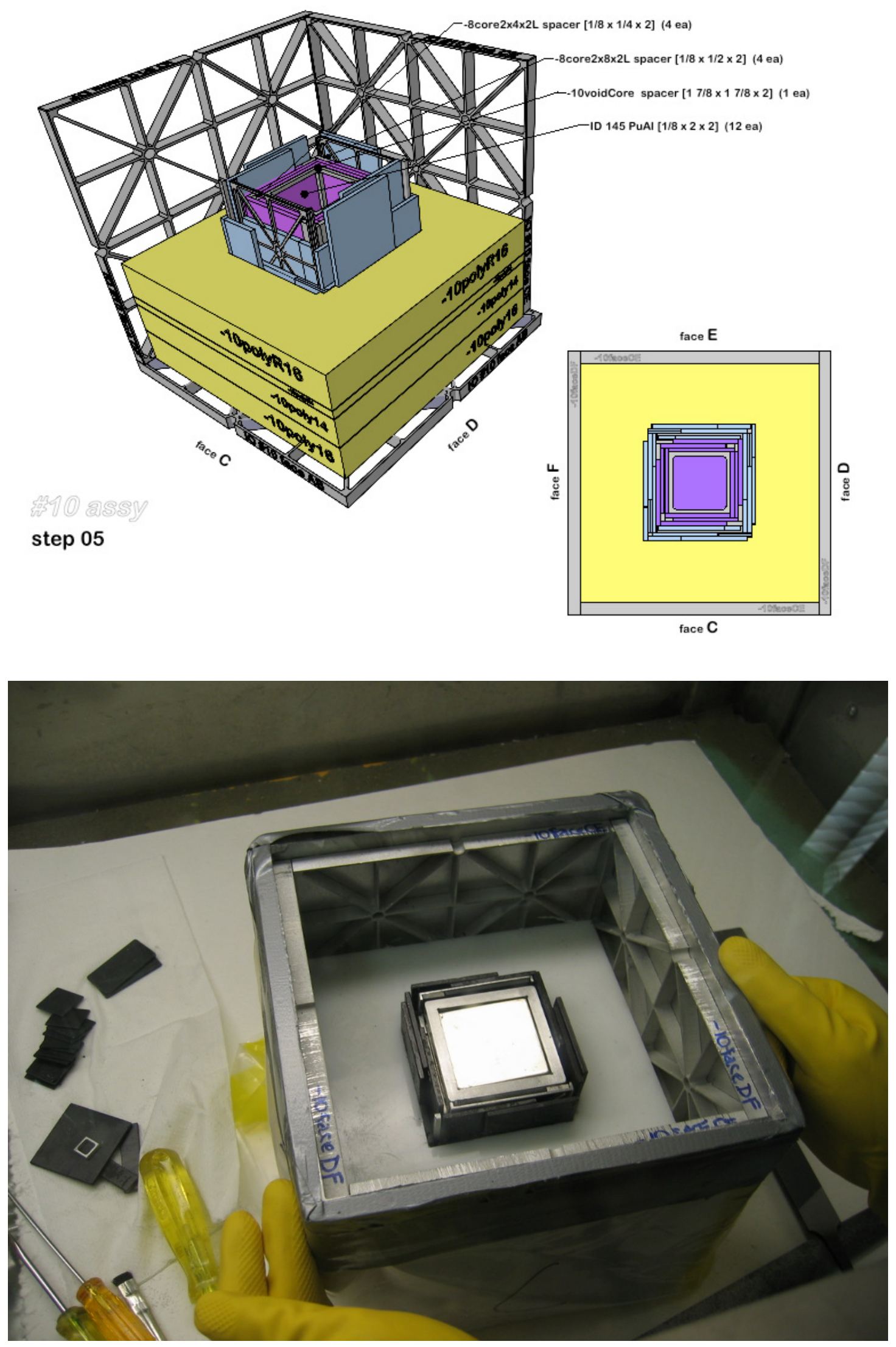

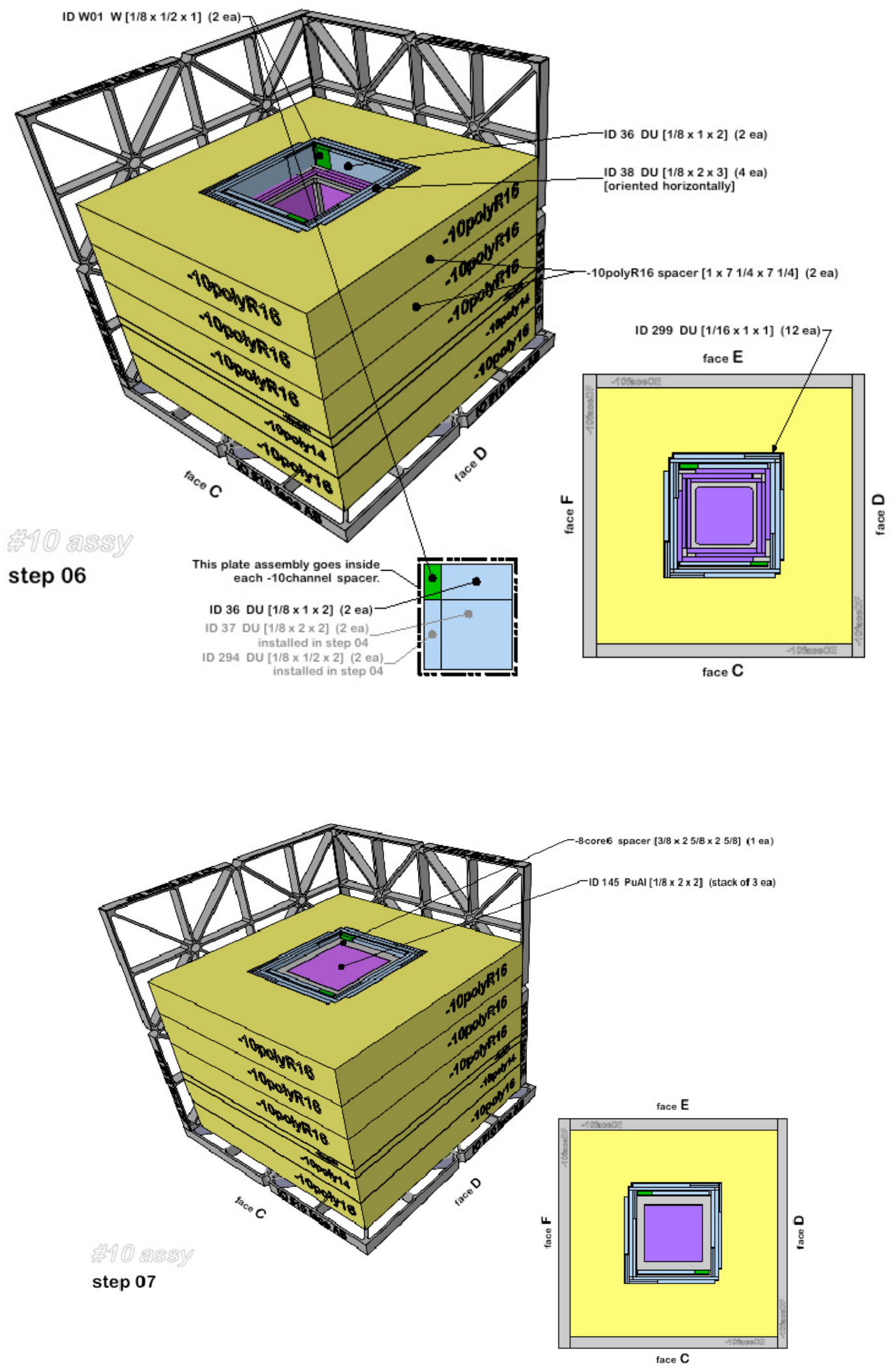

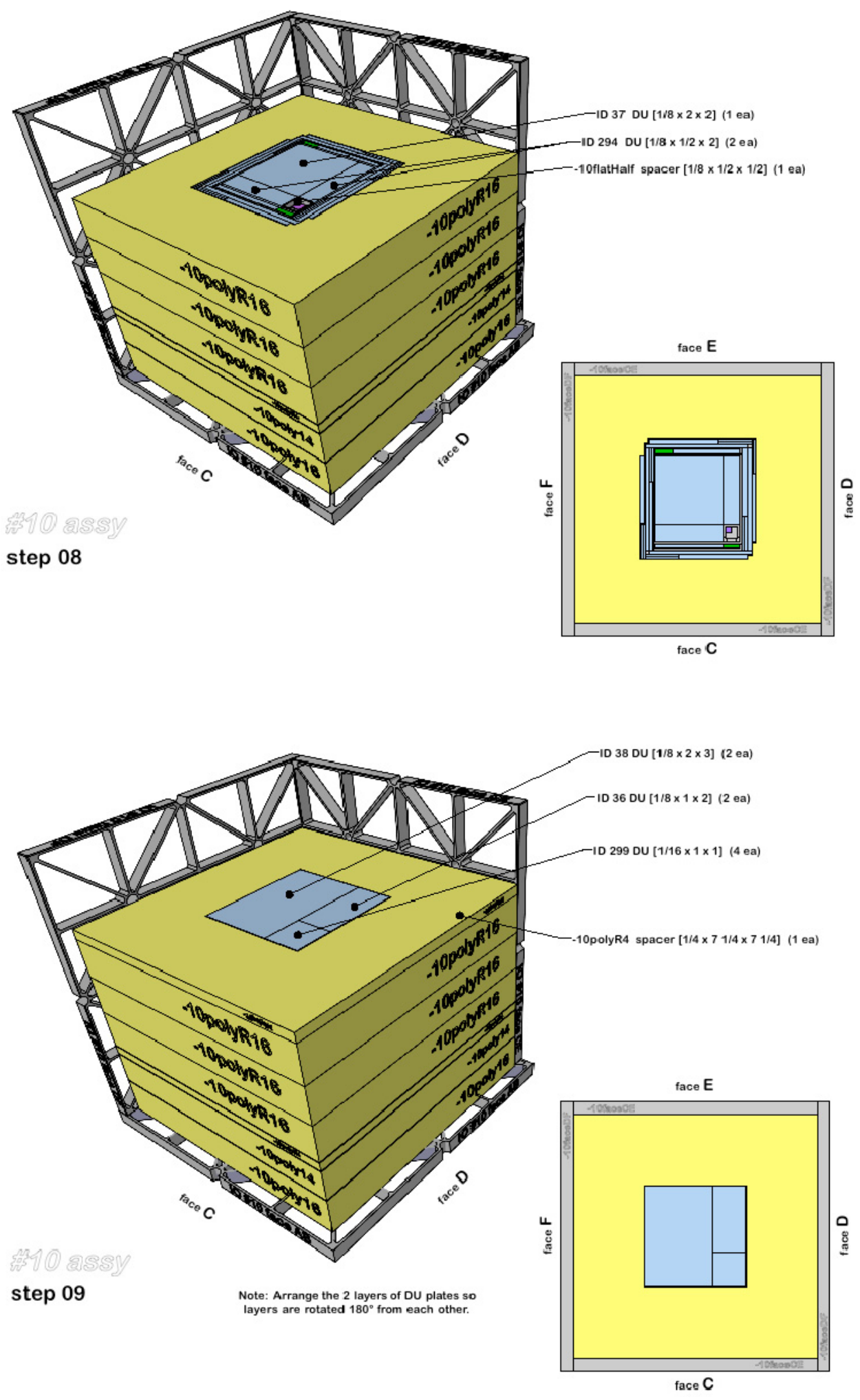

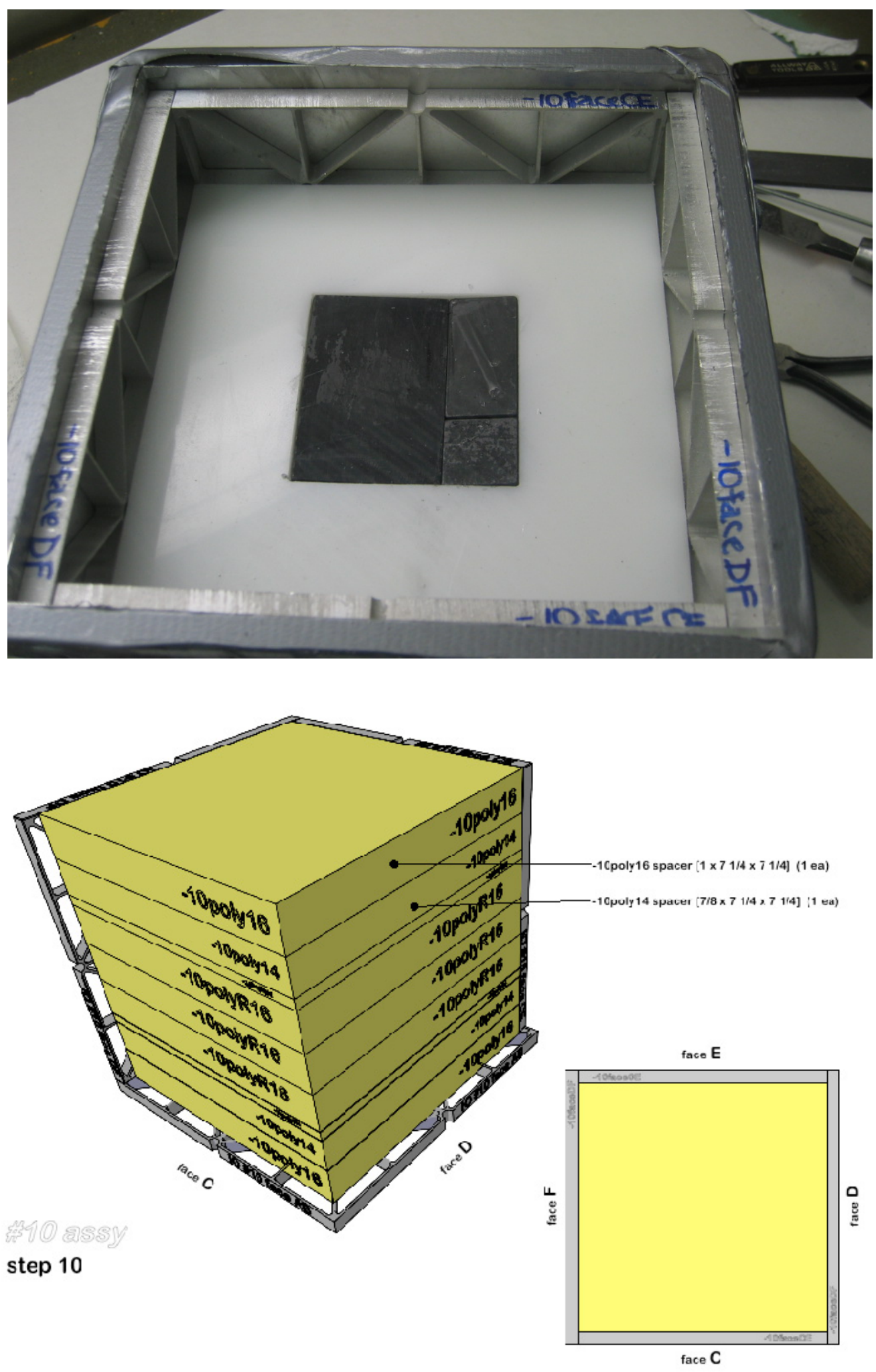


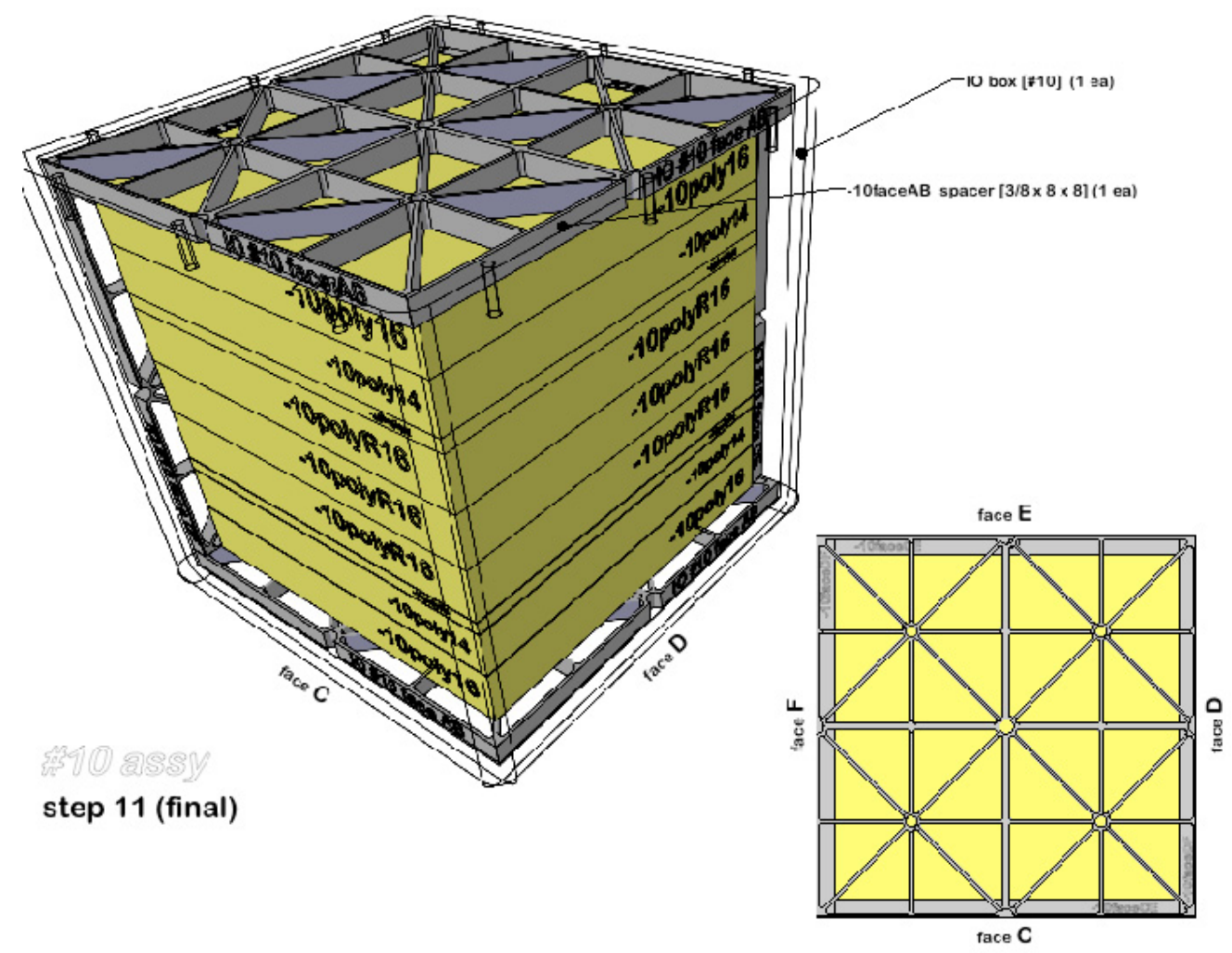

